\title{
Traditional knowledge hiding in plain sight - twenty-first century ethnobotany of the Chácobo in Beni, Bolivia
}

\author{
Narel Y. Paniagua Zambrana ${ }^{*}$, Rainer W. Bussmann², Robbie E. Hart ${ }^{3}$, Araceli L. Moya Huanca' ${ }^{1}$, Gere Ortiz Soria ${ }^{4}$, \\ Milton Ortiz Vaca ${ }^{4}$, David Ortiz Álvarez ${ }^{4}$, Jorge Soria Morán ${ }^{4}$, María Soria Morán ${ }^{5}$, Saúl Chávez ${ }^{5}$, \\ Bertha Chávez Moreno ${ }^{6}$, Gualberto Chávez Moreno ${ }^{6}$, Oscar Roca ${ }^{7}$ and Erlin Siripi ${ }^{8}$
}

\begin{abstract}
Background: The Chácobo are a Panoan speaking tribe of about 1000 members (300+ adults) in Beni, Bolivia. Originally nomadic, the Chácabo were relocated to their current main location in the 1960s. Researchers have visited the Chácabo since 1911. A first more detailed anthropological report exists from the late 1960s, and ecological-ethnobotanical studies were conducted in the 1980s and 1990s. The presented work represents a complete ethnobotanical inventory of the entire adult Chácobo population, with interviews and plant collection conducted directly by Chácobo counterparts.
\end{abstract}

Methods: Based on previous reports and our preliminary studies, we hypothesized that twenty-first century Chácobo plant use centered on income generation, and that traditional plant use related to household utensils, medicine and traditional crop varieties had almost disappeared. To test this hypothesis, we started the "Chácobo Ethnobotany Project," training 10 indigenous Chácobo participants in ethnobotanical interview and plant collection techniques, in order to more fully document Chácobo knowledge and avoid the influence of foreign interviewers.

Results: Our study found 331 useful plant species in 241 genera of 95 plant families, with leaves, roots and bark being the most commonly used plant parts The comprehensive documentation that these methods enabled completely nullified our initial hypothesis of knowledge loss. Traditional crop varieties are still widely grown and traditional knowledge is alive. Moreover, it is being actively recuperated in certain domains by the younger generation. Most Chácobo know, and can name, traditional utensils and tools, although only the older generation has still the skills to manufacture them. While many Chácobo still know the names and uses of medicinal species, the younger generation is however often unsure how to identify them.

Conclusions: In this paper we illustrate the complexity of perspectives on knowledge at different ages, and the persistence of knowledge over almost a century. We found that traditional knowledge was only partially affected by the processes of exposure to a market economy, and that different knowledge domains experienced different trends as a result of these changes. Overall knowledge was widely distributed, and we did not observe a directional knowledge loss.

We stress the importance to not directly conclude processes of knowledge loss, cultural erosion or acculturation when comparing the knowledge of different age groups.

Keywords: Traditional knowledge, Knowledge loss, Conservation, Indices

\footnotetext{
* Correspondence: nyaroslava@yahoo.es

'Herbario Nacionál de Bolivia, Universidad Mayor de San Andrés, Casilla

10077 Correo Central, La Paz, Bolivia

Full list of author information is available at the end of the article
} 


\section{Background}

The Chácobo tribe, living in Northeastern Bolivia, were first visited by the European traveler Erland Nordenskjöld in 1911 [1], followed by an anthropologist only in 1956, who published the last account of Chácobo life before the tribe came under the influence of American Evangelist missionaries [2]. The Summer Institute of Linguistics (SIL) worked with Chácobo communities from 1953 to 1980, and produced the first account of Chácobo linguistics [3], and an unpublished work on Chácobo customs, with a strong focus on evangelist development [4]. This account is in interesting juxtaposition to the writings of German anthropologist Kelm [5], who visited the Chácobo in 1970, in the middle of SIL rule. The SIL finally was replaced in 1980 by the Swiss Protestant mission. Missionary rule led to a profound change of lifestyle, and a permanent process of acculturation [6]. From 1983 to 84, Brian Boom (New York Botanical Garden) led the first ethnobotanical study of Chácobo, documenting their knowledge after almost 30 years of cultural change [7]. Boom did however base his work on the plants collected from a single 1 ha forest plot. In 1995 the Institut Franjáis d'Etudes Andines financed a re-survey of Boom's plot, but the results were never released to the public, and a planned publication [8] existed in a single volume in the Institute's main library in Lima. Muñoz et al. [9] published a study on anti-malarial plants used by the Chácobo. Given the availability of previous studies, the Chácobo are an outstanding possibility to study traditional knowledge over time.

Traditional knowledge (TK) has been recognized for its importance for the protection of ecosystem services and biodiversity $[10,11]$. However, researchers and policymakers have equally expressed concern about its possible loss as societies modernize. A growing number of studies have reported changes and losses in TK (e.g. medical TK [12-15], nutritional TK [16], and agricultural TK [17-19]. The hypothesis that TK systems are able to adapt to external changes and internal pressures has discussed for some time (e.g., [20]). Traditional.

Knowledge is an important part of the adaptive capacity of many rural and indigenous communities that have been conserving biodiversity while enhancing livelihoods and adapting to disturbance and change [21, 22]. Few studies have however examined whether and how loss or alteration of TK in fact occurs [17, 23-25]. Consequently, our understanding of the resilience of TK systems and their ability to evolve and adapt is highly limited. The assumption of loss of TK, when younger people know less, is one of the common errors in ethnobotany [26]. This problem can be remedied when analyzing the effects of age and age cohorts separately [27, 28]. Not all TK domains might however be shared between generations, and as such there can be domains that would be more vulnerable to TK loss, and domains in which new knowledge is generated as an adaptation to environmental change [29].

Traditional knowledge is also seen as an important component in improving the management of natural resources $[10,20,30]$ and practices relating to the protection of ecosystems and species [11]. Factors such as gender, age, ethnicity, birthplace, and level of education have been identified as important on an individual level [31-34]. Family size, integration into the market economy (e.g. sale of animals and agricultural products), or amount of material goods at family level (e.g., possessions of farm animals, tools, and transport) have been linked to the household levels $[35,36]$. Access to commercial centers, and to health, education, electricity or water, as well as land tenure systems and settlement history have shown a greater relevance at the community level [37-39]. In the absence of a unifying theory or common research methods, it is however difficult to clearly recognize whether or not these patterns exist at broader scales [40]. Several studies have used literature metadata to analyze large-scale usage patterns of plants [41-43]. In many cases, however, comparisons are difficult to make, given the diversity of the objectives and methods employed.

Based on previous reports mentioned, and our own preliminary studies [44], we hypothesized that twenty-first century Chácobo plant use centered on income generation through collection of forest products and agricultural production, and that traditional plant use related to household artifacts and medicine, as well as traditional crop varieties, had almost disappeared. We also hypothesized that the "missionary generation" - the first age group growing up under restrictive evangelist rule, would report less TK than other age groups. Because access to markets and services has been reported as a major cause for TK loss [28], we also hypothesized that in villages most distant from the main market center (Riberalta), knowledge about the use of plants, and the number of useful species would be more homogeneously distributed through the generations [25], and expected that this TK distribution show different patterns when analyzing the different domains of knowledge about the use of plants [29].

To test our hypotheses, we started the "Chácobo Ethnobotany Project," training 10 indigenous Chácobo participants in ethnobotanical interview and plant collection techniques, to comprehensively document contemporary Chácobo TK and avoid the limiting influence of foreign interviewers. 


\section{Methods}

\section{The study area -- The Chácobo and Pacahuara}

The Chácobo belong to the Panoan linguistic group, which includes about twelve tribes (Chácobo, Pacahuara, Matis, Matses, Yaminahua, Ese Eja and others). At the end of the 1890s, the Chácobo lived as semi-nomadic hunters and cassava and maize cultivators, probably in two groups, one with six families and one with four, in north Bolivia, between Lake Roguagnado and the river Mamore, south of their current territory. During the rubber boom in the early 1900s, they were forced by more aggressive tribes to move north, where rubber tappers, who also brought disease and epidemics to the tribe, threatened them. While other tribes were enslaved to work in rubber stations, the Chácobo managed to avoid most of the outside influences. Their first permanent contact with the outside world occurred only in 1953 with members of the the Tribes Missions, and in 1954 the Bolivian government established an agency about $15 \mathrm{~km}$ from the current location of Puerto Limones. The missionary linguist Gilbert Prost arrived in 1955 under the auspices of the Summer Institute of Linguistics (SIL). According to [4] there were four Chácobo groups living between the Benicito and Yata rivers at that time, numbering about 200 people [7]. Prost and his wife continued to live among the Chácobo until 1980. In addition to translating the New Testament into Chácobo, they made some observations on cultural

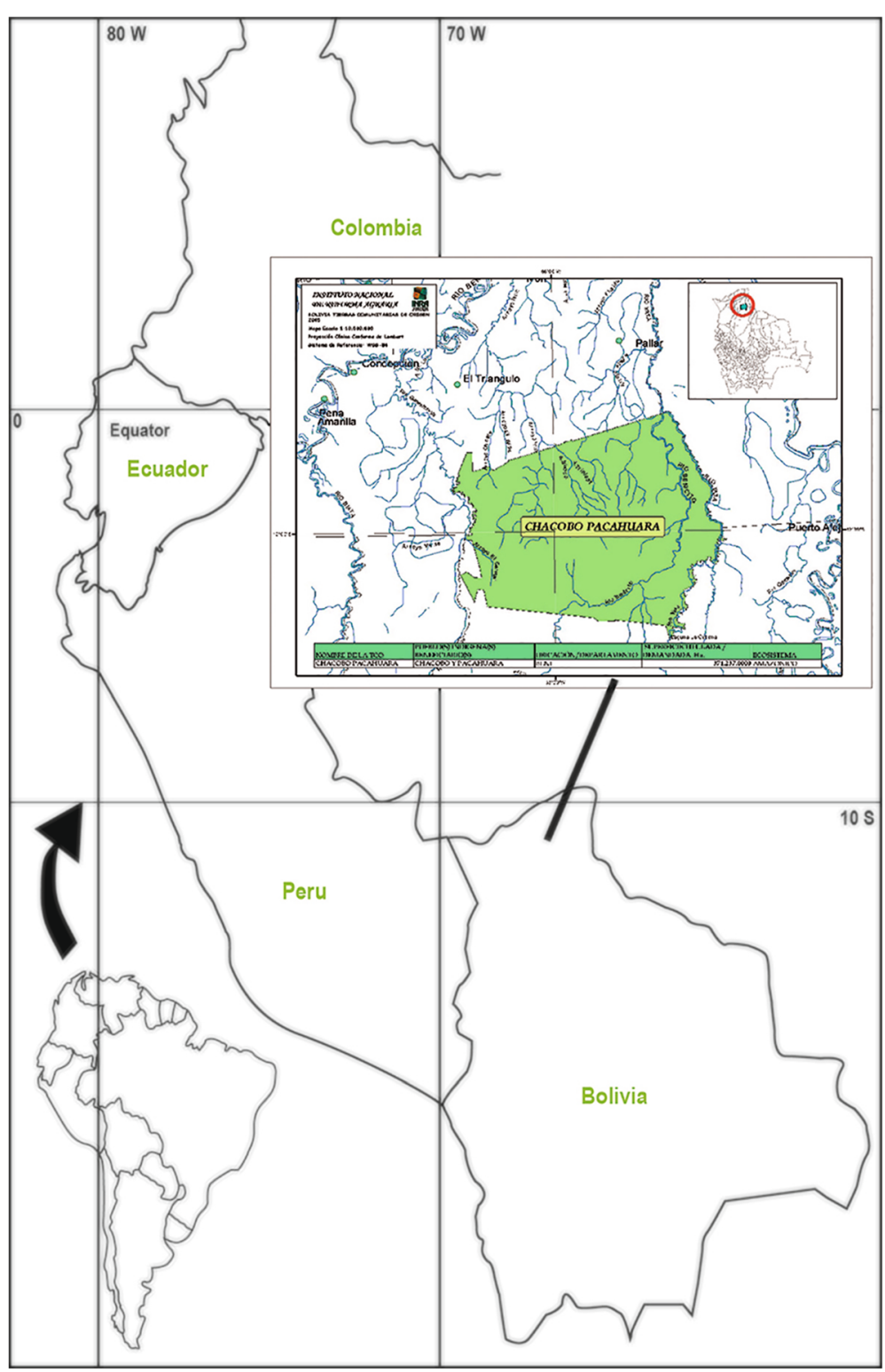

Fig. 1 Chácobo territory 2013 
Table 1 Plant species used by the Chácobo

FAMILY / SCIENTIFIC USES

NAME

Amaranthaceae

Chenopodium ambrosioides $\mathrm{L}$.

MEDVET: Digestive system (Appendicitis, Leaf; Diarrhea, Leaf); General Ailments with Unspecific Symptoms (Chest pain, Leaf); Respiratory system (Bronchitis, Leaf)

Amaryllidaceae

Allium cepa $\mathrm{L}$.

HUMFOOD: Food (Edible, Root); MEDVET: Infections and infestations (Tuberculosis, Root); Respiratory system (Cold and flu, Root)

Allium sativum $\mathrm{L}$.

MEDVET: Cultural diseases and disorders (Bad air and scare - Ratëaina, Root); General Ailments with Unspecific Symptoms (Chest pain, Root); Infections and infestations (Malaria and fever, Root); Reproductive system and sex health (Menstrual pain, Root); Snakebites and Ray stings (Sankebites, Root)

Anacardiaceae

Anacardium occidentale L.

\section{Astronium sp.}

HUMFOOD: Food (Edible, Fruit); MEDVET: Dental health (Toothache, Seeds); Digestive system (Diarrhea, Bark, fruit, leaf and young leaf; Stomach ache, Leaf); Endocrine system (Diabetes, Bark; Liver pain, Leaf); General Ailments with Unspecific Symptoms (Vomit, Bark, fruit, leaf and young leaf); Skin and subcutaneous tissue (Puchichi, Leaf); Urinary system (Kidney infection, Bark)

Mangifera indica L. HUMFOOD: Food (Edible, Fruit); MEDVET: Infections and infestations (Malaria and fever, Bark); UTEN\&TOOL: Labour tools (Shovel, Trunk)

Spondias venosa C. HUMFOOD: Food (Edible, Fruit) Martius ex Colla

Spondias venulosa C. Martius ex Colla

Tapirira guianensis Aubl.

MEDVET: Musculo-skeletal system (Fractures, Bark)

CONST: Houses (Frame house, Trunk: House postJibamë, Trunk); MEDVET: Digestive system (Diarrhea, Bark, Stomach ache, Bark); Endocrine system (Gallbladder, Bark); General Ailments with Unspecific Symptoms (Vomit, Bark); Infections and infestations (Malaria and fever, Bark); Skin and subcutaneous tissue (Caracha, Bark; Skin fungus, Bark)

Annonaceae

Annona hypoglauca Mart.

Annona montana Macfad.

Annona sp.

Cymbopetalum brasiliense (Vell.) Benth. ex Baill.

Duguetia quitarensis Benth.

Guatteria discolor R. E. Fries
HUMFOOD: Food (Edible, Fruit); MEDVET: Musculoskeletal system (Blows, Bark; Bone pain, Bark; Rheumatism, Bark); Respiratory system (Cold and flu, Bark)

CONST: Houses (Frame house, Trunk); HUMFOOD:

Food (Edible, Fruit)

HUMFOOD: Food (Edible, Fruit)

HUMFOOD: Food (Edible, Fruit and seeds); MEDVET: Infections and infestations (Leishmaniasis, Root); Skin and subcutaneous tissue (Wounds and cuts, Root); Snakebites and Ray stings (Sankebites, Root)

HUMFOOD: Food (Edible, Fruit)

CONST: Houses (Frame house, Trunk; To tie house, Bark)
VERNACULAR NAMES (Ch-Chácobo, Sp-Spanish)

Coll \#

Caré (Ch)

GOS 44, JSM 13,

ORC 5

Cebolla (Sp)

Ajo (Sp)

Ajo (Sp) 
Table 1 Plant species used by the Chácobo (Continued)

\begin{tabular}{|c|c|c|c|}
\hline $\begin{array}{l}\text { Guatteria } \\
\text { hyposericea Diels }\end{array}$ & $\begin{array}{l}\text { CONST: Houses (Muchacho - Ninotí, Trunk; Tie - } \\
\text { Xahui, Bark); Thatch (To tie roof, Bark); FUEL: Firewood } \\
\text { (Firewood - Caro, Trunk) }\end{array}$ & Ahuabaca (Ch); Pavo (Sp) & $\mathrm{CH} 7$ \\
\hline $\begin{array}{l}\text { Xylopia ligustrifolia } \\
\text { Humb. \& Bonpl. ex } \\
\text { Dunal }\end{array}$ & $\begin{array}{l}\text { CONST: Houses (Tie - Xahui, Bark; Tirante corto - Cano } \\
\text { Bësëcamë, Trunk; To tie house, Bark); Other } \\
\text { constructions (Huaracha, Trunk); Thatch (To tie roof, } \\
\text { Bark); FUEL: Firewood (Firewood - Caro, Trunk) }\end{array}$ & Xahuisi (Ch) & MSM 14, SCO 2 \\
\hline $\begin{array}{l}\text { Xylopia peruviana } \\
\text { R.E. Fr. }\end{array}$ & $\begin{array}{l}\text { CONST: Houses (Frame house, Trunk; Hedge - Panë, } \\
\text { Trunk; House post- Jibamë, Trunk, Jihuixaca, Trunk, } \\
\text { Muchacho - Ninotí, Trunk; Nasëcamëti, Trunk; Pasa } \\
\text { ratón - Xoya jabati, Trunk; Ridgepole - Maracatí, Trunk; } \\
\text { Roof beam - Canoxoco, Trunk; Solera - Chitao, Trunk; } \\
\text { Tie - Xahui, Bark; Tirante - Cano bëpotó, Trunk; Tirante } \\
\text { corto - Cano Bësëcamë, Trunk; Tirante largo - Cano } \\
\text { pixquëna, Trunk; To tie fence, Bark; To tie house, } \\
\text { Bark); Other constructions (Huaracha, Trunk); Thatch } \\
\text { (Techo - Xëhuahacacató, Bark; To tie roof, Bark); FUEL: } \\
\text { Firewood (Firewood - Caro, Trunk); HUMFOOD: Food } \\
\text { (Edible, Fruit and root); MEDVET: Musculo-skeletal } \\
\text { system (Bone pain, Seeds); Skin and subcutaneous } \\
\text { tissue (Haemorrhage, Leaf); UTEN\&TOOL: Domestic } \\
\text { utensils (Basket - Chichabëcasa, Bark; Basket - } \\
\text { Chichama, Bark; Basket - Nishicacano, Bark; Basket - } \\
\text { Purupachi, Bark; Hammock - Nishi, Bark); Hunting \& } \\
\text { fishing tools (Arrow - Paca, Trunk); Rope (Rope - } \\
\text { Rispichi, Bark) }\end{array}$ & Tëtëmëtsisi / Xahui (Ch); Piraquina / Pancho (Sp) & MOV 37 \\
\hline $\begin{array}{l}\text { Xylopia polyantha } \\
\text { R.E. Fr. }\end{array}$ & $\begin{array}{l}\text { CONST: Houses (Muchacho - Ninotí, Trunk; Pasa ratón } \\
\text { - Xoya jabatí, Trunk; Roof beam - Canoxoco, Trunk; } \\
\text { Tirante corto - Cano Bësëcamë, Trunk); Thatch (To tie } \\
\text { roof, Bark); FUEL: Firewood (Firewood - Caro, Trunk) }\end{array}$ & Xahuiria (Ch) & $\mathrm{CH} 8$ \\
\hline Xylopia sp. & $\begin{array}{l}\text { CONST: Houses (Frame house, Trunk; Jihuixaca, Trunk; } \\
\text { Muchacho - Ninotí, Trunk; Pasa ratón - Xoya jabatí, } \\
\text { Trunk; Ridgepole - Maracatí, Trunk; Roof beam - } \\
\text { Canoxoco, Trunk; Tie - Xahui, Bark; Tirante - Cano } \\
\text { bëpotó, Trunk; Tirante corto - Cano Bësëcamë, Trunk; } \\
\text { Tirante largo - Cano pixquëna, Trunk); FUEL: Firewood } \\
\text { (Firewood - Caro, Trunk) }\end{array}$ & Capëtërëbó (Ch) & ORC 7 \\
\hline \multicolumn{4}{|l|}{ Apiaceae } \\
\hline Daucus carota $\mathrm{L}$. & $\begin{array}{l}\text { HUMFOOD: Food (Edible, Root); MEDVET: Sensory } \\
\text { system (Inflammation of eyes, Root) }\end{array}$ & Zanahoria (Sp) & \\
\hline \multicolumn{4}{|l|}{ Apocynaceae } \\
\hline $\begin{array}{l}\text { Aspidosperma } \\
\text { excelsum Benth. }\end{array}$ & FUEL: Firewood (Firewood - Caro, Trunk) & Tiorcorihua (Ch) & SCO 37 \\
\hline $\begin{array}{l}\text { Aspidosperma } \\
\text { megalocarpon Müll. } \\
\text { Arg. }\end{array}$ & $\begin{array}{l}\text { FUEL: Firewood (Firewood - Caro, Trunk); HUMFOOD: } \\
\text { Food (Edible, Fruit); MEDVET: Endocrine system } \\
\text { (Gallbladder, Bark); Infections and infestations (Malaria } \\
\text { and fever, Bark and root); Respiratory system (Cold } \\
\text { and flu, Bark and seeds); Skin and subcutaneous } \\
\text { tissue (Caracha, Bark); UTEN\&TOOL: Domestic utensils } \\
\text { (Basket - Chichama, Bark; Pestle of Tacu, Trunk; Tacú - } \\
\text { Arusa timatí, Trunk); Labour tools (Axe - Maquë } \\
\text { poroma, Trunk; Planting stick - Xësati, Trunk) }\end{array}$ & Poroma Jihui / Cháchama (Ch); Gabetillo (Sp) & $\mathrm{CH} 9$ \\
\hline $\begin{array}{l}\text { Geissospermum } \\
\text { reticulatum (Jacq.) K. } \\
\text { Schum. }\end{array}$ & $\begin{array}{l}\text { MEDVET: Infections and infestations (Malaria and } \\
\text { fever, Bark) }\end{array}$ & Jihui Moca (Ch) & GOS 22, SCO 20 \\
\hline \multirow[t]{2}{*}{$\begin{array}{l}\text { Hancornia speciosa } \\
\text { Gomes }\end{array}$} & $\begin{array}{l}\text { HUMFOOD: Food (Edible, Fruit); MEDVET: Endocrine } \\
\text { system (Liver, Bark) }\end{array}$ & Xabá motoha (Ch); Magaba (Sp) & $\begin{array}{l}\text { GOS 16, RBU } \\
17833\end{array}$ \\
\hline & & Jihui bëpiya (Ch); Sucuba (Sp) & \\
\hline
\end{tabular}


Table 1 Plant species used by the Chácobo (Continued)

\begin{tabular}{|c|c|c|c|}
\hline $\begin{array}{l}\text { Himatanthus } \\
\text { sucuuba (Spruce ex } \\
\text { Müll. Arg.) Woodson }\end{array}$ & $\begin{array}{l}\text { MEDVET: Cultural diseases and disorders (Bad air and } \\
\text { scare - Ratëaina, Trunk); Digestive system } \\
\text { (Appendicitis, Bark, and exhudate; Diarrhea); } \\
\text { Endocrine system (Gallbladder, Exudate; Pancreas, } \\
\text { Exudate); General Ailments with Unspecific } \\
\text { Symptoms (Body pain, Bark and exhudate; Chest } \\
\text { pain, Bark; Headache, Bark); Infections and infestations } \\
\text { (Anthelmintic, Bark; Boro, Exudate; Malaria and fever, } \\
\text { Exudate); Musculo-skeletal system (Blows, Exudate; } \\
\text { Fractures, Bark; Hernia, Exudate; Rheumatism, Leaf) }\end{array}$ & & $\begin{array}{l}\text { DOA 2, 52, ESR } \\
19, \text { GOS } 8,56 \\
\text { MOV } 14\end{array}$ \\
\hline $\begin{array}{l}\text { Tabernaemontana } \\
\text { linkii A. DC. }\end{array}$ & $\begin{array}{l}\text { MEDVET: Infections and infestations (Malaria and } \\
\text { fever, Bark, leaf and root) }\end{array}$ & Bahua Quëxti (Ch) & $\begin{array}{l}\text { MOV 54, RBU } \\
17863\end{array}$ \\
\hline $\begin{array}{l}\text { Woytkowskia } \\
\text { spermatochorda } \\
\text { Woodson }\end{array}$ & $\begin{array}{l}\text { CULT: Personal adornment (Ornament - Maxëití, } \\
\text { Seeds; Ornament - Mënëxëtí, Seeds; Ornament - } \\
\text { Shinoxëta, Seeds); FUEL: Firewood (Firewood - Caro, } \\
\text { Trunk) }\end{array}$ & Quisi / Chishinicato (Ch) & $\mathrm{CH} 10$ \\
\hline Anthurium sp. & MEDVET: Digestive system (Appendicitis, Trunk) & Buca Pëhi (Ch) & JSM 52 \\
\hline $\begin{array}{l}\text { Philodendron } \\
\text { bipinnatifidum SCOtt }\end{array}$ & $\begin{array}{l}\text { CONST: Houses (Tirante largo - Cano pixquëna, } \\
\text { Trunk); UTEN\&TOOL: Domestic utensils (Basket - } \\
\text { Chichama, Trunk) }\end{array}$ & Guembé (Sp) & $\mathrm{CH} 11$ \\
\hline $\begin{array}{l}\text { Philodendron } \\
\text { quinquelobum } \mathrm{K} \text {. } \\
\text { Krause }\end{array}$ & CONST: Houses (Frame house, Trunk) & Oi Nihi (Ch) & $\mathrm{CH} 12$ \\
\hline $\begin{array}{l}\text { Xanthosoma } \\
\text { sagittifolium L. Scott }\end{array}$ & HUMFOOD: Food (Edible, Root) & Xëca (Ch); Huaylusa (Sp) & $\mathrm{CH} 13$ \\
\hline $\begin{array}{l}\text { Xanthosoma } \\
\text { striolatum Mart. ex } \\
\text { Scott }\end{array}$ & $\begin{array}{l}\text { HUMFOOD: Beberages (Beberage - Chicha, Root); } \\
\text { Food (Edible, Root); MEDVET: Skin and subcutaneous } \\
\text { tissue (Caracha, Trunk) }\end{array}$ & Mataca (Ch); Huaylusa / Huaylusa amarilla (Sp) & $\mathrm{CH} 14$ \\
\hline \multicolumn{4}{|l|}{ Araliaceae } \\
\hline \multicolumn{4}{|l|}{ Arecaceae } \\
\hline $\begin{array}{l}\text { Acrocomia aculeata } \\
\text { (Jacq.) Lodd. ex Mart. }\end{array}$ & $\begin{array}{l}\text { HUMFOOD: Food (Edible, Fruit); UTEN\&TOOL: Hunting } \\
\text { \& fishing tools (Bow - Canatí, Trunk) }\end{array}$ & Totaí (Ch); Totaí (Sp) & \\
\hline $\begin{array}{l}\text { Allagoptera } \\
\text { leucocalyx (Drude) } \\
\text { Kuntze }\end{array}$ & MEDVET: Digestive system (Ulcers, Root) & Xahuë jina (Ch); Palmera de la sabana (Sp) & MOV 7 \\
\hline $\begin{array}{l}\text { Astrocaryum } \\
\text { aculeatum G. Mey. }\end{array}$ & $\begin{array}{l}\text { ANIMFOOD: Fodder (Edible, Fruit and seeds); CONST: } \\
\text { Houses (Frame house, Trunk; House post- Jibamë, } \\
\text { Trunk; Muchacho - Ninotí, Trunk; Tirante - Cano } \\
\text { bëpotó, Trunk); Other constructions (Huaracha, Trunk); } \\
\text { Thatch (Roof - Xëhuahacacató, Leaf and trunk); CULT: } \\
\text { Personal adornment (Ear piercing, Spine; Ornament - } \\
\text { Amënoxëta, Spine; Ornament - Anillo, Fruit; } \\
\text { Ornament - Rësëti, Spine; To drill seeds, Spine); } \\
\text { HUMFOOD: Food (Edible, Palm heart; Edible, Fruit); } \\
\text { MEDVET: General Ailments with Unspecific Symptoms } \\
\text { (Chest pain, Seeds); Infections and infestations (To } \\
\text { get nigua, Spine); Respiratory system (Cold and flu, } \\
\text { Seeds; Cough, Seeds); UTEN\&TOOL: Domestic utensils } \\
\text { (Basket - Bano, Leaf; Basket - Chichabëcasa, Young } \\
\text { leaf; Basket - Chichama, Young leaf; Basket - } \\
\text { Nishicacano, Young leaf; Basket - Purupachi, Young } \\
\text { leaf; Fan - Huëquëti, Young leaf; Hammock - Nishi, } \\
\text { Young leaf; Knife, Trunk; Man basket, Young leaf; Mat, } \\
\text { Leaf); Hunting \& fishing tools (Arrow - Bicobi, Trunk; }\end{array}$ & Huana / Panimá (Sp) & $\begin{array}{l}\text { DOA 40, RBU } \\
17850, \text { ESR } 13\end{array}$ \\
\hline
\end{tabular}


Table 1 Plant species used by the Chácobo (Continued)

\begin{tabular}{|c|c|}
\hline & $\begin{array}{l}\text { Arrow - Notsi, Trunk; Arrow - Quërëquë, Trunk; Arrow } \\
\text { - Quëspini, Trunk; Arrow - Tahua Quëspini, Trunk; } \\
\text { Arrow - Tiopi, Trunk; Arrow, Trunk; Bow - Canatí, } \\
\text { Trunk); Labour tools (Axe - Maquë poroma, Trunk; } \\
\text { Machete handle, Trunk); Rope (Rope - Rispichi, Young } \\
\text { leaf) }\end{array}$ \\
\hline $\begin{array}{l}\text { Astrocaryum ulei } \\
\text { Burret }\end{array}$ & $\begin{array}{l}\text { CONST: Houses (Hedge - Panë, Trunk); HUMFOOD: } \\
\text { Food (Edible, Fruit); UTEN\&TOOL: Domestic utensils } \\
\text { (Basket - Chichama, Young leaf; Fan - Huëquëti, } \\
\text { Young leaf) }\end{array}$ \\
\hline $\begin{array}{l}\text { Attalea butyracea } \\
\text { (Mutis ex L.f.) Wess. } \\
\text { Boer }\end{array}$ & $\begin{array}{l}\text { CONST: Thatch (Roof - Xëhuahacacató, Leaf); } \\
\text { UTEN\&TOOL: Domestic utensils (Tacú - Arusa timatí, } \\
\text { Trunk); Labour tools (Axe - Maquë poroma, Trunk; } \\
\text { Machete handle, Trunk; Planting stick - Xësati, Trunk) }\end{array}$ \\
\hline $\begin{array}{l}\text { Attalea maripa } \\
\text { (Aubl.) Mart. }\end{array}$ & $\begin{array}{l}\text { CONST: Houses (Frame house, Leaf; Ridgepole - } \\
\text { Maracatí, Trunk; Tie - Xahui, Young leaf; Tirante - } \\
\text { Cano bëpotó, Leaf; To tie house, Young leaf); Thatch } \\
\text { (Huaracha roof, Leaf; Ridgepole - Xobomapatí, Leaf; } \\
\text { Roof - Xëhuahacacató, Leaf; To tie roof, Young leaf); } \\
\text { CULT: Recreational (Toys, Trunk); FUEL: Other fuel } \\
\text { (Ceramics - Chomo, Leaf); HUMFOOD: Food (Edible, } \\
\text { Palm heart and fruit); MEDVET: Digestive system } \\
\text { (Diarrhea); UTEN\&TOOL: Domestic utensils (Basket - } \\
\text { Bano, Leaf; Basket - Chichama, Young leaf; Basket - } \\
\text { Nishicacano, Young leaf; Basket - Purupachi, Young } \\
\text { leaf; Basket - Yamachi, Young leaf; Fan - Huëquëti, } \\
\text { Young leaf; Knife, Trunk; Mat, Leaf; Pestle of Batan - } \\
\text { Chapi, Leaf); Hunting \& fishing tools (Arrow - } \\
\text { Quëspini, Trunk; Arrow - Tahua Quëspini, Trunk); } \\
\text { Labour tools (Axe - Maquë poroma, Trunk; Machete } \\
\text { handle, Trunk; Shovel, Trunk); Rope (Rope - Rispichi, } \\
\text { Young leaf) }\end{array}$ \\
\hline
\end{tabular}

Attalea phalerata CONST: Houses (Frame house, Trunk; Ridgepole Mart. ex Spreng Maracatí, Trunk; Roof beam - Canoxoco, Young leaf; Tie - Xahui, Young leaf; To tie house, Young leaf); Thatch (Huaracha roof, Leaf; Ridgepole - Xobomapatí, Leaf; Roof - Xëhuahacacató, Leaf; To tie roof, Young leaf); CULT: Clothes \& accessories (Dress - Moro, Young leaf); Ritual (Fragile children, Root); FUEL: Other fuel (Ceramics - Chomo, Leaf); HUMFOOD: Food (Edible, Fruit); MEDVET: Blood and Cardiovascular system (Anemia, Root); Dental health (Toothache, Seeds); Digestive system (Diarrhea, Fruit); Infections and infestations (Amoebas, Root; Anthelmintic, Root); Metabolic system and nutrition (Vitamin, Root); Sensory system (Earache, Seeds); Urinary system (Kidneys, Root); UTEN\&TOOL: Domestic utensils (Asalle, Young leaf; Basket - Bano, Leaf; Basket - Chichabëcasa, Young leaf; Basket Chichama, Young leaf; Basket - Nishicacano, Young leaf; Basket - Purupachi, Young leaf; Basket - Yamachi, Young leaf; Batán - Xaxo, Trunk; Fan - Huëquëti, Young leaf; Knife, Trunk; Mat, Leaf); Hunting \& fishing tools (Arrow - Quëspini, Trunk; Fishing bait, Seeds); Labour tools (Axe - Maquë poroma, Trunk; Machete handle, Trunk; Planting stick - Xësati, Trunk); Rope (Rope - Rispichi, Young leaf)

Attalea speciosa Mart. ex Spreng.
CONST: Houses (Frame house, Trunk; Tirante - Cano bëpotó, Leaf); Thatch (Ridgepole - Xobomapatí, Leaf; Roof - Xëhuahacacató, Leaf); HUMFOOD: Food (Edible, Fruit); MEDVET: Infections and infestations (Leishmaniasis, Seeds); Musculo-skeletal system (Bone pain, Seeds); Skin and subcutaneous tissue (Puchichi, Seeds) 
Table 1 Plant species used by the Chácobo (Continued)

\begin{tabular}{cl}
\hline $\begin{array}{c}\text { Bactris } \\
\text { acanthocarpa Mart. }\end{array}$ & CONST: Thatch (Huaracha roof, Trunk); HUMFOOD: \\
Bactris gasipaes & CULT: Cosmetic (Hair oil, Fruit); HUMFOOD: Food \\
Kunth. & (Edible, Fruit); UTEN\&TOOL: Domestic utensils (Basket \\
& - Chichama, Young leaf; Bow to clean cotton, Trunk; \\
& Hammock - Nishi, Young leaf; Knife, Trunk; Needle, \\
& Spine; Spinning wheel - Ihui bëro, Trunk; Spinning \\
& wheel - Ihui, Trunk; Tacú - Arusa timatí, Trunk); \\
& Hunting \& fishing tools (Arrow - Bicobi, Trunk; Arrow \\
& - Notsi, Trunk; Arrow - Paca, Trunk; Arrow - Pio, Trunk; \\
& Arrow - Quërëquë, Trunk; Arrow - Quëspini, Trunk; \\
& Arrow - Tahua Quëspini, Trunk; Arrow - Tiopi, Trunk; \\
& Arrow - Xeña, Trunk; Arrow, Trunk; Bow - Canatí, \\
& Trunk); Labour tools (Rake, Leaf; Shovel, Trunk) \\
& HuMFOOD: Food (Edible, Fruit): MEDVET: Sensory
\end{tabular}

is gasipaes var. chichagui $(\mathrm{H}$ Karst.) A.J. Hend.

. Food (Edible Fruit); MEDVET. Sensory system (Inflammation of eyes, Palm heart);

UTEN\&TOOL: Domestic utensils (Basket -

Chichabëcasa, Young leaf; Basket - Chichama, Young leaf; Hunting \& fishing tools; Bow - Canatí, Trunk);

Labour tools (Axe - Maquë poroma, Trunk)

Chelyocarpus chuco (Mart.) H.E. Moore

CONST: Thatch (Roof - Xëhuahacacató, Young leaf); UTEN\&TOOL: Domestic utensils (Basket - Chichama, Young leaf; Fan - Huëquëti, Young leaf; Knife, Petiole); Labour tools (Axe - Maquë poroma, Young leaf; Machete handle, Young leaf)

Cocos nucifera L. HUMFOOD: Food (Edible, Fruit); MEDVET: Skin and subcutaneous tissue (Haemorrhage, Seeds)

Euterpe oleracea Mart.

Euterpe precatoria Mart.

Geonoma deversa (Poit.) Kunth

Geonoma juruana Dammer
CONST: Thatch (Roof - Xëhuahacacató, Leaf); UTEN\&TOOL: Domestic utensils (Basket - Bano, Leaf)

CONST: Houses (Frame house, Trunk; Hedge - Panë, Trunk; Ridgepole - Maracatí, Trunk); Other constructions (Huaracha, Trunk; Food); Thatch (Huaracha roof, Leaf; Roof - Xëhuahacacató, Leaf); CULT: Personal adornment (Ornament - Maxëití, Fruit; Root); FUEL: Other fuel (Ceramics - Chomo, Leaf); HUMFOOD: Beberages (Beberage - Milk, Fruit); Food (Edible, Palm heart, fruit and young leaf); MEDVET: Blood and Cardio-vascular system (Anemia, Root); General Ailments with Unspecific Symptoms (Weakness, Root); Infections and infestations (Amoebas, Root); Insect and athropod bites (Buna bite, Young leaf); Metabolic system and nutrition (Vitamin, Root); Not specified at all (Not specified, Root); Skin and subcutaneous tissue (Caracha, Leaf) Snakebites and Ray stings (Sankebites, Fruit, palm heart, root and trunk); Urinary system (Kidneys, Root); UTEN\&TOOL: Domestic utensils (Basket - Bano, Leaf; Basket - Chichama, Young leaf; Basket - Nishicacano, Leaf; Basket - Purupachi, Young leaf; Basket Yamachi, Leaf; Batán - Xaxo, Trunk; Fan - Huëquëti, Young leaf; Hammock - Nishi, Young leaf; Knife, Trunk; Pestle of Batan - Chapi, Leaf); Hunting \& fishing tools (Bow - Canatí, Trunk); Labour tools (Axe Maquë poroma, Trunk; Hoe, Trunk; Machete handle, Trunk; Planting stick - Xësati, Trunk; Shovel, Trunk); Rope (Rope - Rispichi, Young leaf)

CONST: Thatch (Roof - Xëhuahacacató, Leaf)

CONST: Houses (Hedge - Panë, Trunk); Other constructions (Huaracha, Trunk); Thatch (Roof Xëhuahacacató, Leaf); HUMFOOD: Food (Edible, Fruit) Ornament - Shinoxëta, Seeds); Ritual (Fragile children,
Canahuanima (Ch)

$\mathrm{CH} 17$

Huanima (Ch); Chima (Sp)

DOA46

Huanima / Huanima Chitahë / Huanimahua (Ch); Chonta / Chontilla / Pupuña (Sp)

MOV 16, NPZ

8825

Hoja Redonda (Sp)

$\mathrm{CH} 18$

Coco (Sp)

Pananë (Ch); Asaí / Palmito (Sp)

Jënë / Pananë (Ch); Asaí / Palmito (Sp) 
Table 1 Plant species used by the Chácobo (Continued)

\begin{tabular}{|c|c|c|c|}
\hline $\begin{array}{l}\text { Geonoma } \\
\text { macrostachys Mart. }\end{array}$ & $\begin{array}{l}\text { CONST: Thatch (Roof - Xëhuahacacató, Leaf); FUEL: } \\
\text { Firewood (Firewood - Caro, Trunk); HUMFOOD: Food } \\
\text { (Edible, Fruit); UTEN\&TOOL: Hunting \& fishing tools } \\
\text { (Weapons, Trunk) }\end{array}$ & Shinibi (Ch) & JSM 24, MOV 27 \\
\hline f. Mauritia flexuosa L. & $\begin{array}{l}\text { CONST: Thatch (Roof - Xëhuahacacató, Leaf); } \\
\text { HUMFOOD: Food (Edible, Fruit); UTEN\&TOOL: } \\
\text { Domestic utensils (Basket - Chichama, Young leaf; } \\
\text { Sieve - Toahi, Young leaf); Labour tools (Axe - Maquë } \\
\text { poroma, Trunk; Machete handle, Trunk) }\end{array}$ & Palma Real (Sp) & $\mathrm{CH} 22$ \\
\hline $\begin{array}{l}\text { Oenocarpus balickii } \\
\text { F. Kahn }\end{array}$ & HUMFOOD: Food (Edible, Fruit) & Xoquëitsama (Ch); Majillo del Tucán (Sp) & RBU 17835 \\
\hline $\begin{array}{l}\text { Oenocarpus bataua } \\
\text { Mart. }\end{array}$ & $\begin{array}{l}\text { CONST: Houses (Ridgepole - Maracatí, Trunk); Other } \\
\text { constructions (Huaracha, Trunk); Thatch (Ridgepole - } \\
\text { Xobomapatí, Leaf; Roof - Xëhuahacacató, Leaf); CULT: } \\
\text { Cosmetic (Hair oil, Fruit); Personal adornment } \\
\text { (Ornament - Maxëití, Seeds; Ornament - Mënëxëtí, } \\
\text { Seeds; Ornament - Shinoxëta, Seeds); HUMFOOD: } \\
\text { Beberages (Beberage - Chicha, Fruit; Beberage - Milk, } \\
\text { Fruit); Food (Edible - Larvae, Trunk - Larvae; Edible, } \\
\text { Fruit); MEDVET: Endocrine system (Gallbladder, Trunk } \\
\text { - Larvae); General Ailments with Unspecific } \\
\text { Symptoms (Chest pain, Trunk - Larvae); Infections and } \\
\text { infestations (Leishmaniasis, Fruit); Respiratory system } \\
\text { (Bronchitis, Trunk - Larvae); Sensory system (Earache, } \\
\text { Fruit and trunk larvae); Skin and subcutaneous tissue } \\
\text { (Puchichi, Fruit); Snakebites and Ray stings } \\
\text { (Sankebites, Fruit); UTEN\&TOOL: Domestic utensils } \\
\text { (Basket - Bano, Leaf; Basket - Chichama, Young leaf; } \\
\text { Basket - Purupachi, Young leaf) }\end{array}$ & Itsama (Ch); Majo (Sp) & $\mathrm{CH} 23$ \\
\hline $\begin{array}{l}\text { Oenocarpus } \\
\text { mapora H. Karst }\end{array}$ & $\begin{array}{l}\text { CONST: Houses (Muchacho - Ninotí, Trunk; Ridgepole } \\
\text { - Maracatí, Trunk); HUMFOOD: Beberages (Beberage - } \\
\text { Milk, Fruit); Food (Edible - Larvae, Trunk; Edible, Fruit); } \\
\text { MEDVET: Snakebites and Ray stings (Sankebites, Trunk } \\
\text { - Larvae); UTEN\&TOOL: Domestic utensils (Basket - } \\
\text { Bano, Leaf; Basket - Purupachi, Young leaf; Tacú - } \\
\text { Arusa timatí, Trunk); Hunting \& fishing tools (Arrow - } \\
\text { Quëspini, Trunk; Bow - Canatí, Trunk) }\end{array}$ & Quëbo itsama (Ch); Majillo (Sp) & $\mathrm{CH} 24$ \\
\hline $\begin{array}{l}\text { Socratea exorrhiza } \\
\text { (Mart.) H. Wendl. }\end{array}$ & $\begin{array}{l}\text { CONST: Houses (Ceiling roof, Trunk; Frame house, } \\
\text { Trunk; Hedge - Panë, Trunk; Jaxca Jaxca, Trunk; Tie - } \\
\text { Xahui, Young leaf; Tirante largo - Cano pixquëna, } \\
\text { Trunk); Other constructions (Chapapa, Trunk; Chicken } \\
\text { coop, Trunk; Huaracha, Trunk; Shelves, Trunk; Store } \\
\text { corn, Trunk); Thatch (Roof - Xëhuahacacató, Leaf; Roof } \\
\text { - Xëhuahacacató, Trunk); HUMFOOD: Food (Edible, } \\
\text { Fruit); UTEN\&TOOL: Domestic utensils (Basket - } \\
\text { Purupachi, Young leaf; Cassava grater, Root; Table, } \\
\text { Trunk); Hunting \& fishing tools (Bow - Canatí, Trunk) }\end{array}$ & Onipa (Ch); Pachuba (Sp) & DOA 34 \\
\hline \multicolumn{4}{|l|}{ Aristolochiaceae } \\
\hline Aristolochia sp. & $\begin{array}{l}\text { MEDVET: Digestive system (Appendicitis, Bark; } \\
\text { Diarrhea, Trunk; Stomach ache, Bark); Endocrine } \\
\text { system (Liver pain, Bark); General Ailments with } \\
\text { Unspecific Symptoms (Headache, Bark; Vomit, Bark) }\end{array}$ & Maca Huatiapi (Ch) & SCO 32 \\
\hline \multicolumn{4}{|l|}{ Asteraceae } \\
\hline Vernonia sp. & $\begin{array}{l}\text { MEDVET: General Ailments with Unspecific Symptoms } \\
\text { (Inflammation, Trunk) }\end{array}$ & Cola de caballo (Sp) & DOA 45 \\
\hline $\begin{array}{l}\text { Wulffia baccata (L.) } \\
\text { Kuntze. }\end{array}$ & MEDVET: Respiratory system (Cold and flu, Leaf) & Bahua Rëxa (Ch) & DOA 29 \\
\hline \multicolumn{4}{|l|}{ Bignoniaceae } \\
\hline $\begin{array}{l}\text { Arrabidaea } \\
\text { brachypoda Bureau }\end{array}$ & $\begin{array}{l}\text { CULT: Personal adornment (Ornament - Shinoxëta, } \\
\text { Seeds); MEDVET: Digestive system (Diarrhea, Bark; }\end{array}$ & Corama / Nishi Raoxo (Ch); Paquío (Sp) & $\begin{array}{l}\text { ESR 1, GOS 7, JSM } \\
16, \text { RBU } 17866\end{array}$ \\
\hline
\end{tabular}


Table 1 Plant species used by the Chácobo (Continued)

\begin{tabular}{|c|c|c|c|}
\hline & $\begin{array}{l}\text { Stomach ache, Bark); General Ailments with } \\
\text { Unspecific Symptoms (Headache, Bark; Vomit, Bark); } \\
\text { UTEN\&TOOL: Domestic utensils (Basket - Nishicacano, } \\
\text { Trunk) }\end{array}$ & & \\
\hline $\begin{array}{c}\text { Arrabidaea } \\
\text { platyphylla DC. }\end{array}$ & $\begin{array}{l}\text { MEDVET: Infections and infestations (Boro, Root; } \\
\text { Malaria and fever, Root) }\end{array}$ & Bahua Quëxti (Ch) & $\mathrm{CH} 25$ \\
\hline Arrabidaea sp. & MEDVET: Sensory system (Inflammation of eyes, Root) & Yoquira (Ch) & $\mathrm{CH} 26$ \\
\hline $\begin{array}{l}\text { Ceratophytum } \\
\text { tetragonolobum } \\
\text { (Jacq.) Sprague \& } \\
\text { Sandwith }\end{array}$ & $\begin{array}{l}\text { MEDVET: Cultural diseases and disorders (Bad air and } \\
\text { scare - Ratëaina, Leaf); General Ailments with } \\
\text { Unspecific Symptoms (Body pain, Leaf; Body pain, } \\
\text { Trunk; Headache, Leaf; Vomit, Whole plant ); } \\
\text { Infections and infestations (Malaria and fever, Trunk); } \\
\text { Musculo-skeletal system (Rheumatism, Leaf) }\end{array}$ & $\begin{array}{l}\text { Boá Nishi / Boá / Bua (Ch); Ajo del monte / } \\
\text { Bejuco (Sp) }\end{array}$ & MOA 4, MOV 65 \\
\hline Clytostoma sp. & $\begin{array}{l}\text { CONST: Houses (Tie - Xahui, Bark; To tie house, Bark); } \\
\text { UTEN\&TOOL: Domestic utensils (Basket - Chichama, } \\
\text { Bark; Basket - Nishicacano, Bark) }\end{array}$ & Shino joxotaë / Shino yáquishi (Ch) & $\mathrm{CH} 26$ \\
\hline Crescentia cujete L. & UTEN\&TOOL: Domestic utensils (Container, Fruit) & Tutuma (Sp) & \\
\hline $\begin{array}{l}\text { Jacaranda copaia } \\
\text { (Aubl.) D. Don. }\end{array}$ & $\begin{array}{l}\text { FUEL: Firewood (Firewood - Caro, Trunk; Firewood, } \\
\text { Trunk); Other fuel (Ceramics - Paítí, Bark); MEDVET: } \\
\text { Infections and infestations (Scabies, Leaf); Musculo- } \\
\text { skeletal system (Ankle pain; Hip pain ); Not specified } \\
\text { at all; Respiratory system (Cold and flu); Skin and } \\
\text { subcutaneous tissue (Caracha; Wounds and cuts, } \\
\text { Leaf) }\end{array}$ & Pitsopi (Ch) & $\begin{array}{l}\text { DOA 20, GOS } 35 \\
\text { MOV } 49\end{array}$ \\
\hline $\begin{array}{l}\text { Jacaranda } \\
\text { obtusifolia Bonpl. }\end{array}$ & $\begin{array}{l}\text { FUEL: Firewood (Firewood - Caro, Trunk); Other fuel } \\
\text { (Ceramics - Tiesto - Pitëxti, Bark); MEDVET: Skin and } \\
\text { subcutaneous tissue (Caracha, Bark) }\end{array}$ & Pitsopi (Ch) & DOA 53, GOS 59 \\
\hline $\begin{array}{l}\text { Mussatia } \\
\text { hyacinthina (Standl.) } \\
\text { Sandw. }\end{array}$ & $\begin{array}{l}\text { CONST: Houses (Tie - Xahui, Bark); MEDVET: Digestive } \\
\text { system (Diarrhea, Bark; Stomach ache, Bark and leaf); } \\
\text { General Ailments with Unspecific Symptoms } \\
\text { (Headache, Bark ); Musculo-skeletal system (Bone } \\
\text { pain, Bark); Urinary system (Kidneys, Bark) }\end{array}$ & $\begin{array}{l}\text { Xoquë Rapotó (Ch); Chamairo / Chamairo negro } \\
\text { (Sp) }\end{array}$ & $\mathrm{CH} 27$ \\
\hline $\begin{array}{l}\text { Pyrostegia } \\
\text { dichotoma Miers ex } \\
\text { K. Schum. }\end{array}$ & $\begin{array}{l}\text { MEDVET: General Ailments with Unspecific Symptoms } \\
\text { (Vomit, Whole plant) }\end{array}$ & Nana Nihi (Ch) & $\mathrm{CH} 28$ \\
\hline $\begin{array}{l}\text { Tabebuia } \\
\text { chrysantha (Jacq.) } \\
\text { Nicholson }\end{array}$ & CONST: Houses (House post- Jibamë, Trunk) & Tajibo amarillo (Sp) & $\mathrm{CH} 29$ \\
\hline $\begin{array}{l}\text { Tabebuia ochracea } \\
\text { (Cham.) Standl. }\end{array}$ & $\begin{array}{l}\text { CONST: Houses (Frame house, Trunk; House post- } \\
\text { Jibamë, Trunk; Muchacho - Ninotí, Trunk; Tirante - } \\
\text { Cano bëpotó, Trunk); Thatch (Roof - Xëhuahacacató, } \\
\text { Trunk); MEDVET: Infections and infestations (Scabies); } \\
\text { Skin and subcutaneous tissue (Blisters ); Urinary } \\
\text { system (Kidneys); UTEN\&TOOL: Domestic utensils } \\
\text { (Gavel to make dress, Trunk; Pestle of Tacu, Trunk) }\end{array}$ & Nishó (Ch); Tajibo negro (Sp) & GOS 4 \\
\hline $\begin{array}{l}\text { Tabebuia serratifolia } \\
\text { (Vahl) G. Nicholson }\end{array}$ & $\begin{array}{l}\text { CONST: Houses (Frame house, Trunk; House post- } \\
\text { Jibamë, Trunk); HUMFOOD: Food (Edible, Trunk); } \\
\text { UTEN\&TOOL: Domestic utensils (Batán - Xaxo, Trunk; } \\
\text { Tacú - Arusa timatí, Trunk) }\end{array}$ & Tajibo (Sp) & $\mathrm{CH} 30$ \\
\hline Tabebuia sp. & $\begin{array}{l}\text { CONST: Houses (Frame house, Trunk; Muchacho - } \\
\text { Ninotí, Trunk; Pasa ratón - Xoya jabatí, Trunk; Solera - } \\
\text { Chitao, Trunk; Tie - Xahui, Bark; Tirante - Cano bëpotó, } \\
\text { Trunk; Tirante largo - Cano pixquëna, Trunk); FUEL: } \\
\text { Firewood (Firewood - Caro, Trunk); HUMFOOD: Food } \\
\text { (Edible, Fruit); MEDVET: Endocrine system } \\
\text { (Gallbladder, Root, seeds and trunk; Liver pain, Bark, } \\
\text { root and seeds); Sensory system (Inflammation of } \\
\text { eyes, Bark, leaf, and root; Conjunctivitis, Root; Earache, } \\
\text { Root) }\end{array}$ & Toromuca (Ch); Yuquilla (Sp) & MSM 6, 9 \\
\hline
\end{tabular}


Table 1 Plant species used by the Chácobo (Continued)

\begin{tabular}{|c|c|c|c|}
\hline Bixa orellana $\mathrm{L}$. & $\begin{array}{l}\text { CULT: Personal adornment (Ornament - Maxëití, } \\
\text { Seeds; Ornament - Xapo, Seeds); HUMFOOD: Food } \\
\text { (Edible, Seeds); MEDVET: Blood and Cardio-vascular } \\
\text { system (Heartache); Cultural diseases and disorders } \\
\text { (Evil eye, Trunk); Digestive system (Stomach ache, } \\
\text { Young leaf); Endocrine system (Liver pain, Young } \\
\text { leaf); General Ailments with Unspecific Symptoms } \\
\text { (Headache, Leaf; Inflammation ); Infections and } \\
\text { infestations (Leishmaniasis, Young leaf; Malaria and } \\
\text { fever, Exudate and leaf); Respiratory system (Cold and } \\
\text { flu); Sensory system (Inflammation of eyes, Exudate } \\
\text { and seeds); Skin and subcutaneous tissue } \\
\text { (Haemorrhage, Root and young leaf; Puchichi, Young } \\
\text { leaf); Urinary system (Kidneys) }\end{array}$ & Maxë (Ch); Urucú (Sp) & $\operatorname{GOS} 13$ \\
\hline \multicolumn{4}{|l|}{ Boraginaceae } \\
\hline $\begin{array}{l}\text { Cordia alliodora } \\
\text { (Ruiz. \& Pav.) Oken. }\end{array}$ & CONST: Houses (Frame house, Trunk) & Pabo (Ch) & JSM 7, 44 \\
\hline $\begin{array}{l}\text { Cordia ucayaliensis } \\
\text { (I.M. Johnst.) I.M. } \\
\text { Johnst. }\end{array}$ & $\begin{array}{l}\text { CONST: Houses (To tie house, Bark); FUEL: Firewood } \\
\text { (Firewood - Caro, Trunk) }\end{array}$ & Pabo (Ch) & MOV 33, SCO 36 \\
\hline \multicolumn{4}{|l|}{ Bromeliaceae } \\
\hline $\begin{array}{l}\text { Ananas comosum } \\
\text { (L.) Merr. }\end{array}$ & $\begin{array}{l}\text { CULT: Ritual (Fragile children, Leaf); HUMFOOD: Food } \\
\text { (Edible, Fruit); MEDVET: Digestive system (Diarrhea, } \\
\text { Leaf); General Ailments with Unspecific Symptoms } \\
\text { (Vomit, Fruit) }\end{array}$ & Piña (Sp) & \\
\hline Indet. sp. 1 & $\begin{array}{l}\text { HUMFOOD: Food (Edible, Fruit); MEDVET: Cultural } \\
\text { diseases and disorders (Bad air and scare - Ratëaina, } \\
\text { Seeds) }\end{array}$ & Xabá cacatao / Xabá Camano (Ch) & MOV 4 \\
\hline \multicolumn{4}{|l|}{ Burseraceae } \\
\hline $\begin{array}{l}\text { Protium } \\
\text { aracouchini (Aubl.) } \\
\text { Marchand }\end{array}$ & $\begin{array}{l}\text { MEDVET: Cultural diseases and disorders (Difficulty } \\
\text { speaking, Leaf) }\end{array}$ & Toshi xeta (Ch) & DOA 10 \\
\hline $\begin{array}{l}\text { Protium } \\
\text { sagotianum } \\
\text { Marchand }\end{array}$ & $\begin{array}{l}\text { FUEL: Firewood (Firewood - Caro, Trunk); HUMFOOD: } \\
\text { Food (Edible, Fruit) }\end{array}$ & Bëisiti Corihua (Ch); Isigo (Sp) & $\mathrm{CH} 31$ \\
\hline \multicolumn{4}{|l|}{ Cannabaceae } \\
\hline $\begin{array}{l}\text { Celtis schippii } \\
\text { Standl. }\end{array}$ & FUEL: Firewood (Firewood - Caro, Trunk) & Cátsisi (Ch) & $\mathrm{CH} 32$ \\
\hline $\begin{array}{l}\text { Trema micrantha } \\
\text { (L.) Blume }\end{array}$ & $\begin{array}{l}\text { ANIMFOOD: Fodder (Edible, Fruit); FUEL: Firewood } \\
\text { (Firewood - Caro, Trunk); HUMFOOD: Food (Edible, } \\
\text { Fruit) }\end{array}$ & Merabí (Ch) & JSM 61 \\
\hline \multicolumn{4}{|l|}{ Capparaceae } \\
\hline $\begin{array}{l}\text { Capparis } \\
\text { coimbrana Cornejo \& } \\
\text { Iltis }\end{array}$ & $\begin{array}{l}\text { FUEL: Firewood (Firewood - Caro, Trunk); HUMFOOD: } \\
\text { Food (Edible, Fruit); MEDVET: Endocrine system } \\
\text { (Gallbladder, Bark); Infections and infestations (Malaria } \\
\text { and fever, Bark) }\end{array}$ & Maca (Ch) & GOS 1, MOV 24 \\
\hline \multicolumn{4}{|l|}{ Caricaceae } \\
\hline Carica papaya $\mathrm{L}$. & $\begin{array}{l}\text { HUMFOOD: Food (Edible, Fruit); MEDVET: Dental } \\
\text { health (Toothache, Root); Digestive system (Diarrhea, } \\
\text { Exudate); Infections and infestations (Amoebas, Leaf } \\
\text { and seeds; Anthelmintic, Leaf and seeds); Insect and } \\
\text { athropod bites (Insectbite, Seeds); Respiratory system } \\
\text { (Cold and flu, Exudate ); Sensory system (Earache, } \\
\text { Exudate); Snakebites and Ray stings (Sankebites, Root) }\end{array}$ & Mapayo (Ch); Papaya (Sp) & GCM 10 \\
\hline $\begin{array}{l}\text { Jacaratia digitata } \\
\text { (Poepp. \& Endl.) } \\
\text { Solms }\end{array}$ & $\begin{array}{l}\text { HUMFOOD: Food (Edible, Fruit); MEDVET: Dental } \\
\text { health (Toothache, Root); General Ailments with } \\
\text { Unspecific Symptoms (Body pain, Trunk; Headache, } \\
\text { Leaf); Musculo-skeletal system (Bone pain, Trunk); Not }\end{array}$ & $\begin{array}{l}\text { Cana bohi / Huaquibí / Mapayo bërë (Ch); Papaya } \\
\text { del monte / papaya macho (Sp) }\end{array}$ & GOS 31 \\
\hline
\end{tabular}


Table 1 Plant species used by the Chácobo (Continued)

\begin{tabular}{|c|c|c|c|}
\hline & $\begin{array}{l}\text { specified at all (Not specified, Fruit); Snakebites and } \\
\text { Ray stings (Sankebites, Root) }\end{array}$ & & \\
\hline \multicolumn{4}{|l|}{ Caryocaraceae } \\
\hline $\begin{array}{l}\text { Caryocar dentatum } \\
\text { Gleason }\end{array}$ & $\begin{array}{l}\text { ANIMFOOD: Fodder (Edible, Fruit); CULT: Clothes \& } \\
\text { accessories (Wash dress, Bark); Personal adornment } \\
\text { (Ornament - Mënëxëtí, Bark); MEDVET: Not specified } \\
\text { at all (Not specified) }\end{array}$ & Jënë carama (Ch) & DOA 57, GOS 54 \\
\hline \multicolumn{4}{|l|}{ Celastraceae } \\
\hline $\begin{array}{l}\text { Salacia elliptica } \\
\text { (Mart. ex Schult.) G. } \\
\text { Don. }\end{array}$ & $\begin{array}{l}\text { FUEL: Firewood (Firewood - Caro, Trunk); HUMFOOD: } \\
\text { Food (Edible, Fruit); MEDVET: Digestive system } \\
\text { (Diarrhea, Leaf); Urinary system (Kidneys, Root) }\end{array}$ & Nëxo quërimati (Ch); Huapamú (Sp) & $\begin{array}{l}\text { DOA } 47, \text { GOS } 42 \\
\text { MOA } 3\end{array}$ \\
\hline $\begin{array}{l}\text { Salacia gigantea } \\
\text { Loes }\end{array}$ & $\begin{array}{l}\text { CONST: Houses (Tie - Xahui, Bark); HUMFOOD: Food } \\
\text { (Edible, Fruit) }\end{array}$ & Ahuax Xtëpoco (Ch) & $\mathrm{CH} 33$ \\
\hline $\begin{array}{l}\text { Tontelea ovalifolia } \\
\text { subsp. richardii (Peyr.) } \\
\text { Görts \& Mennega }\end{array}$ & $\begin{array}{l}\text { HUMFOOD: Food (Edible, Fruit); MEDVET: Endocrine } \\
\text { system (Liver pain, Fruit) }\end{array}$ & Quërë matí (Ch); Guapomó (Sp) & $\mathrm{CH} 34$ \\
\hline \multicolumn{4}{|l|}{ Chrysobalanaceae } \\
\hline $\begin{array}{l}\text { Hirtella gracilipes } \\
\text { (Hook. f.) Prance }\end{array}$ & $\begin{array}{l}\text { MEDVET: Skin and subcutaneous tissue (Caracha, } \\
\text { Bark) }\end{array}$ & Xaba chana (Ch) & $\begin{array}{l}\text { MSM 4, RBU } \\
17832\end{array}$ \\
\hline $\begin{array}{l}\text { Hirtella pilosissima } \\
\text { Mart. \& Zucc. }\end{array}$ & $\begin{array}{l}\text { CONST: Houses (House post- Jibamë, Trunk); CULT: } \\
\text { Clothes \& accessories (Dress - Moro, Bark); FUEL: } \\
\text { Firewood (Firewood - Caro, Trunk); HUMFOOD: Food } \\
\text { (Edible, Fruit); MEDVET: Musculo-skeletal system } \\
\text { (Fractures, Bark); Skin and subcutaneous tissue } \\
\text { (Caracha, Bark); UTEN\&TOOL: Domestic utensils (Gavel } \\
\text { to make dress, Trunk; Pestle of Tacu, Trunk; Tacú - } \\
\text { Arusa timatí, Trunk); Labour tools (Machete handle, } \\
\text { Trunk; Planting stick - Xësati, Trunk; Spade handle, } \\
\text { Trunk) }\end{array}$ & $\begin{array}{l}\text { Chanahua / Moro choxtí (Ch); Coloradillo / Cuchi } \\
\text { (Sp) }\end{array}$ & $\mathrm{CH} 34$ \\
\hline $\begin{array}{l}\text { Licania } \\
\text { intrapetiolaris Spruce } \\
\text { ex. Hook f. }\end{array}$ & $\begin{array}{l}\text { CONST: Houses (Frame house, Trunk; Hedge - Panë, } \\
\text { Trunk; House post- Jibamë, Trunk; Jihuixaca, Trunk; } \\
\text { Manipoatí, Trunk; Muchacho - Ninotí, Trunk; Pasa } \\
\text { ratón - Xoya jabatí, Trunk; Ridgepole - Maracatí, Trunk; } \\
\text { Roof beam - Canoxoco, Trunk; Sabrillo, Trunk; Solera - } \\
\text { Chitao, Trunk; Tirante largo - Cano pixquëna, Trunk); } \\
\text { Other constructions (Huaracha, Trunk); FUEL: } \\
\text { Firewood (Firewood - Caro, Trunk); Other fuel } \\
\text { (Ceramics - Chomo, Bark; Ceramics - Comëno, Bark; } \\
\text { Ceramics - Paítí, Bark); HUMFOOD: Food (Edible, Fruit); } \\
\text { MEDVET: General Ailments with Unspecific Symptoms } \\
\text { (Chest pain, Seeds); Insect and athropod bites } \\
\text { (Insectbite, Bark); Musculo-skeletal system (Bone pain, } \\
\text { Seeds); UTEN\&TOOL: Domestic utensils (Pestle of } \\
\text { Tacu, Trunk) }\end{array}$ & Shishaxë (Ch); Cacharí (Sp) & $\mathrm{CH} 35$ \\
\hline $\begin{array}{l}\text { Licania octandra } \\
\text { subsp. pallida (Hook. } \\
\text { f.) Prance }\end{array}$ & $\begin{array}{l}\text { CONST: Houses (Hedge - Panë, Trunk; Xano, Trunk); } \\
\text { FUEL: Firewood (Firewood - Caro, Trunk); Other fuel } \\
\text { (Ceramics - Chomo, Bark; Ceramics - Comëno, Bark; } \\
\text { Ceramics - Paítí, Bark; Ceramics - Tiesto - Pitëxti, Bark); } \\
\text { HUMFOOD: Food (Edible, Fruit); UTEN\&TOOL: } \\
\text { Domestic utensils (Basket - Chichabëcasa, Bark; Basket } \\
\text { - Chichama, Bark; Batán - Xaxo, Trunk) }\end{array}$ & Mëhi (Ch); Caripe (Sp) & MSM 10 \\
\hline \multicolumn{4}{|l|}{ Clusiaceae } \\
\hline $\begin{array}{l}\text { Garcinia madruno } \\
\text { (Kunth) Hammel }\end{array}$ & $\begin{array}{l}\text { ANIMFOOD: Fodder (Edible, Fruit); HUMFOOD: Food } \\
\text { (Edible, Fruit); Food aditives (Additive coca chewing, } \\
\text { Fruit); MEDVET: Digestive system (Diarrhea, Bark; } \\
\text { Stomach ache, Bark); Skin and subcutaneous tissue } \\
\text { (Puchichi, Young leaf) }\end{array}$ & Shiquishi / Tahuatë (Ch); Achachairú (Sp) & DOA 12, JSM 33 \\
\hline Tovomita sp. & FUEL: Firewood (Firewood - Caro, Trunk) & Áhuara Macha (Ch) & MOV 28 \\
\hline
\end{tabular}


Table 1 Plant species used by the Chácobo (Continued)

\begin{tabular}{|c|c|c|c|}
\hline Indet. sp. 1 & $\begin{array}{l}\text { CONST: Houses (Frame house, Trunk; Hedge - Panë, } \\
\text { Trunk; House post- Jibamë, Trunk; Muchacho - Ninotí, } \\
\text { Trunk; Ridgepole - Maracatí, Trunk; Roof beam - } \\
\text { Canoxoco, Trunk; Solera - Chitao, Trunk; Tie - Xahui, } \\
\text { Bark; Tirante - Cano bëpotó, Trunk; Tirante largo - } \\
\text { Cano pixquëna, Trunk); HUMFOOD: Food (Edible, } \\
\text { Fruit); UTEN\&TOOL: Domestic utensils (Tacú - Arusa } \\
\text { timatí, Trunk) }\end{array}$ & Bacurí (Ch); Motoa (Sp) & $\mathrm{CH} 36$ \\
\hline \multicolumn{4}{|l|}{ Cochleospermaceae } \\
\hline $\begin{array}{l}\text { Cochlospermum } \\
\text { orinocense (H.B.K.) } \\
\text { Steudel }\end{array}$ & CONST: Houses (Tie - Xahui, Bark) & Algodoncillo (Sp) & $\mathrm{CH} 37$ \\
\hline \multicolumn{4}{|l|}{ Combretaceae } \\
\hline $\begin{array}{l}\text { Terminalia } \\
\text { amazonica (Gmel.) } \\
\text { Exell }\end{array}$ & $\begin{array}{l}\text { MEDVET: Skin and subcutaneous tissue (Wounds and } \\
\text { cuts, Bark and leaf) }\end{array}$ & Verdolago (Sp) & $\mathrm{CH} 38$ \\
\hline \multicolumn{4}{|l|}{ Connaraceae } \\
\hline $\begin{array}{l}\text { Connarus ruber } \\
\text { (Poepp. \& Endl.) } \\
\text { Planch. }\end{array}$ & CULT: Recreational (Toys, Fruit and leaf) & Pitso tapa (Ch) & GCM 6, MSM 15 \\
\hline \multicolumn{4}{|l|}{ Convolvulaceae } \\
\hline $\begin{array}{l}\text { Ipomoea batas } \\
\text { Lam. }\end{array}$ & $\begin{array}{l}\text { HUMFOOD: Beberages (Beberage - Chicha, Root); } \\
\text { Food (Edible, Root); MEDVET: Digestive system } \\
\text { (Appendicitis, Leaf; Stomach ache, Flower); Endocrine } \\
\text { system (Gallbladder, Seeds); General Ailments with } \\
\text { Unspecific Symptoms (For bathing sick chlidren, } \\
\text { Whole plant; Headache, Root); Infections and } \\
\text { infestations (Malaria and fever, Leaf); Respiratory } \\
\text { system (Bronchitis, Leaf and root; Cold and flu, Leaf } \\
\text { and root) }\end{array}$ & Cari (Ch); Camote (Sp) & \\
\hline \multicolumn{4}{|l|}{ Costaceae } \\
\hline $\begin{array}{l}\text { Costus scaber Ruiz. } \\
\text { \& Pav. }\end{array}$ & $\begin{array}{l}\text { MEDVET: Blood and Cardio-vascular system } \\
\text { (Heartache, Trunk); Cultural diseases and disorders } \\
\text { (Bad air and scare - Ratëaina, Root); Dental health } \\
\text { (Toothache, Root and seeds); Digestive system } \\
\text { (Appendicitis, Whole plant; Diarrhea, Fruit, root, trunk } \\
\text { and young leaf ; Stomach ache, Trunk); Endocrine } \\
\text { system (Gallbladder, Trunk and whole plant; } \\
\text { Gallbladder, Whole plant and root); Pancreas, Trunk); } \\
\text { General Ailments with Unspecific Symptoms } \\
\text { (Headache, Root; Vomit, Fruit, leaf, root, seeds, trunk } \\
\text { and whole plant); Infections and infestations } \\
\text { (Hepatitis, Whole plant); Musculo-skeletal system } \\
\text { (Swelling, Trunk); Skin and subcutaneous tissue } \\
\text { (Burns, Leaf); Urinary system (Kidney infection, Trunk; } \\
\text { Kidney pain, Leaf and trunk; Kidneys, Leaf and trunk; } \\
\text { Yellow urine, Trunk) }\end{array}$ & Bushishi (Ch); Cahuasha / Caña / Caña agria (Sp) & $\begin{array}{l}\text { DOA } 48, \operatorname{GOS} 45 \\
\text { MOA 6, SCO 29, } \\
\text { JSM } 56\end{array}$ \\
\hline \multicolumn{4}{|l|}{ Crassulaceae } \\
\hline Bryophyllum sp. & $\begin{array}{l}\text { MEDVET: Infections and infestations (Leishmaniasis, } \\
\text { Leaf); Musculo-skeletal system (Blows, Leaf; Swelling, } \\
\text { Leaf); Skin and subcutaneous tissue (Puchichi, Leaf) }\end{array}$ & Bai Ati (Ch); Fortuna (Sp) & $\mathrm{CH} 39$ \\
\hline \multicolumn{4}{|l|}{ Cucurbitaceae } \\
\hline $\begin{array}{l}\text { Citrullus vulgaris } \\
\text { Schrad. }\end{array}$ & $\begin{array}{l}\text { HUMFOOD: Food (Edible, Fruit); UTEN\&TOOL: } \\
\text { Domestic utensils (Container, Fruit) }\end{array}$ & Sania (Ch); Sandía (Sp) & \\
\hline Cucumis sativus $\mathrm{L}$. & HUMFOOD: Food (Edible, Fruit) & Pepino (Sp) & \\
\hline $\begin{array}{l}\text { Cucurbita } \\
\text { moschata Duchesne }\end{array}$ & HUMFOOD: Food (Edible, Fruit) & Zapallo (Sp) & \\
\hline Cucurbita sp. & & Mate / Mate bejuco (Sp) & \\
\hline
\end{tabular}


Table 1 Plant species used by the Chácobo (Continued)

\begin{tabular}{|c|c|c|c|}
\hline & $\begin{array}{l}\text { HUMFOOD: Food (Edible, Seeds); MEDVET: Skin and } \\
\text { subcutaneous tissue (Caracha, Leaf; Skin fungus, Leaf); } \\
\text { UTEN\&TOOL: Domestic utensils (Container, Fruit) }\end{array}$ & & \\
\hline Indet. sp. 1 & HUMFOOD: Food (Edible, Fruit) & Huaramë (Ch); Joco (Sp) & $\mathrm{CH} 40$ \\
\hline \multicolumn{4}{|l|}{ Cyperaceae } \\
\hline Cyperus sp. & $\begin{array}{l}\text { MEDVET: Digestive system (Appendicitis, Whole plant; } \\
\text { Diarrhea, Root and trunk; Stomach ache, Trunk); } \\
\text { Endocrine system (Liver pain, Root); General Ailments } \\
\text { with Unspecific Symptoms (Inflammation, Leaf; Vomit, } \\
\text { Root, seeds and trunk); Infections and infestations } \\
\text { (Malaria and fever, Root) }\end{array}$ & Tsanona (Ch); Cahuasha (Sp) & GOS 41 \\
\hline $\begin{array}{l}\text { Diplasia karatifolia } \\
\text { Rich. }\end{array}$ & $\begin{array}{l}\text { MEDVET: Digestive system (Constipation, Trunk); } \\
\text { Pregnancy, birth and puerperial (Birth, Root) }\end{array}$ & Cortadera (Sp) & ESR 16 \\
\hline \multicolumn{4}{|l|}{ Dennstaedtiaceae } \\
\hline Pteridium sp. & $\begin{array}{l}\text { MEDVET: Digestive system (Stomach ache, Root); } \\
\text { Endocrine system (Gallbladder, Root) }\end{array}$ & Jasini huitahuo (Ch) & MOV 53 \\
\hline \multicolumn{4}{|l|}{ Dichapetalaceae } \\
\hline $\begin{array}{l}\text { Dichapetalum } \\
\text { spruceanum Baill. }\end{array}$ & FUEL: Firewood (Firewood - Caro, Trunk) & Nishi cobo (Ch) & MOV 43 \\
\hline \multicolumn{4}{|l|}{ Dilleniaceae } \\
\hline $\begin{array}{l}\text { Curatella } \\
\text { americana L. }\end{array}$ & $\begin{array}{l}\text { FUEL: Firewood (Firewood - Caro, Trunk); MEDVET: } \\
\text { Digestive system (Diarrhea); Endocrine system (Liver); } \\
\text { General Ailments with Unspecific Symptoms (Chest } \\
\text { pain, Bark); Infections and infestations (Malaria and } \\
\text { fever, Bark); Respiratory system (Cough, Bark) }\end{array}$ & Xaba tapahua (Ch) & $\begin{array}{l}\text { JSM 9, RBU 17846, } \\
\text { GCM } 3\end{array}$ \\
\hline Doliocarpus sp. & $\begin{array}{l}\text { CONST: Houses (Ridgepole - Maracatí, Trunk; Tie - } \\
\text { Xahui, Bark; To tie house, Bark); Thatch (To tie roof, } \\
\text { Bark); MEDVET: Digestive system (Diarrhea, Bark) }\end{array}$ & Quëbo xamahua (Ch) & $\mathrm{CH} 41$ \\
\hline \multicolumn{4}{|l|}{ Dioscoreaceae } \\
\hline $\begin{array}{l}\text { Dioscorea latifolia } \\
\text { Benth. }\end{array}$ & $\begin{array}{l}\text { HUMFOOD: Beberages (Beberage - Chicha, Root); } \\
\text { Food (Edible - Chive, Root; Edible, Root) }\end{array}$ & Chaxo Poa (Ch); Bachi (Sp) & $\mathrm{CH} 42$ \\
\hline \multicolumn{4}{|l|}{ Erythroxylaceae } \\
\hline $\begin{array}{l}\text { Erythroxylum coca } \\
\text { Lam. }\end{array}$ & $\begin{array}{l}\text { FUEL: Firewood (Firewood - Caro, Trunk); MEDVET: } \\
\text { Cultural diseases and disorders (Bad air and scare - } \\
\text { Ratëaina, Leaf); Digestive system (Stomach ache, } \\
\text { Leaf); Endocrine system (Liver pain, Leaf); } \\
\text { UTEN\&TOOL: Labour tools (Awl, Trunk) }\end{array}$ & Huara huara (Ch); Coca (Sp) & DOA 8, JSM 28 \\
\hline \multicolumn{4}{|l|}{ Euphorbiaceae } \\
\hline Alchornea sp. & $\begin{array}{l}\text { CONST: Houses (House post- Jibamë, Trunk; } \\
\text { Muchacho - Ninotí, Trunk; Pasa ratón - Xoya jabatí, } \\
\text { Trunk; Tirante - Cano bëpotó, Trunk; Tirante corto - } \\
\text { Cano Bësëcamë, Trunk; Tirante largo - Cano pixquëna, } \\
\text { Trunk); Other constructions (Huaracha, Trunk); CULT: } \\
\text { Ritual (Fragile children, Leaf); FUEL: Firewood } \\
\text { (Firewood - Caro, Trunk); MEDVET: Skin and } \\
\text { subcutaneous tissue (Caracha, Bark) }\end{array}$ & Manahuita (Ch); Cama (Sp) & $\mathrm{CH} 43$ \\
\hline Cleidion sp. & $\begin{array}{l}\text { ANIMFOOD: Fodder (Edible, Fruit); CONST: Houses } \\
\text { (Hedge - Panë, Trunk); FUEL: Firewood (Firewood - } \\
\text { Caro, Trunk) }\end{array}$ & Huacaxapo (Ch) & MOV 45, MSM 13 \\
\hline $\begin{array}{l}\text { Croton lechleri Müll. } \\
\text { Arg. }\end{array}$ & $\begin{array}{l}\text { MEDVET: Skin and subcutaneous tissue (Puchichi, } \\
\text { Exudate; Wounds and cuts) }\end{array}$ & Sangre de Grado (Sp) & $\mathrm{CH} 44$ \\
\hline $\begin{array}{l}\text { Croton matourensis } \\
\text { Aublet }\end{array}$ & $\begin{array}{l}\text { CONST: Houses (Hedge - Panë, Trunk; Muchacho - } \\
\text { Ninotí, Trunk: Tirante largo - Cano pixquëna, Trunk): }\end{array}$ & Aliso (Sp) & $\mathrm{CH} 45$ \\
\hline
\end{tabular}


Table 1 Plant species used by the Chácobo (Continued)

\begin{tabular}{|c|c|c|c|}
\hline $\begin{array}{l}\text { Croton trinitatis } \\
\text { Millsp. }\end{array}$ & MEDVET: Veterinary (Distemper) & Taxa Bahueti (Ch); Malvilla (Sp) & DOA 1 \\
\hline Croton sp. & $\begin{array}{l}\text { MEDVET: Endocrine system (Gallbladder); General } \\
\text { Ailments with Unspecific Symptoms (Headache, Leaf); } \\
\text { Infections and infestations (Malaria and fever, Leaf); } \\
\text { Musculo-skeletal system (Haematoma, Whole plant); } \\
\text { Not specified at all (Insomnia in chlidren); Respiratory } \\
\text { system (Cold and flu, Whole plant); Sensory system } \\
\text { (Inflammation of eyes, Leaf); UTEN\&TOOL: Domestic } \\
\text { utensils (Broom, Whole plant) }\end{array}$ & Matsëti (Ch); Malva (Sp) & MOV 64 \\
\hline $\begin{array}{l}\text { Hevea brasiliensis } \\
\text { (Willd. ex A. Juss.) } \\
\text { Müll. Arg. }\end{array}$ & $\begin{array}{l}\text { CULT: Clothes \& accessories (Rubber shoes, Exudate); } \\
\text { Personal adornment (Ornament - Shinoxëta, Seeds); } \\
\text { FUEL: Firewood (Firewood - Caro, Trunk); Other fuel } \\
\text { (Ceramics - Comëno, Bark); MEDVET: Infections and } \\
\text { infestations (Boro, Exudate; Malaria and fever, Leaf); } \\
\text { Musculo-skeletal system (Bone pain, Bark); Skin and } \\
\text { subcutaneous tissue (Facila blemishes, Bark); SALE: } \\
\text { Sale (Siringa, Exudate) }\end{array}$ & Carama (Ch); Caucho / Siringa (Sp) & $\mathrm{CH} 45$ \\
\hline Jatropha curcas L. & $\begin{array}{l}\text { MEDVET: Infections and infestations (Malaria and } \\
\text { fever, Leaf) }\end{array}$ & Piñon (Sp) & $\mathrm{CH} 46$ \\
\hline $\begin{array}{l}\text { Jatropha } \\
\text { gossypiifolia L. }\end{array}$ & $\begin{array}{l}\text { HUMFOOD: Food (Edible, Fruit); MEDVET: Cultural } \\
\text { diseases and disorders (Bad air and scare - Ratëaina, } \\
\text { Leaf); Insect and athropod bites (Centipede bite, Bark } \\
\text { and leaf); Musculo-skeletal system (Bone pain, Seeds; } \\
\text { Cramps, Seeds; Fractures, Seeds; Rheumatism, Seeds); } \\
\text { Reproductive system and sex health (Contraceptive, } \\
\text { Seeds); Respiratory system (Cramps, Seeds and seeds); } \\
\text { Skin and subcutaneous tissue (Wounds and cuts, } \\
\text { Seeds); Snakebites and Ray stings (Sankebites, Bark } \\
\text { and leaf); Urinary system (Kidneys, Bark, leaf and } \\
\text { seeds) }\end{array}$ & Raë (Ch); Copaiba / Piñón morado (Sp) & $\begin{array}{l}\text { DOA 43, GCM 9, } \\
\text { GOS } 51\end{array}$ \\
\hline $\begin{array}{l}\text { Mabea fistulifera } \\
\text { Mart. }\end{array}$ & $\begin{array}{l}\text { ANIMFOOD: Fodder (Edible, Fruit); MEDVET: Infections } \\
\text { and infestations (Anthelmintic, Exudate; Boro, } \\
\text { Exudate); Insect and athropod bites (Insectbite, } \\
\text { Exudate); UTEN\&TOOL: Hunting \& fishing tools } \\
\text { (Barbasco - Axa, Fruit) }\end{array}$ & Piri (Ch); Leche leche (Sp) & DOA 5, JSM 35 \\
\hline $\begin{array}{l}\text { Manihot esculenta } \\
\text { Crantz }\end{array}$ & $\begin{array}{l}\text { HUMFOOD: Beberages (Beberage - Chicha, Root); } \\
\text { Food (Edible - Chive, Root; Edible, Root); MEDVET: } \\
\text { Dental health (Toothache, Seeds); Endocrine system } \\
\text { (Liver pain, Leaf); Musculo-skeletal system (Swelling, } \\
\text { Root); Skin and subcutaneous tissue (Puchichi, Root; } \\
\text { Wounds and cuts, Root); Urinary system (Kidney pain, } \\
\text { Root; Kidneys, Root ) }\end{array}$ & $\begin{array}{l}\text { Atsa / Atsa Chëquë / Atsa Hosho / Atsa Nasisi / } \\
\text { Atsa Noa / Atsa Pohi Quinihua / Atsa Raoxo / Atsa } \\
\text { Shini / Atsa Tocha / Kanaki / Raox tëtoya / Rono } \\
\text { Atsa / Shoshapo / Xëto itsa / Xoya atsa (Ch); Rama } \\
\text { blanca / Rama morada / Yuca / Yuca de rama } \\
\text { choca o café / Yuca piraquina (Sp) }\end{array}$ & \\
\hline L. & CULT: Personal adornment (Ornament - Chimo, Bark) & Chimo / Jianati (Ch); Bejuco (Sp) & \\
\hline Ricinus comunis $\mathrm{L}$. & $\begin{array}{l}\text { CULT: Personal adornment (Ornament - Maxëití, } \\
\text { Seeds); MEDVET: Musculo-skeletal system (Bone pain, } \\
\text { Leaf; Fractures, Leaf); Respiratory system (Cold and flu, } \\
\text { Leaf) }\end{array}$ & Rarë (Ch); Macororo / Matapalo (Sp) & ESR 22, MOA 2 \\
\hline \multicolumn{4}{|l|}{ Fabaceae } \\
\hline $\begin{array}{l}\text { Acacia loretensis } \\
\text { J.F. Macbr. }\end{array}$ & $\begin{array}{l}\text { CONST: Houses (House post- Jibamë, Trunk; Tie - } \\
\text { Xahui, Bark; Tirante - Cano bëpotó, Trunk); FUEL: } \\
\text { Firewood (Firewood - Caro, Trunk); Other fuel } \\
\text { (Ceramics - Chomo, Bark); MEDVET: Respiratory } \\
\text { system (Cough, Bark); Skin and subcutaneous tissue } \\
\text { (Caracha, Bark; Empeine, Bark) }\end{array}$ & $\begin{array}{l}\text { Caxcono / Capë Caxcono / Isnëpa (Ch); Cari cari } \\
(\mathrm{Sp})\end{array}$ & BCM 11, DOA 23 \\
\hline Acacia sp. & $\begin{array}{l}\text { CONST: Houses (Frame house, Bark); HUMFOOD: } \\
\text { Food (Edible, Fruit); MEDVET: Digestive system } \\
\text { (Stomach ache, Bark); Endocrine system (Diabetes, } \\
\text { Bark; Gallbladder, Bark); Reproductive system and sex } \\
\text { health (Vaginal douche, Bark); Respiratory system }\end{array}$ & Sipamë (Ch); Tipa (Sp) & GOS 53 \\
\hline
\end{tabular}


Table 1 Plant species used by the Chácobo (Continued)

\begin{tabular}{|c|c|c|c|}
\hline & $\begin{array}{l}\text { (Cold and flu, Bark and root); Skin and subcutaneous } \\
\text { tissue (Haemorrhage, Bark; Wounds and cuts, Bark ) }\end{array}$ & & \\
\hline $\begin{array}{l}\text { Amburana } \\
\text { cearensis (Allemão) } \\
\text { A.C. Sm. }\end{array}$ & $\begin{array}{l}\text { CONST: Houses (Tie - Xahui, Bark); Other } \\
\text { constructions (Huaracha, Trunk); HUMFOOD: Food } \\
\text { (Edible, Fruit); MEDVET: Cultural diseases and } \\
\text { disorders (Bad air and scare - Ratëaina, Bark and leaf); } \\
\text { General Ailments with Unspecific Symptoms } \\
\text { (Headache, Bark); Infections and infestations (Malaria } \\
\text { and fever, Bark); Skin and subcutaneous tissue (Facila } \\
\text { blemishes); Veterinary (Distemper, Bark ); } \\
\text { UTEN\&TOOL: Domestic utensils (Batán - Xaxo, Trunk; } \\
\text { Pestle of Tacu, Trunk; Spoon, Trunk; Tacú - Arusa } \\
\text { timatí, Trunk); Transportation (Canoe, Trunk) }\end{array}$ & Quixono (Ch); Tumi / Roble (Sp) & $\mathrm{CH} 47$ \\
\hline $\begin{array}{l}\text { Apuleia leiocarpa } \\
\text { (Vogel) J.F. Macbr. }\end{array}$ & $\begin{array}{l}\text { CONST: Houses (Frame house, Trunk; Hedge - Panë, } \\
\text { Trunk; House post- Jibamë, Trunk; Muchacho - Ninotí, } \\
\text { Trunk; Roof beam - Canoxoco, Trunk; Tirante - Cano } \\
\text { bëpotó, Trunk; Xano, Trunk); FUEL: Firewood } \\
\text { (Firewood - Caro, Trunk); Other fuel (Ceramics - Paítí, } \\
\text { Bark); HUMFOOD: Food (Edible, Fruit); MEDVET: } \\
\text { Digestive system (Diarrhea, Bark fruit and root); } \\
\text { Endocrine system (Liver pain, Leaf); Sensory system } \\
\text { (Inflammation of eyes, Bark); Skin and subcutaneous } \\
\text { tissue (Haemorrhage, Seeds; Wounds and cuts, Bark } \\
\text { and fruit); UTEN\&TOOL: Domestic utensils (Batán - } \\
\text { Xaxo, Trunk; Pestle of Batan - Chapi, Root; Pestle of } \\
\text { Batan - Chapi, Trunk; Pestle of Tacu, Trunk; Tacú - } \\
\text { Arusa timatí, Trunk); Labour tools (Planting stick - } \\
\text { Xësati, Trunk) }\end{array}$ & $\begin{array}{l}\text { Mani / Mani tapono (Ch); Almendrillo / Amarillo } \\
\text { (Sp) }\end{array}$ & $\mathrm{CH} 48$ \\
\hline $\begin{array}{l}\text { Bauhinia guianensis } \\
\text { Aubl. }\end{array}$ & $\begin{array}{l}\text { MEDVET: Cultural diseases and disorders (Bad air and } \\
\text { scare - Ratëaina, Root); Digestive system (Diarrhea, } \\
\text { Trunk); Endocrine system (Diabetes, Leaf); General } \\
\text { Ailments with Unspecific Symptoms (Vomit, Bark and } \\
\text { seeds); Infections and infestations (Amoebas, Trunk; } \\
\text { Leishmaniasis, Trunk); Musculo-skeletal system (Hip } \\
\text { pain, Trunk); Respiratory system (Cold and flu, Trunk); } \\
\text { Sensory system (Eyes, Trunk); Urinary system (Kidneys, } \\
\text { Trunk) }\end{array}$ & $\begin{array}{l}\text { Nishi isanuma / Nishi para (Ch); Bejuco blana / } \\
\text { Pataigue (Sp) }\end{array}$ & $\begin{array}{l}\text { GOS } 40, \text { MOV } 44, \\
\text { RBU } 17855, \text { SCO } \\
17\end{array}$ \\
\hline Bauhinia sp. & $\begin{array}{l}\text { CULT: Ritual (To make hunting dogs, Leaf); MEDVET: } \\
\text { Endocrine system (Diabetes, Trunk) }\end{array}$ & Camanó pahoqui (Ch) & GOS 52 \\
\hline $\begin{array}{l}\text { Bauhinia } \\
\text { straussiana Harms }\end{array}$ & $\begin{array}{l}\text { CULT: Clothes \& accessories (Dress - Moro, Bark); } \\
\text { HUMFOOD: Food (Edible, Fruit); MEDVET: Insect and } \\
\text { athropod bites (Buna bite, Exudate); Skin and } \\
\text { subcutaneous tissue (Burns, Exudate) }\end{array}$ & Chirimoya (Sp) & GOS 27 \\
\hline $\begin{array}{l}\text { Chamaecrista } \\
\text { nictitans (L.) Moench }\end{array}$ & $\begin{array}{l}\text { CULT: Ritual (Crying children, Leaf); MEDVET: Cultural } \\
\text { diseases and disorders (Bad air and scare - Ratëaina, } \\
\text { Bark and leaf) }\end{array}$ & Oxa nihi (Ch); Dormilón (Sp) & DOA 55, GOS 58 \\
\hline $\begin{array}{l}\text { Deguelia } \\
\text { amazonica Killip }\end{array}$ & $\begin{array}{l}\text { MEDVET: Infections and infestations (Leishmaniasis, } \\
\text { Trunk); UTEN\&TOOL: Hunting \& fishing tools } \\
\text { (Barbasco - Capëltsa, Root and trunk) }\end{array}$ & Capë Itsa (Ch); Barbasco (Sp) & $\mathrm{CH} 49$ \\
\hline $\begin{array}{l}\text { Derris amazonica } \\
\text { Killip }\end{array}$ & $\begin{array}{l}\text { UTEN\&TOOL: Hunting \& fishing tools (Barbasco - Axa, } \\
\text { Trunk and root) }\end{array}$ & Axaria (Ch) & $\mathrm{CH} 50$ \\
\hline $\begin{array}{l}\text { Derris floribunda } \\
\text { (Benth.) Ducke }\end{array}$ & $\begin{array}{l}\text { UTEN\&TOOL: Hunting \& fishing tools (Barbasco - Axa, } \\
\text { Bark, leaf and root) }\end{array}$ & Axa (Ch); Barbasco / Bejuco blanco (Sp) & $\mathrm{CH} 51$ \\
\hline $\begin{array}{l}\text { Dipteryx alata } \\
\text { Vogel }\end{array}$ & $\begin{array}{l}\text { MEDVET: Skin and subcutaneous tissue (Caracha, } \\
\text { Bark) }\end{array}$ & Nihi pëpëcho (Ch) & GOS 32 \\
\hline $\begin{array}{l}\text { Dipteryx odorata } \\
\text { (Aubl.) Willd. }\end{array}$ & $\begin{array}{l}\text { CONST: Houses (Frame house, Trunk); CULT: Personal } \\
\text { adornment (Ornament - Maxëití, Seeds) }\end{array}$ & Boë (Ch); Yatorana (Sp) & SCO 1 \\
\hline $\begin{array}{l}\text { Hymenaea } \\
\text { courbaril L. }\end{array}$ & $\begin{array}{l}\text { CONST: Houses (Frame house, Trunk; Solera - Chitao, } \\
\text { Trunk); FUEL: Firewood (Firewood - Caro, Trunk); } \\
\text { Other fuel (Ceramics - Comëno, Trunk); HUMFOOD: } \\
\text { Food (Edible, Fruit); MEDVET: Digestive system }\end{array}$ & Corama / Cura pisi (Ch); Paquío (Sp) & MOV 25 \\
\hline
\end{tabular}


Table 1 Plant species used by the Chácobo (Continued)

\begin{tabular}{|c|c|c|c|}
\hline & $\begin{array}{l}\text { (Diarrhea, Bark); General Ailments with Unspecific } \\
\text { Symptoms (Body pain, Bark); Infections and } \\
\text { infestations (Amoebas, Bark; Malaria and fever, Bark); } \\
\text { Musculo-skeletal system (Hip pain, Bark; Rheumatism, } \\
\text { Bark); Respiratory system (Cold and flu, Bark and } \\
\text { seeds); Veterinary (Distemper, Bark); UTEN\&TOOL: } \\
\text { Domestic utensils (Batán - Xaxo, Trunk; Mattress, Bark; } \\
\text { Pestle of Tacu, Trunk; Tacú - Arusa timatí, Trunk) }\end{array}$ & & \\
\hline Inga edulis Mart. & $\begin{array}{l}\text { CONST: Houses (Xano, Trunk); FUEL: Firewood } \\
\text { (Firewood - Caro, Trunk); HUMFOOD: Food (Edible, } \\
\text { Fruit); UTEN\&TOOL: Hunting \& fishing tools (Arrow, } \\
\text { Trunk) }\end{array}$ & Xënanë (Ch); Pacai (Sp) & DOA 51, JSM 1 \\
\hline $\begin{array}{l}\text { Inga fagifolia G. } \\
\text { Don. }\end{array}$ & HUMFOOD: Food (Edible, Fruit) & Ahuapi Xënanë (Ch); Pacai del Monte (Sp) & $\mathrm{CH} 52$ \\
\hline $\begin{array}{l}\text { Inga marginata } \\
\text { Willd. }\end{array}$ & $\begin{array}{l}\text { HUMFOOD: Food (Edible, Fruit); MEDVET: Not } \\
\text { specified at all (Not specified, Leaf) }\end{array}$ & Shipi Xënanë (Ch); Pacai (Sp) & $\operatorname{GOS} 38$ \\
\hline Inga sp. 1 & HUMFOOD: Food (Edible, Fruit) & Roho xënanë (Ch); Pacai (Sp) & $\mathrm{CH} 53$ \\
\hline Inga sp. 2 & $\begin{array}{l}\text { MEDVET: Infections and infestations (Anthelmintic, } \\
\text { Fruit) }\end{array}$ & Xënanë (Ch) & GOS 36 \\
\hline Inga sp. 3 & $\begin{array}{l}\text { FUEL: Firewood (Firewood - Caro, Trunk); HUMFOOD: } \\
\text { Food (Edible, Fruit) }\end{array}$ & Comoni (Ch); Pacai (Sp) & $\mathrm{CH} 54$ \\
\hline Inga sp. 4 & $\begin{array}{l}\text { CONST: Houses (Tie - Xahui, Bark); Thatch (To tie roof, } \\
\text { Bark) }\end{array}$ & Chërë Xahui (Ch) & $\mathrm{CH} 55$ \\
\hline Inga sp. 5 & $\begin{array}{l}\text { CONST: Houses (Muchacho - Ninotí, Trunk; Pasa ratón } \\
\text { - Xoya jabatí, Trunk; Roof beam - Canoxoco, Trunk; } \\
\text { Solera - Chitao, Trunk) }\end{array}$ & Chira Xahui (Ch) & $\mathrm{CH} 56$ \\
\hline Inga sp. 6 & HUMFOOD: Food (Edible, Fruit) & Huayhuatia Xënanë (Ch); Pacai (Sp) & $\mathrm{CH} 57$ \\
\hline Inga sp. 7 & HUMFOOD: Food (Edible, Fruit) & Rayo xënanë (Ch) & $\mathrm{CH} 58$ \\
\hline $\begin{array}{l}\text { Machaerium } \\
\text { acutifolium Vogel }\end{array}$ & $\begin{array}{l}\text { MEDVET: Infections and infestations (Malaria and } \\
\text { fever, Root) }\end{array}$ & Jihui rashia (Ch) & GOS 37 \\
\hline Ormosia nobilis Tul. & $\begin{array}{l}\text { ANIMFOOD: Fodder (Edible, Fruit); CULT: Personal } \\
\text { adornment (Ornament - Shinoxëta, Seeds); MEDVET: } \\
\text { Infections and infestations (Malaria and fever, Bark); } \\
\text { Reproductive system and sex health (Menstrual pain, } \\
\text { Bark and seeds); Skin and subcutaneous tissue } \\
\text { (Haemorrhage, Seeds; Puchichi, Bark) }\end{array}$ & Tëhuëti / Xëta tarati / Xëta tënëti (Ch); Sirari (Sp) & $\mathrm{CH} 59$ \\
\hline $\begin{array}{l}\text { Poeppigia procera } \\
\text { C. Presl. }\end{array}$ & $\begin{array}{l}\text { CONST: Houses (House post- Jibamë, Trunk); Other } \\
\text { constructions (Huaracha, Trunk); FUEL: Firewood } \\
\text { (Firewood - Caro, Trunk) }\end{array}$ & Matsa Quití (Ch) & $\mathrm{CH} 60$ \\
\hline $\begin{array}{l}\text { Pithocellobium } \\
\text { corymbosum (Rich.) } \\
\text { Benth. }\end{array}$ & $\begin{array}{l}\text { CONST: Houses (House post- Jibamë, Trunk; Roof } \\
\text { beam - Canoxoco, Trunk); MEDVET: Digestive system } \\
\text { (Diarrhea, Bark); Skin and subcutaneous tissue } \\
\text { (Wounds and cuts); UTEN\&TOOL: Domestic utensils } \\
\text { (Batán - Xaxo, Trunk; Pestle of Batan - Chapi, Trunk; } \\
\text { Pestle of Tacu, Trunk; Tacú - Arusa timatí, Trunk) }\end{array}$ & Maní (Sp) & $\mathrm{CH} 61$ \\
\hline $\begin{array}{l}\text { Platymiscium } \\
\text { stipulare Benth. }\end{array}$ & $\begin{array}{l}\text { MEDVET: Digestive system (Diarrhea, Leaf); General } \\
\text { Ailments with Unspecific Symptoms (Vomit, Leaf); } \\
\text { Skin and subcutaneous tissue (Acne, Leaf) }\end{array}$ & Boë xëni (Ch) & GOS 17 \\
\hline $\begin{array}{l}\text { Samanea tubulosa } \\
\text { (Benth.) Barneby \& } \\
\text { J.W. Grimes }\end{array}$ & $\begin{array}{l}\text { MEDVET: General Ailments with Unspecific Symptoms } \\
\text { (Headache, Bark) }\end{array}$ & & GOS 39 \\
\hline $\begin{array}{l}\text { Sclerolobium } \\
\text { radlkoferi Rusby }\end{array}$ & $\begin{array}{l}\text { MEDVET: Skin and subcutaneous tissue (Caracha, } \\
\text { Bark) }\end{array}$ & Huasi Canó (Ch) & $\mathrm{CH} 62$ \\
\hline \multirow[t]{2}{*}{$\begin{array}{l}\text { Senna herzogii } \\
\text { (Harms) H.S. Irwin \& } \\
\text { Barneby }\end{array}$} & $\begin{array}{l}\text { CONST: Houses (To tie house, Bark); FUEL: Firewood } \\
\text { (Firewood - Caro, Bark) }\end{array}$ & Pabo (Ch) & JSM 59 \\
\hline & & Túsa (Ch) & MOV 1 \\
\hline
\end{tabular}


Table 1 Plant species used by the Chácobo (Continued)

\begin{tabular}{|c|c|c|c|}
\hline $\begin{array}{l}\text { Senna occidentalis } \\
\text { (L.) Link. }\end{array}$ & $\begin{array}{l}\text { HUMFOOD: Food (Edible, Fruit); MEDVET: Digestive } \\
\text { system (Diarrhea); General Ailments with Unspecific } \\
\text { Symptoms (Vomit, Fruit) }\end{array}$ & & \\
\hline $\begin{array}{l}\text { Stryphnodendron } \\
\text { guianense (Aubl.) } \\
\text { Benth. }\end{array}$ & FUEL: Firewood (Firewood - Caro, Trunk) & Ihui pisi (Ch); Carachupa (Sp) & MOV 48, SCO 34 \\
\hline $\begin{array}{l}\text { Sweetia fruticosa } \\
\text { Spreng. }\end{array}$ & $\begin{array}{l}\text { CONST: Houses (Frame house, Trunk; House post- } \\
\text { Jibamë, Trunk) }\end{array}$ & Canamashía (Ch) & $\mathrm{CH} 53$ \\
\hline $\begin{array}{l}\text { Tamarindus indica } \\
\text { L. }\end{array}$ & $\begin{array}{l}\text { HUMFOOD: Food (Edible, Fruit); MEDVET: Digestive } \\
\text { system (Stomach ache, Seeds) }\end{array}$ & Tamarindo (Sp) & $\mathrm{CH} 54$ \\
\hline $\begin{array}{l}\text { Vataireopsis } \\
\text { speciosa Ducke }\end{array}$ & FUEL: Firewood (Firewood - Caro, Trunk) & Ihui pisi (Ch) & $\mathrm{CH} 55$ \\
\hline $\begin{array}{l}\text { Vigna unguiculata } \\
\text { (L.) Walp. }\end{array}$ & HUMFOOD: Food (Edible, Seeds) & Birijori (Ch); Frejol (Sp) & $\mathrm{CH} 56$ \\
\hline Zornia latifolia Sm. & CULT: Ritual (Crying children) & Hoxa Nihi (Ch); Mujer Yoxa (Sp) & $\mathrm{CH} 57$ \\
\hline Indet. sp. 1 & CULT: Ritual (Good luck, Leaf) & Tëtëmabaspá (Ch) & $\mathrm{CH} 58$ \\
\hline \multicolumn{4}{|l|}{ Flacourtiaceae } \\
\hline Indet. sp. 1 & $\begin{array}{l}\text { CONST: Houses (Frame house, Trunk; Jihuixaca, Trunk; } \\
\text { Muchacho - Ninotí, Trunk; Pasa ratón - Xoya jabatí, } \\
\text { Trunk; Ridgepole - Maracatí, Trunk; Roof beam - } \\
\text { Canoxoco, Trunk; Solera - Chitao, Trunk; Tirante - } \\
\text { Cano bëpotó, Trunk; Tirante largo - Cano pixquëna, } \\
\text { Trunk; Xano, Trunk); Thatch (Roof - Xëhuahacacató, } \\
\text { Bark); UTEN\&TOOL: Domestic utensils (Batán - Xaxo, } \\
\text { Trunk) }\end{array}$ & Xaxo atí (Ch); Canelon (Sp) & $\mathrm{CH} 59$ \\
\hline \multicolumn{4}{|l|}{ Gesneriaceae } \\
\hline $\begin{array}{l}\text { Codonanthe } \\
\text { calcarata (Miq.) } \\
\text { Hanst. }\end{array}$ & MEDVET: Digestive system (Diarrhea, Trunk) & Chixopa (Ch) & $\mathrm{CH} 60$ \\
\hline \multicolumn{4}{|l|}{ Heliconiaceae } \\
\hline $\begin{array}{l}\text { Heliconia hirsuta } \\
\text { L.f. }\end{array}$ & UTEN\&TOOL: Domestic utensils (Pestle of Tacu, Trunk) & Tsacahuico (Ch) & $\begin{array}{l}\text { RBU } 17852, \text { SCO } \\
11\end{array}$ \\
\hline Heliconia sp. & $\begin{array}{l}\text { CONST: Thatch (Roof - Xëhuahacacató, Leaf); MEDVET: } \\
\text { Digestive system (Diarrhea, Trunk) }\end{array}$ & Tsacahuico (Ch) & $\mathrm{CH} 61$ \\
\hline \multicolumn{4}{|l|}{ Hernandiaceae } \\
\hline $\begin{array}{l}\text { Sparattanthelium } \\
\text { amazonum Mart. }\end{array}$ & MEDVET: Digestive system (Stomach ache, Trunk) & Nishi Tsanóna (Ch) & $\mathrm{CH} 62$ \\
\hline \multicolumn{4}{|l|}{ Hippocrateaceae } \\
\hline $\begin{array}{l}\text { Cheiloclinum } \\
\text { cognatum (Miers.) } \\
\text { A.C. Smith }\end{array}$ & $\begin{array}{l}\text { MEDVET: Digestive system (Diarrhea, Bark); General } \\
\text { Ailments with Unspecific Symptoms (Vomit, Bark and } \\
\text { root); Musculo-skeletal system (Bone pain, Bark; } \\
\text { Rheumatism, Bark); Respiratory system (Cold and flu, } \\
\text { Bark) }\end{array}$ & Chuchuasa (Sp) & $\mathrm{CH} 63$ \\
\hline \multicolumn{4}{|l|}{ Hypericaceae } \\
\hline $\begin{array}{l}\text { Vismia glaziovii } \\
\text { Ruhland }\end{array}$ & $\begin{array}{l}\text { CONST: Houses (Muchacho - Ninotí, Trunk; Ridgepole } \\
\text { - Maracatí, Trunk; Tirante - Cano bëpotó, Trunk) }\end{array}$ & Bisatamanë (Ch) & $\mathrm{CH} 64$ \\
\hline $\begin{array}{l}\text { Vismia macrophylla } \\
\text { Kunth }\end{array}$ & $\begin{array}{l}\text { CONST: Houses (Chira Xahui, Trunk; Frame house, } \\
\text { Bark; House post- Jibamë, Trunk; Jënë Jabati, Trunk; } \\
\text { Jihuixaca, Trunk; Manipoatí, Trunk; Muchacho - Ninotí, } \\
\text { Trunk; Nasëcamëti , Trunk; Pasa ratón - Xoya jabatí, } \\
\text { Trunk; Ridgepole - Maracatí, Trunk; Roof beam - } \\
\text { Canoxoco, Trunk; Solera - Chitao, Trunk; Tëtëmatsisi, } \\
\text { Trunk; Tie - Xahui, Bark; Tirante - Cano bëpotó, Trunk; } \\
\text { Tirante corto - Cano Bësëcamë, Trunk; Tirante largo - } \\
\text { Cano pixquëna, Trunk; To tie house, Bark); Other } \\
\text { constructions (Huaracha, Trunk); Thatch (To tie roof, }\end{array}$ & $\begin{array}{l}\text { Bisatamanë / Sipó / Sirari / Sisi (Ch); Palo Santo } \\
\text { (Sp) }\end{array}$ & GS 48 \\
\hline
\end{tabular}


Table 1 Plant species used by the Chácobo (Continued)

\begin{tabular}{|c|c|c|c|}
\hline & $\begin{array}{l}\text { Bark); CULT: Personal adornment (Ornament - Maxëití, } \\
\text { Seeds; Ornament - Shinoxëta, Seeds); FUEL: Firewood } \\
\text { (Firewood - Caro, Trunk); HUMFOOD: Food (Edible, } \\
\text { Fruit); MEDVET: Digestive system (Malaria and fever, } \\
\text { Leaf; Stomach ache, Leaf); Endocrine system (Liver } \\
\text { pain, Leaf and seeds); Infections and infestations } \\
\text { (Malaria and fever, Bark and leaf); Not specified at all } \\
\text { (Cancer, Bark); Skin and subcutaneous tissue (Basket - } \\
\text { Nishicacano, Trunk and exhudate; Haemorrhage, } \\
\text { Bark); UTEN\&TOOL: Domestic utensils (Basket - } \\
\text { Chichabëcasa, Bark; Basket - Coquita, Bark; Basket - } \\
\text { Nishicacano, Bark; Basket - Nishicacano, Trunk; Man } \\
\text { basket, Bark; Tacú - Arusa timatí, Trunk); Labour tools } \\
\text { (Hoe, Trunk) }\end{array}$ & & \\
\hline $\begin{array}{l}\text { Vismia pozuzoensis } \\
\text { Engl. }\end{array}$ & $\begin{array}{l}\text { CONST: Houses (Jihuixaca, Trunk; Muchacho - Ninotí, } \\
\text { Trunk; Ridgepole - Maracatí, Trunk; Tirante - Cano } \\
\text { bëpotó, Trunk; Tirante largo - Cano pixquëna, Trunk) }\end{array}$ & $\begin{array}{l}\text { Bisatamanë / Jihui bapia (Ch); Leche leche / } \\
\text { Piraquina (Sp) }\end{array}$ & $\begin{array}{l}\text { DOA } 17,59, \text { MSM } \\
16, \text { SCO } 13\end{array}$ \\
\hline \multicolumn{4}{|l|}{ Lamiaceae } \\
\hline $\begin{array}{l}\text { Clerodendrum } \\
\text { tessmannii Moldenke }\end{array}$ & $\begin{array}{l}\text { FUEL: Firewood (Firewood - Caro, Trunk); HUMFOOD: } \\
\text { Food (Edible, Fruit); MEDVET: Digestive system } \\
\text { (Diarrhea, Bark, fruit and leaf; Stomach ache, Leaf); } \\
\text { General Ailments with Unspecific Symptoms (Vomit, } \\
\text { Bark, fruit and leaf); Respiratory system (Cold and flu, } \\
\text { Leaf); Skin and subcutaneous tissue (Puchichi, Leaf); } \\
\text { Urinary system (Kidney infection, Bark) }\end{array}$ & Guayagua (Ch); Guayaba (Sp) & BCM 9 \\
\hline Vitex triflora Vahl & $\begin{array}{l}\text { FUEL: Firewood (Firewood - Caro, Trunk); MEDVET: } \\
\text { Sensory system (Earache, Trunk) }\end{array}$ & Chaxo paoquí / Chaxo romë (Ch) & DOA 25, JSM 27 \\
\hline Vitex sp. & MEDVET: Veterinary (Distemper, Bark) & lene carama (Ch) & MOV 62 \\
\hline \multicolumn{4}{|l|}{ Lauraceae } \\
\hline Nectandra sp. & FUEL: Firewood (Firewood - Caro, Trunk) & Xanë Yobini (Ch) & MOV 40 \\
\hline $\begin{array}{l}\text { Ocotea diospyrifolia } \\
\text { aff. (Meisn.) Mez }\end{array}$ & $\begin{array}{l}\text { HUMFOOD: Food (Edible, Fruit); MEDVET: Skin and } \\
\text { subcutaneous tissue (Caracha, Bark) }\end{array}$ & Nahuëshí (Ch) & $\mathrm{CH} 65$ \\
\hline $\begin{array}{l}\text { Persea americana } \\
\text { Mill. }\end{array}$ & $\begin{array}{l}\text { HUMFOOD: Food (Edible, Fruit); MEDVET: General } \\
\text { Ailments with Unspecific Symptoms (Vomit, Leaf); } \\
\text { Infections and infestations (Leishmaniasis, Young leaf); } \\
\text { Musculo-skeletal system (Hip pain, Leaf); Urinary } \\
\text { system (Kidney pain, Leaf, root and seeds; Kidneys, } \\
\text { Fruit, leaf, seeds and trunk) }\end{array}$ & Xane yubini cuota (Ch); Palta (Sp) & JSM 29 \\
\hline \multicolumn{4}{|l|}{ Lecythidaceae } \\
\hline $\begin{array}{l}\text { Bertholletia excelsa } \\
\text { Bonpl. }\end{array}$ & $\begin{array}{l}\text { CONST: Houses (Hedge - Panë, Trunk; Jihuixaca, } \\
\text { Trunk; Muchacho - Ninotí, Trunk; Ridgepole - } \\
\text { Maracatí, Trunk; Solera - Chitao, Trunk; Tirante - Cano } \\
\text { bëpotó, Trunk; Tirante largo - Cano pixquëna, Trunk); } \\
\text { Other constructions (Huaracha, Trunk); CULT: Dyes } \\
\text { (Dye, Seeds); Personal adornment (Ornament - } \\
\text { Maxëití, Seeds); HUMFOOD: Beberages (Beberage - } \\
\text { Milk, Seeds); Food (Edible, Seeds); Oils (Oil, Seeds); } \\
\text { MEDVET: Digestive system (Appendicitis, Seeds; } \\
\text { Diarrhea, Seeds; Stomach ache, Seeds); Pregnancy, } \\
\text { birth and puerperial (Haemorrhage after childbirth, } \\
\text { Seeds); Skin and subcutaneous tissue (Caracha, Seeds; } \\
\text { Haemorrhage, Bark, leaf and seeds; Wounds and cuts, } \\
\text { Seeds); Urinary system (Gallstones, Seeds); } \\
\text { UTEN\&TOOL: Domestic utensils (Batán - Xaxo, Trunk) }\end{array}$ & Tapa / Tapa ristí / Tsixo (Ch); Almendro (Sp) & SCO 16 \\
\hline $\begin{array}{l}\text { Eschweilera } \\
\text { albiflora L. }\end{array}$ & $\begin{array}{l}\text { CONST: Houses (To tie house, Bark); Thatch (Roof - } \\
\text { Xëhuahacacató, Trunk; To tie roof, Bark); FUEL: } \\
\text { Firewood (Firewood - Caro, Trunk); MEDVET: Musculo- } \\
\text { skeletal system (Fractures, Bark); UTEN\&TOOL: } \\
\text { Domestic utensils (Basket - Chichama, Bark; Hammock } \\
\text { - Nishi, Bark) }\end{array}$ & $\begin{array}{l}\text { Maquë Tashi (Ch); Bitiumbo de bajio / Bitumbo / } \\
\text { Campanilla / Cuchi / Piraquina (Sp) }\end{array}$ & MOV 58 \\
\hline Eschweilera sp. & HUMFOOD: Food (Edible, Fruit) & Tapa (Ch); Almendro (Sp) & MOV 51 \\
\hline
\end{tabular}


Table 1 Plant species used by the Chácobo (Continued)

\begin{tabular}{|c|c|c|c|}
\hline $\begin{array}{l}\text { Gustavia } \\
\text { hexapetala (Aubl.) } \\
\text { Sm. }\end{array}$ & $\begin{array}{l}\text { CONST: Houses (Frame house, Trunk; Hedge - Panë, } \\
\text { Trunk; House post- Jibamë, Trunk; Jihuixaca, Trunk; } \\
\text { Manipoatí, Trunk; Muchacho - Ninotí, Trunk; Pasa } \\
\text { ratón - Xoya jabatí, Trunk; Ridgepole - Maracatí, Trunk; } \\
\text { Roof beam - Canoxoco, Trunk; Sabrillo, Trunk; Solera - } \\
\text { Chitao, Trunk; Tirante - Cano bëpotó, Trunk; Tirante } \\
\text { largo - Cano pixquëna, Trunk); Other constructions } \\
\text { (Huaracha, Trunk); Thatch (Roof - Xëhuahacacató, } \\
\text { Trunk); HUMFOOD: Food (Edible, Fruit); MEDVET: } \\
\text { Sensory system (Inflammation of eyes, Root); } \\
\text { UTEN\&TOOL: Domestic utensils (Batán - Xaxo, Trunk; } \\
\text { Pestle of Batan - Chapi, Trunk; Pestle of Tacu, Trunk; } \\
\text { Spinning wheel - Ihui, Bark; Tacú - Arusa timatí, } \\
\text { Trunk); Labour tools (Hammer, Trunk; Planting stick - } \\
\text { Xësati, Trunk) }\end{array}$ & Yunishi (Ch); Itauba (Sp) & $\mathrm{CH} 66$ \\
\hline $\begin{array}{l}\text { Lecythis serrata S.A. } \\
\text { Mori }\end{array}$ & $\begin{array}{l}\text { CULT: Ritual (Santeria, Seeds); MEDVET: Digestive } \\
\text { system (Diarrhea, Seeds); Skin and subcutaneous } \\
\text { tissue (Haemorrhage, Seeds) }\end{array}$ & Tapa (Ch); Almendro (Sp) & MSM 7 \\
\hline Lecythis sp.1 & $\begin{array}{l}\text { HUMFOOD: Beberages (Beberage - Milk, Fruit); Food } \\
\text { (Edible, Fruit); Oils (Oil, Fruit); MEDVET: Skin and } \\
\text { subcutaneous tissue (Haemorrhage, Fruit) }\end{array}$ & Almendro (Sp) & ESR 18 \\
\hline Lecythis sp.2 & $\begin{array}{l}\text { MEDVET: Not specified at all (Not specified, Fruit); } \\
\text { Skin and subcutaneous tissue (Puchichi, Fruit) }\end{array}$ & Tapa (Ch) & GOS 34 \\
\hline \multicolumn{4}{|l|}{ Loganiaceae } \\
\hline Strychnos sp. & $\begin{array}{l}\text { HUMFOOD: Food (Edible, Fruit); MEDVET: General } \\
\text { Ailments with Unspecific Symptoms (Headache, Leaf); } \\
\text { Urinary system (Kidneys, Leaf) }\end{array}$ & Huani Kuhuësa (Ch) & $\operatorname{GOS} 28$ \\
\hline \multicolumn{4}{|l|}{ Loranthaceae } \\
\hline $\begin{array}{l}\text { Phthirusa pyrifolia } \\
\text { (Kunth) Eichler }\end{array}$ & $\begin{array}{l}\text { FUEL: Firewood (Firewood - Caro, Trunk); HUMFOOD: } \\
\text { Food (Edible, Fruit); MEDVET: Endocrine system (Liver, } \\
\text { Bark and leaf); Musculo-skeletal system (Fractures, } \\
\text { Bark and leaf) }\end{array}$ & Nishi moishi (Ch); Suelda con suelda (Sp) & $\begin{array}{l}\text { DOA 41, 58, GOS } \\
60, \text { JSM } 31\end{array}$ \\
\hline \multicolumn{4}{|l|}{ Lythraceae } \\
\hline $\begin{array}{l}\text { Physocalymma } \\
\text { scaberrimum Pohl }\end{array}$ & UTEN\&TOOL: Domestic utensils (Batán - Xaxo, Trunk) & Chaquillo (Sp) & $\begin{array}{l}\text { JSM 46, RBU } \\
17851\end{array}$ \\
\hline \multicolumn{4}{|l|}{ Malpighiaceae } \\
\hline $\begin{array}{l}\quad \text { Bunchosia } \\
\text { glandulifera (Jacq.) } \\
\text { Kunth }\end{array}$ & HUMFOOD: Food (Edible, Fruit) & Mermelada (Sp) & ESR 21 \\
\hline $\begin{array}{l}\text { Byrsonima crispa A. } \\
\text { Juss. }\end{array}$ & FUEL: Firewood (Firewood - Caro, Trunk) & Xëchi (Ch) & $\mathrm{CH} 67$ \\
\hline $\begin{array}{l}\text { Heteropterys } \\
\text { coriacea A. Juss. }\end{array}$ & $\begin{array}{l}\text { CONST: Houses (Hedge - Panë, Trunk; House post- } \\
\text { Jibamë, Trunk); Other constructions (Huaracha, Trunk) }\end{array}$ & Xaba yunishi (Ch) & JSM 2, RBU 17808 \\
\hline $\begin{array}{l}\text { Mascagnia } \\
\text { macrophylla Rusby }\end{array}$ & $\begin{array}{l}\text { UTEN\&TOOL: Domestic utensils (Bow to clean cotton, } \\
\text { Trunk) }\end{array}$ & Ascana (Ch) & $\mathrm{CH} 68$ \\
\hline \multicolumn{4}{|l|}{ Malvaceae } \\
\hline $\begin{array}{l}\text { Apeiba tibourbou } \\
\text { Aubl. }\end{array}$ & $\begin{array}{l}\text { CONST: Houses (Frame house, Bark; Hedge - Panë, } \\
\text { Trunk; Muchacho - Ninotí, Trunk; Pasa ratón - Xoya } \\
\text { jabatí, Trunk; Ridgepole - Maracatí, Trunk; Roof beam } \\
\text { - Canoxoco, Trunk; Tie - Xahui, Bark; Tirante - Cano } \\
\text { bëpotó, Trunk; Tirante largo - Cano pixquëna, Trunk; } \\
\text { To tie fence, Bark); Other constructions (Huaracha, } \\
\text { Trunk); Thatch (To tie roof, Bark); CULT: Clothes \& } \\
\text { accessories (Dress - Moro, Bark); FUEL: Firewood } \\
\text { (Firewood - Caro, Trunk); Other fuel (Ceramics - } \\
\text { Chomo, Bark); HUMFOOD: Food (Edible, Fruit); } \\
\text { MEDVET: General Ailments with Unspecific Symptoms } \\
\text { (Headache, Bark); Sensory system (Earache, Young } \\
\text { leaf); Skin and subcutaneous tissue (Caracha, Bark); }\end{array}$ & Bitumbo (Sp) & $\begin{array}{l}\text { DOA 44, GOS 25, } \\
\text { JSM 60, RBU } \\
17867\end{array}$ \\
\hline
\end{tabular}


Table 1 Plant species used by the Chácobo (Continued)

UTEN\&TOOL: Domestic utensils (Basket - Bano, Bark;
Basket - Cacachuquëxnia, Bark; Basket - Chichama,
Bark; Basket - Nishicacano, Bark; Basket - Purupachi,
Bark; Basket - Yamachi, Bark; Hammock - Nishi, Bark);
Hunting \& fishing tools (Bow - Canatí, Trunk); Rope
(Rope - Rispichi, Bark)

Eriotheca sp.

MEDVET: Infections and infestations (Malaria and fever, Bark); UTEN\&TOOL: Domestic utensils (Pestle of Tacu, Trunk; Tacú - Arusa timatí, Trunk)

Gossypium barbadense L.

Lueheopsis schultesii Cuatrec.

Ochroma pyramidale (Cav. ex Lam.) Urb.

Pseudobombax septenatum (Jacq.) Dugand

Theobroma grandiflorum (Willd. ex Spreng.) K. Schum.

Theobroma speciosum (Willd. ex spreng.) K. Schum.

ANIMFOOD: Fodder (Edible, Fruit); FUEL: Firewood (Firewood - Caro, Trunk); HUMFOOD: Food (Edible, Seeds); MEDVET: Infections and infestations (Malaria and fever, Leaf); Not specified at all (Not specified, Fruit); Sensory system (Earache, Flower)

Marantaceae

Calathea sp.

CONST: Houses (Tie - Xahui, Bark); CULT: Clothes \& accessories (Dress - Moro, Seeds); Personal adornment (Ornament - Amënoxëta, Seeds; Ornament - Baxëxëtí, Seeds; Ornament - Chaha, Seeds; Ornament - Chinoxëta, Seeds; Ornament Chua, Seeds; Ornament - Matsamití, Seeds; Ornament - Maxëití, Seeds; Ornament - Mënëxëtí, Seeds; Ornament - Rësëti, Seeds; Ornament - Shinoxëta, Seeds; Ornament - Tsirispi, Seeds; Ornament - Xapo, Seeds); Recreational (Toys, Seeds); FUEL: Firewood (Firewood - Caro, Trunk); HUMFOOD: Food (Edible, Seeds); MEDVET: Digestive system (Diarrhea, Trunk); General Ailments with Unspecific Symptoms (Body pain, Trunk; Headache, Leaf and leaf; Vomit, Leaf); Musculo-skeletal system (Bone pain, Leaf); Respiratory system (Cold and flu, Leaf); Sensory system (Earache, Flower, leaf and seeds); Skin and subcutaneous tissue (Caracha, Leaf; Haemorrhage, Leaf; Puchichi, Leaf); Urinary system (Kidney pain, Leaf); UTEN\&TOOL: Domestic utensils (Basket - Nishicacano, Bark; Hammock - Nishi, Seeds); Hunting \& fishing tools (Arrow, Seeds; Fishing lines, Seeds); Labour tools (Planting stick - Xësati, Trunk); Rope (Rope - Rispichi, Seeds; Rope, Seeds)

CULT: Personal adornment (Ornament Huaxmënëhua, Seeds)

CONST: Houses (Hedge - Panë, Trunk; Tie - Xahui, Bark; To tie house, Bark); Other constructions (Huaracha, Trunk); Thatch (To tie roof, Bark); CULT: Recreational (Toys, Trunk; Zampoña - Bistó, Bark); HUMFOOD: Food (Edible, Fruit); MEDVET: General Ailments with Unspecific Symptoms (Chest pain, Seeds); Infections and infestations (Scabies); Skin and subcutaneous tissue (Caracha, Bark; Skin fungus, Bark); UTEN\&TOOL: Domestic utensils (Basket -

Cacachuquëxnia, Bark; Basket - Chichama, Bark; Basket - Nishicacano, Bark; Hammock - Nishi, Bark; Table, Trunk); Rope (Rope - Rispichi, Bark)

FUEL: Firewood (Firewood - Caro, Trunk); MEDVET: General Ailments with Unspecific Symptoms (Headache, Leaf); Infections and infestations (Malaria and fever, Leaf)

HUMFOOD: Food (Edible, Fruit)
Copoazú (Sp)

$\mathrm{CH} 70$

Chocolate / Chocolatillo (Sp) ESR 10, DOA 16 39, GOS 21, JSM $5,30, \operatorname{SCO} 30$
GCM 8, GOS 11, MOV 21, ORC 6
Huaxmënëhua (Ch)

Balsa (Sp)
CH69

ESR 23, JSM 17
DOA 36, JSM 57 
Table 1 Plant species used by the Chácobo (Continued)

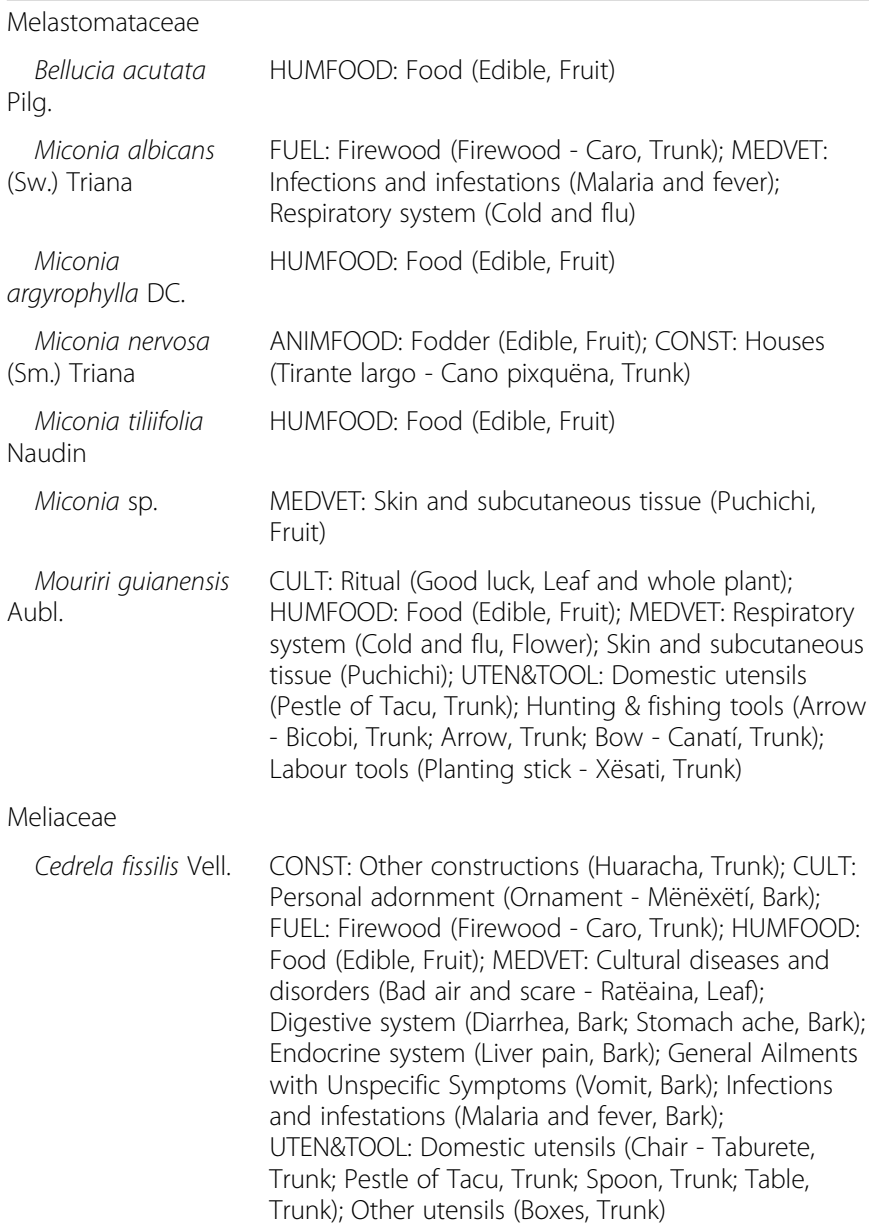

Meliaceae

Cedrela fissilis Vell.

HUMFOOD: Food (Edible, Fruit)

FUEL: Firewood (Firewood - Caro, Trunk); MEDVET: Infections and infestations (Malaria and fever); Respiratory system (Cold and flu)

HUMFOOD: Food (Edible, Fruit)

ANIMFOOD: Fodder (Edible, Fruit); CONST: Houses (Tirante largo - Cano pixquëna, Trunk)

HUMFOOD: Food (Edible, Fruit)

MEDVET: Skin and subcutaneous tissue (Puchichi, Fruit)

CULT: Ritual (Good luck, Leaf and whole plant); HUMFOOD: Food (Edible, Fruit); MEDVET: Respiratory system (Cold and flu, Flower); Skin and subcutaneous tissue (Puchichi); UTEN\&TOOL: Domestic utensils (Pestle of Tacu, Trunk): Hunting \& fishing tools (Arrow - Bicobi, Trunk; Arrow, Trunk; Bow - Canatí, Trunk); Labour tools (Planting stick - Xësati, Trunk)

CONST: Other constructions (Huaracha, Trunk); CULT: Personal adornment (Ornament - Mënëxëtí, Bark);

FUEL: Firewood (Firewood - Caro, Trunk); HUMFOOD: Food (Edible, Fruit); MEDVET: Cultural diseases and disorders (Bad air and scare - Ratëaina, Leaf);

Digestive system (Diarrhea, Bark; Stomach ache, Bark); Endocrine system (Liver pain, Bark); General Ailments with Unspecific Symptoms (Vomit, Bark); Infections and infestations (Malaria and fever, Bark):

UTEN\&TOOL: Domestic utensils (Chair - Taburete, Trunk: Pestle of Tacu, Trunk; Spoon, Trunk; Table,

Trunk); Other utensils (Boxes, Trunk)

Menispermaceae

Abuta grandifolia (Mart.) Sandwich

Moraceae

Brosimum gaudichaudii Trécul

Brosimum guianense (Aubl.) Huber

Brosimum utile subsp. ovatifolium (Ducke) C.C. Berg

Chlorophora tinctoria (L.) Gaudich. ex Benth.

Ficus gomelleira Kunth \& C.D. Bouché
HUMFOOD: Food (Edible, Fruit)

FUEL: Firewood (Firewood - Caro, Trunk); HUMFOOD: Food (Edible, Fruit); MEDVET: Not specified at all (Not specified, Bark); UTEN\&TOOL: Domestic utensils (Tacú - Arusa timatí, Trunk)

FUEL: Firewood (Firewood - Caro, Trunk); HUMFOOD: Food (Edible, Fruit)

CONST: Other constructions (Huaracha, Bark); CULT: Clothes \& accessories (Dress - Pío, Bark); UTEN\&TOOL: Domestic utensils (Raití, Bark); Tacú - Arusa timatí, Trunk (Hunting \& fishing tools)

ANIMFOOD: Fodder (Edible, Fruit); CONST: Houses (Tirante largo - Cano pixquëna, Trunk)

CULT: Clothes \& accessories (Dress - Isaca pohi, Bark; Dress - Moro, Bark); Recreational (Comëno, Bark); MEDVET: Musculo-skeletal system (Fractures, Bark; Fractures, Exudate); Skin and subcutaneous tissue (Wounds and cuts, Bark); UTEN\&TOOL: Domestic
Guayabilla (Sp)

Blanquillo (Ch)

BCM 5, ESR 15, MOV 6

JSM 3, MOV 17, RBU 17818

MSM 2

DOA 26

Nigua (Ch)

ESR 2, RBU 17819 17838

Pao (Ch)

DOS 60

Llave (Sp)

DOA 37

$\mathrm{CH} 71$

$\mathrm{CH} 72$

Pío (Ch); Bibosi (Sp)

$\mathrm{CH} 73$

Nibosa (Ch)

$\mathrm{CH} 74$

Matapalo (Sp)

$\mathrm{CH} 75$ 
Table 1 Plant species used by the Chácobo (Continued)

\begin{tabular}{|c|c|c|c|}
\hline & $\begin{array}{l}\text { utensils (Pestle of Tacu, Trunk; Raití, Bark); Rope (Rope } \\
\text { - Rispichi, Bark) }\end{array}$ & & \\
\hline $\begin{array}{l}\text { Ficus gomelleria } \\
\text { Kunth \& C.D. Bouché }\end{array}$ & CULT: Clothes \& accessories (Dress - Xóa, Bark) & Xoá (Ch); Bibosi blanco (Sp) & $\mathrm{CH} 76$ \\
\hline $\begin{array}{l}\text { Ficus mathewsii (Miq.) } \\
\text { Miq. }\end{array}$ & $\begin{array}{l}\text { CULT: Clothes \& accessories (Dress - Isaca pohi, Bark); } \\
\text { MEDVET: Insect and athropod bites (Buna bite, Bark); } \\
\text { CONST: Houses (To tie house, Bark); Other } \\
\text { constructions (Huaracha, Trunk); CULT: Clothes \& } \\
\text { accessories (Dress - Moro, Bark; Dress - Mororia, Bark); } \\
\text { Personal adornment (Ornament - Amënoxëta, Seeds; } \\
\text { Ornament - Rësëti; Ornament - Shinoxëta, Bark; } \\
\text { Ornament - Xapo, Bark); FUEL: Firewood (Firewood - } \\
\text { Caro, Trunk); MEDVET: Dental health (Toothache, } \\
\text { Exudate); Infections and infestations (Malaria and } \\
\text { fever, Bark); Musculo-skeletal system (Fractures, Bark } \\
\text { and exhudate); Skin and subcutaneous tissue } \\
\text { (Wounds and cuts, Trunk); UTEN\&TOOL: Domestic } \\
\text { utensils (Basket - Yamachi, Bark; Batán - Xaxo, Trunk; } \\
\text { Chair - Taburete, Trunk; Hammock - Nishi, Bark); } \\
\text { Hunting \& fishing tools (Bow - Canatí, Bark); Rope } \\
\text { (Rope - Rispichi, Bark; Rope, Bark) }\end{array}$ & & GOS 50, MOA 7 \\
\hline $\begin{array}{l}\text { Ficus sphenophylla } \\
\text { Standl. }\end{array}$ & $\begin{array}{l}\text { CULT: Clothes \& accessories (Dress - Isaca pohi, Bark); } \\
\text { MEDVET: Insect and athropod bites (Buna bite, } \\
\text { Exudate); CONST: Other constructions (Huaracha, } \\
\text { Bark); CULT: Clothes \& accessories (Dress - Moro, } \\
\text { Bark); Personal adornment (Ornament - Xapo, Bark); } \\
\text { MEDVET: Musculo-skeletal system (Fractures, Exudate) }\end{array}$ & Isaca Pohi (Ch); Bibosi (Sp) & $\mathrm{CH} 77$ \\
\hline Ficus trigona L.f. & $\begin{array}{l}\text { CONST: Other constructions (Huaracha, Bark); CULT: } \\
\text { Clothes \& accessories (Dress - Moro, Bark); Personal } \\
\text { adornment (Ornament - Xapo, Bark); MEDVET: } \\
\text { Musculo-skeletal system (Fractures, Exudate) }\end{array}$ & Moro (Ch); Bibosi (Sp) & JSM 51 \\
\hline Ficus sp. & $\begin{array}{l}\text { CONST: Houses (To tie house, Bark); Other } \\
\text { constructions (Huaracha, Trunk); CULT: Clothes \& } \\
\text { accessories (Dress - Moro, Bark; Dress - Mororia, Bark); } \\
\text { Personal adornment (Ornament - Amënoxëta, Seeds; } \\
\text { Ornament - Rësëti; Ornament - Shinoxëta, Bark; } \\
\text { Ornament - Xapo, Bark); FUEL: Firewood (Firewood - } \\
\text { Caro, Trunk); MEDVET: Dental health (Toothache, } \\
\text { Exudate); Infections and infestations (Malaria and } \\
\text { fever, Bark); Musculo-skeletal system (Fractures, Bark } \\
\text { and exhudate); Skin and subcutaneous tissue } \\
\text { (Wounds and cuts, Trunk); UTEN\&TOOL: Domestic } \\
\text { utensils (Basket - Yamachi, Bark; Batán - Xaxo, Trunk; } \\
\text { Chair - Taburete, Trunk; Hammock - Nishi, Bark); } \\
\text { Hunting \& fishing tools (Bow - Canatí, Bark); Rope } \\
\text { (Rope - Rispichi, Bark; Rope, Bark) }\end{array}$ & Mororía (Ch); Bibosi (Sp) & $\mathrm{CH} 78$ \\
\hline $\begin{array}{l}\text { Helicostylis } \\
\text { tomentosa (Poepp. \& } \\
\text { Endl.) Rusby }\end{array}$ & $\begin{array}{l}\text { FUEL: Firewood (Firewood - Caro, Trunk); HUMFOOD: } \\
\text { Food (Edible, Fruit); MEDVET: Insect and athropod } \\
\text { bites (Buna bite, Exudate; Insectbite, Exudate); Skin } \\
\text { and subcutaneous tissue (Wounds and cuts, Exudate) }\end{array}$ & Nui (Sp) & $\begin{array}{l}\text { DOA } 15, \text { MOV } 42, \\
\text { SCO } 26\end{array}$ \\
\hline $\begin{array}{l}\text { Perebea } \\
\text { angustifolia (Poepp. \& } \\
\text { Endl.) C. C. Berg }\end{array}$ & $\begin{array}{l}\text { FUEL: Firewood (Firewood - Caro, Trunk); HUMFOOD: } \\
\text { Food (Edible, Fruit) }\end{array}$ & & $\mathrm{CH} 79$ \\
\hline
\end{tabular}

Perebea mollis (Poepp. \& Endl.) Huber

Pseudolmedia macrophylla Trécul

Pseudolmedia sp.
Food (Edible, Fruit); MEDVET: Insect and athropod bites (Buna bite, Bark)

CONST: Houses (To tie house, Bark); FUEL: Firewood (Firewood - Caro, Trunk); HUMFOOD: Food (Edible, Fruit)

FUEL: Firewood (Firewood - Caro, Trunk): HUMFOOD: Food (Edible, Fruit)
MOV 63, SCO 40 
Table 1 Plant species used by the Chácobo (Continued)

\begin{tabular}{|c|c|}
\hline $\begin{array}{l}\quad \text { Sorocea } \\
\text { guilleminiana } \\
\text { Gaudich }\end{array}$ & $\begin{array}{l}\text { CONST: Houses (Tie - Xahui, Bark; To tie house, Bark); } \\
\text { HUMFOOD: Food (Edible, Fruit) }\end{array}$ \\
\hline $\begin{array}{l}\text { Sorocea muriculata } \\
\text { Miq. } \\
\text { Musaceae }\end{array}$ & $\begin{array}{l}\text { CULT: Personal adornment (Ornament - Maxëití, } \\
\text { Fruit); Ritual (Marriage ceremony; Symbology, Trunk) }\end{array}$ \\
\hline $\begin{array}{l}\text { Musa x paradisiaca } \\
\text { L. }\end{array}$ & $\begin{array}{l}\text { HUMFOOD: Beberages (Beberage - Chicha, Fruit; } \\
\text { Beberage, Fruit); Food (Edible - Chipilo, Fruit; Edible } \\
\text { Chive, Fruit; Edible, Fruit); MEDVET: Dental health } \\
\text { (Blisters mouth, Fruit; Toothache, Root); Digestive } \\
\text { system (Diarrhea, Exudate); Skin and subcutaneous } \\
\text { tissue (Burns, Fruit; Empeine, Fruit); UTEN\&TOOL: } \\
\text { Domestic utensils (Basket - Bano, Leaf) }\end{array}$ \\
\hline
\end{tabular}

Myristicaceae

Iryanthera juruensis Warb.

Iryanthera sp. $\mathrm{Sm}$.

Virola flexuosa A.C.

Virola sebifera Aubl. CULT: Cosmetic (Hair oil, Exudate)

Myrtaceae

Eugenia sp. 1
Eugenia sp. 2
Myrcia mollis
Kunth) DC.
Myrcia regnelliana
. Berg

Myrciaria floribunda $(\mathrm{H}$. West ex Willd.) O. Berg

Psidium guajava L. HUMFOOD: Food (Edible, Fruit) MEDVET: Skin and subcutaneous tissue (Caracha) FUEL: Firewood (Firewood - Caro, Trunk)

MEDVET: Skin and subcutaneous tissue (Caracha, Bark and fruit; Wounds and cuts, Bark and root)

MEDVET: General Ailments with Unspecific Symptoms Hoja del monte (Ch) (Chest pain, Bark); Musculo-skeletal system (Cramps, Bark, Rheumatism, Bark)

Exudate): Skin and subcutaneous tissue (Caracha, Exudate)

CONST: Houses (Tie - Xahui, Bark); FUEL: Firewood Fruit); MEDVET: Insect and athropod bites (Insectbite)

Bach rao (Ch)

$\mathrm{CH} 81$

Suelda con suelda (Sp)

Toro (Ch)

JSM 32

CH82

RBU 17824

Mëtëquë (Ch)

JSM 12

BCM 8

$\mathrm{CH} 83$

$\mathrm{CH} 84$

BCM 10, ORC 1

Bahua quëxti (Ch) fever, Bark)

Ochnaceae

Ouratea angulata Tiegh.

Ouratea sp.

MEDVET: Musculo-skeletal system (Rheumatism, Bark)

Chuchuhuaso monte alto (Sp)

Xaba pëpëcho (Ch)

JSM 10

Olacaceae

Minquartia guianensis Aubl.

FUEL: Firewood (Firewood - Caro, Trunk)

CONST: Houses (House post- Jibamë, Trunk); MEDVET: Cacharí (Ch) Skin and subcutaneous tissue (Hand blisters, Bark)

Oxalidaceae

Agonandra $b$ HUMFOOD: Food (Edible, Fruit)

Aceituna (Sp)

$\mathrm{CH} 85$ rasiliensis Miers ex Benth.

Averrhoa carambola L.

HUMFOOD: Food (Edible, Fruit)

Carambola (Sp)

Passifloraceae 
Table 1 Plant species used by the Chácobo (Continued)

\begin{tabular}{|c|c|c|c|}
\hline $\begin{array}{l}\text { Passiflora coccinea } \\
\text { Aubl. }\end{array}$ & $\begin{array}{l}\text { UTEN\&TOOL: Hunting \& fishing tools (Barbasco - } \\
\text { Iscoró, Trunk) }\end{array}$ & & \\
\hline $\begin{array}{l}\text { Passiflora miniata } \\
\text { Aubl. }\end{array}$ & HUMFOOD: Food (Edible, Fruit) & Pachio fuerte (Sp) & MOV 10, SCO 21 \\
\hline $\begin{array}{l}\text { Passiflora tripartita } \\
\text { (Juss.) Poir. }\end{array}$ & $\begin{array}{l}\text { UTEN\&TOOL: Domestic utensils (Basket - Nishicacano, } \\
\text { Trunk) }\end{array}$ & Tumbo (Sp) & $\mathrm{CH} 87$ \\
\hline \multicolumn{4}{|l|}{ Piperaceae } \\
\hline $\begin{array}{l}\text { Peperomia } \\
\text { pellucida (L.) Kunth }\end{array}$ & $\begin{array}{l}\text { MEDVET: General Ailments with Unspecific Symptoms } \\
\text { (Chest pain, Fruit) }\end{array}$ & & $\mathrm{CH} 88$ \\
\hline $\begin{array}{l}\text { Piper bartlingianum } \\
\text { (Miq.) C. DC. }\end{array}$ & $\begin{array}{l}\text { MEDVET: Skin and subcutaneous tissue (Caracha, } \\
\text { Root); UTEN\&TOOL: Domestic utensils (Basket - Bano) }\end{array}$ & & JSM 34, MSM 8 \\
\hline Piper hispidum Sw. & $\begin{array}{l}\text { MEDVET: Dental health (Toothache, Root); Not } \\
\text { specified at all (Operations, Trunk); Skin and } \\
\text { subcutaneous tissue (Burns, Leaf; Caracha, Leaf, root, } \\
\text { trunk and whole plant; Wounds and cuts, Leaf and } \\
\text { trunk) }\end{array}$ & & SCO 10, GOS 12 \\
\hline $\begin{array}{l}\text { Piper nigrispicum } \\
\text { Sw. }\end{array}$ & $\begin{array}{l}\text { MEDVET: Digestive system (Stomach ache, Bark); } \\
\text { Endocrine system (Liver pain, Trunk); Sensory system } \\
\text { (Inflammation of eyes) }\end{array}$ & Nishipara / Yunquilla (Ch) & $\mathrm{CH} 89$ \\
\hline Piper peltatum Sw. & $\begin{array}{l}\text { MEDVET: General Ailments with Unspecific Symptoms } \\
\text { (Vomit, Leaf); Respiratory system (Cold and flu, Bark } \\
\text { and leaf); Sensory system (Earache, Root) }\end{array}$ & Boca de Hombre (Sp) & GOS 43, MOV 60 \\
\hline $\begin{array}{l}\text { Piper piscatorum } \\
\text { Sw. }\end{array}$ & $\begin{array}{l}\text { MEDVET: Dental health (Toothache, Exudate, root and } \\
\text { trunk); Digestive system (Diarrhea, Trunk); Musculo- } \\
\text { skeletal system (Bone pain, Root); Not specified at all } \\
\text { (Not specified, Root); Skin and subcutaneous tissue } \\
\text { (Caracha, Leaf) }\end{array}$ & Nucaperi (Ch) & DOA 7 \\
\hline Piper sp. & $\begin{array}{l}\text { MEDVET: Respiratory system (Cold and flu, Whole } \\
\text { plant); Urinary system (Kidney pain, Whole plant) }\end{array}$ & Matico (Sp) & MOA 9 \\
\hline \multicolumn{4}{|l|}{ Poaceae } \\
\hline $\begin{array}{l}\text { Cymbopogon } \\
\text { citratus (DC.) Stapf }\end{array}$ & $\begin{array}{l}\text { MEDVET: Digestive system (Stomach ache, Leaf); } \\
\text { General Ailments with Unspecific Symptoms (Vomit, } \\
\text { Leaf); Infections and infestations (Malaria and fever, } \\
\text { Leaf and root); Pregnancy, birth and puerperial } \\
\text { (Accelerator for birth, Root; Birth, Leaf; Haemorrhage } \\
\text { after childbirth, Leaf); Reproductive system and sex } \\
\text { health (Menstrual pain, Leaf); Respiratory system (Cold } \\
\text { and flu, Leaf); Sensory system (Inflammation of eyes, } \\
\text { Leaf); Skin and subcutaneous tissue (Haemorrhage, } \\
\text { Leaf) }\end{array}$ & Cedrón (Sp) & \\
\hline Guadua sp. 1 & $\begin{array}{l}\text { UTEN\&TOOL: Domestic utensils (Chair - Taburete, } \\
\text { Trunk) }\end{array}$ & & DOA 22 \\
\hline Guadua sp. 2 & $\begin{array}{l}\text { CULT: Recreational (Zampoña - Bistó, Trunk); MEDVET: } \\
\text { Pregnancy, birth and puerperial (To cut umbilical } \\
\text { cord, Trunk); UTEN\&TOOL: Domestic utensils (Knife, } \\
\text { Trunk) }\end{array}$ & & MOV 57 \\
\hline $\begin{array}{l}\text { Gynerium } \\
\text { sagittatum (Aubl.) P. } \\
\text { Beauv. }\end{array}$ & $\begin{array}{l}\text { CONST: Houses (Hedge - Panë, Trunk); CULT: Clothes } \\
\text { \& accessories (Comb, Trunk); Personal adornment } \\
\text { (Ornament - Maxëití, Seeds; Ornament - Rësëti, } \\
\text { Trunk); Recreational (Zampoña - Bistó, Trunk); } \\
\text { MEDVET: Musculo-skeletal system (Fractures); } \\
\text { Snakebites and Ray stings (Sankebites, Trunk); } \\
\text { UTEN\&TOOL: Domestic utensils (Mat, Leaf); Hunting \& } \\
\text { fishing tools (Arrow - Bicobi, Trunk; Arrow - Notsi, } \\
\text { Trunk; Arrow - Pio, Trunk; Arrow - Quërëquë, Trunk; } \\
\text { Arrow - Quëspini, Trunk; Arrow - Tahua Quëspini, } \\
\text { Trunk; Arrow - Tiopi, Trunk; Arrow, Fruit; Bow - Canatí, } \\
\text { Trunk; Weapons, Trunk) }\end{array}$ & Tacuara (Ch); Chuchío / Paja corona (Sp) & $\mathrm{CH} 90$ \\
\hline Gynerium sp. & UTEN\&TOOL: Domestic utensils (Knife, Trunk) & & MOV 30 \\
\hline
\end{tabular}


Table 1 Plant species used by the Chácobo (Continued)

\begin{tabular}{|c|c|c|c|}
\hline $\begin{array}{l}\text { Lasiacis ligulata } \\
\text { Hitchc. \& Chase. }\end{array}$ & $\begin{array}{l}\text { CULT: Recreational (Zampoña - Bistó, Trunk); MEDVET: } \\
\text { Dental health (Blisters mouth, Fruit) }\end{array}$ & Tacuarilla (Ch) & $\mathrm{CH} 91$ \\
\hline $\begin{array}{l}\text { Olyra micrantha } \\
\text { Kunth }\end{array}$ & $\begin{array}{l}\text { CULT: Personal adornment (Ornament - Matsamití, } \\
\text { Trunk; Ornament - Rësëti, Trunk); Recreational } \\
\text { (Zampoña - Bistó, Trunk); FUEL: Other fuel (Ceramics - } \\
\text { Comëno, Trunk); UTEN\&TOOL: Hunting \& fishing tools } \\
\text { (Arrow - Bicobi, Trunk; Arrow - Notsi, Trunk; Arrow - } \\
\text { Quërëquë, Trunk; Arrow - Quëspini, Trunk; Arrow - } \\
\text { Tahua Quëspini, Trunk; Arrow - Tiopi, Trunk) }\end{array}$ & Tacuarilla (Ch) & $\mathrm{CH} 92$ \\
\hline Oryza sativa $\mathrm{L}$. & $\begin{array}{l}\text { CULT: Recreational (Zampoña - Bistó, Trunk); } \\
\text { HUMFOOD: Food (Edible, Seeds) }\end{array}$ & Arroz (Sp) & \\
\hline Pharus latifolius L. & $\begin{array}{l}\text { UTEN\&TOOL: Hunting \& fishing tools (Barbasco - Axa, } \\
\text { Trunk) }\end{array}$ & Jënë arosa (Ch); Barbasco (Sp) & $\mathrm{CH} 92$ \\
\hline $\begin{array}{l}\text { Saccharum } \\
\text { officinarum } L \text {. }\end{array}$ & $\begin{array}{l}\text { CONST: Houses (House post- Jibamë, Trunk); FUEL: } \\
\text { Firewood (Firewood - Caro, Trunk); HUMFOOD: } \\
\text { Beberages (Beberage, Trunk); Food (Edible, Trunk); } \\
\text { MEDVET: Urinary system (Kidneys, Trunk) }\end{array}$ & $\begin{array}{l}\text { Shita chëque / Shita sihoyá / Shitaria / Shitatë } \\
\text { (Ch); Caña (Sp) }\end{array}$ & \\
\hline $\begin{array}{l}\text { Streptogyna } \\
\text { americana C.E. Hubb }\end{array}$ & $\begin{array}{l}\text { CONST: Houses (Frame house, Trunk); MEDVET: } \\
\text { Endocrine system (Liver pain, Root); General Ailments } \\
\text { with Unspecific Symptoms (Vomit, Root); Urinary } \\
\text { system (Kidney infection, Root; Kidneys, Root); } \\
\text { Veterinary (Distemper, Root) }\end{array}$ & Huasimapoa (Ch); Sujo (Sp) & $\mathrm{CH} 93$ \\
\hline Zea mays L. & $\begin{array}{l}\text { ANIMFOOD: Fodder (Edible, Seeds); HUMFOOD: } \\
\text { Beberages (Beberage - Chicha, Seeds; Beberage - } \\
\text { Wiñapo, Seeds); Food (Edible - Chive, Seeds; Edible - } \\
\text { Flour, Seeds; Edible - Tamales, Seeds; Edible, Seeds) }\end{array}$ & $\begin{array}{l}\text { Cahuayo Xëqui / Canashibati / Chítoco / Itëma / } \\
\text { Jimi Xëqui / Xëqui / Xëqui bëtëmë / xëqui joxo / } \\
\text { Xëquiria / Xino xëqui (Ch); Maíz / máiz amarillo / } \\
\text { Maíz blanco / Maíz colorado / Maíz corto / Maíz } \\
\text { cubano / Maíz negro (Sp) }\end{array}$ & \\
\hline \multicolumn{4}{|l|}{ Polygalaceae } \\
\hline $\begin{array}{l}\text { Bredemeyera } \\
\text { myrtifolia Spruce ex } \\
\text { A.W. Benn. }\end{array}$ & $\begin{array}{l}\text { CULT: Personal adornment (Ornament - Shinoxëta, } \\
\text { Trunk) }\end{array}$ & Bahuino Nihi (Ch) & BCM 4, ESR 3 \\
\hline \multicolumn{4}{|l|}{ Polygonaceae } \\
\hline $\begin{array}{l}\text { Triplaris americana } \\
\text { L. }\end{array}$ & $\begin{array}{l}\text { MEDVET: Digestive system (Diarrhea, Bark and leaf; } \\
\text { Stomach ache, Seeds); General Ailments with } \\
\text { Unspecific Symptoms (Chest pain; Headache, Seeds; } \\
\text { Vomit, Leaf); Infections and infestations (Malaria and } \\
\text { fever, Bark and leaf); Musculo-skeletal system } \\
\text { (Fractures, Bark); Respiratory system (Cough) }\end{array}$ & Janina (Ch); Palo Diablo (Sp) & $\begin{array}{l}\text { GOS 47, JSM 58, } \\
\text { MOA 5, MOV 59, } \\
\text { ORC 2 }\end{array}$ \\
\hline \multicolumn{4}{|l|}{ Polypodiaceae } \\
\hline $\begin{array}{l}\text { Phlebodium } \\
\text { decumanum (Willd.) J. } \\
\text { Sm. }\end{array}$ & $\begin{array}{l}\text { MEDVET: Infections and infestations (Leishmaniasis, } \\
\text { Bark); Respiratory system (Cold and flu, Bark); Skin and } \\
\text { subcutaneous tissue (Caracha, Root); Urinary system } \\
\text { (Kidneys, Bark, leaf and root) }\end{array}$ & Roho jina (Ch); Cola de manechi (Sp) & DOA 9, ORC 4 \\
\hline \multicolumn{4}{|l|}{ Proteaceae } \\
\hline Roupala sp. & MEDVET: Sensory system (Earache, Leaf) & Mahi No Nihi (Ch) & $\mathrm{CH} 94$ \\
\hline \multicolumn{4}{|l|}{ Pteridaceae } \\
\hline $\begin{array}{l}\text { Adiantum } \\
\text { latifolium Lam. }\end{array}$ & $\begin{array}{l}\text { CONST: Houses (Tie - Xahui, Bark; To tie house, Trunk); } \\
\text { Thatch (Roof - Xëhuahacacató, Trunk; To tie roof, } \\
\text { Trunk); CULT: Personal adornment (Ornament - } \\
\text { Mënëxëtí, Trunk; Ornament - Shinoxëta); UTEN\&TOOL: } \\
\text { Domestic utensils (Basket - Nishicacano, Trunk) }\end{array}$ & Mitaisa (Ch); Bejuco (Sp) & MOV 67 \\
\hline $\begin{array}{l}\text { Adiantum lucidum } \\
\text { (Cav.) Sw. }\end{array}$ & $\begin{array}{l}\text { CONST: Houses (To tie house, Trunk); MEDVET: Skin } \\
\text { and subcutaneous tissue (Caracha, Exudate) }\end{array}$ & Mitsisi (Ch) & $\mathrm{CH} 95$ \\
\hline $\begin{array}{l}\text { Adiantum } \\
\text { obliquum Willd. }\end{array}$ & $\begin{array}{l}\text { MEDVET: Not specified at all (Not specified); } \\
\text { UTEN\&TOOL: Rope (Rope - Rispichi, Trunk) }\end{array}$ & Mitsisi (Ch) & $\mathrm{CH} 96$ \\
\hline $\begin{array}{l}\text { Adiantum } \\
\text { petiolatum Desv. }\end{array}$ & $\begin{array}{l}\text { MEDVET: Infections and infestations (Scabies); Skin } \\
\text { and subcutaneous tissue (Skin infection) }\end{array}$ & Mitsisi (Ch) & $\mathrm{CH} 97$ \\
\hline
\end{tabular}


Table 1 Plant species used by the Chácobo (Continued)

\begin{tabular}{|c|c|c|c|}
\hline Pteris sp. & MEDVET: Urinary system (Kidney infection, Trunk) & Bushishi (Ch); Shico (Sp) & DOA 50 \\
\hline \multicolumn{4}{|l|}{ Rosaceae } \\
\hline $\begin{array}{l}\text { Prunus amplifolia } \\
\text { Pilger }\end{array}$ & $\begin{array}{l}\text { CONST: Houses (Hedge - Panë, Trunk; Roof beam - } \\
\text { Canoxoco, Trunk); FUEL: Firewood (Firewood - Caro, } \\
\text { Trunk); UTEN\&TOOL: Hunting \& fishing tools (Bow - } \\
\text { Canatí, Trunk); Labour tools (Planting stick - Xësati, } \\
\text { Trunk; Shovel, Trunk) }\end{array}$ & Jihui (Ch) & $\mathrm{CH} 98$ \\
\hline \multicolumn{4}{|l|}{ Rubiaceae } \\
\hline $\begin{array}{l}\text { Alibertia edulis } \\
\text { (Rich.) A. Rich. ex DC. }\end{array}$ & $\begin{array}{l}\text { HUMFOOD: Food (Edible, Fruit); MEDVET: Digestive } \\
\text { system (Diarrhea, Fruit and leaf); General Ailments } \\
\text { with Unspecific Symptoms (Vomit) }\end{array}$ & Tosa (Ch); Guayabilla / Tutumilla (Sp) & ESR 12, MOV 1,15 \\
\hline $\begin{array}{l}\text { Amaioua } \\
\text { guianensis Aubl. }\end{array}$ & $\begin{array}{l}\text { FUEL: Firewood (Firewood - Caro, Trunk); } \\
\text { UTEN\&TOOL: Labour tools (Axe - Maquë poroma, } \\
\text { Trunk; Machete handle, Trunk; Planting stick - Xësati, } \\
\text { Trunk) }\end{array}$ & Cai Osho (Ch) & DOA 32 \\
\hline $\begin{array}{l}\text { Capirona } \\
\text { decorticans Spruce }\end{array}$ & $\begin{array}{l}\text { FUEL: Firewood (Firewood - Caro, Trunk); HUMFOOD: } \\
\text { Food (Edible, Fruit); MEDVET: Infections and } \\
\text { infestations (Scabies, Bark); Insect and athropod bites } \\
\text { (Buna bite, Bark; Insectbite, Bark); Not specified at all } \\
\text { (Cepta, Bark); Reproductive system and sex health } \\
\text { (Contraceptive, Bark); Respiratory system (Cold and } \\
\text { flu, Bark and flower); Skin and subcutaneous tissue } \\
\text { (Burns, Bark; Caracha, Bark; Haemorrhage, Bark; } \\
\text { Wounds and cuts, Bark); Snakebites and Ray stings } \\
\text { (Sankebites, Bark); UTEN\&TOOL: Domestic utensils } \\
\text { (Pestle of Tacu, Trunk); Labour tools (Planting stick - } \\
\text { Xësati, Trunk; Shovel, Trunk) }\end{array}$ & Batahua (Ch); Guayabochi (Sp) & $\begin{array}{l}\text { DOA 28, ESR 14, } \\
\text { JSM 22, MOV 36, } \\
\text { RBU 17823, SCO } \\
39\end{array}$ \\
\hline $\begin{array}{l}\text { Coutarea hexandra } \\
\text { (Jacq.) K. Schum. }\end{array}$ & $\begin{array}{l}\text { MEDVET: Digestive system (Diarrhea, Bark, leaf and } \\
\text { root; Stomach ache, Bark); Endocrine system } \\
\text { (Gallbladder, Bark); Infections and infestations (Malaria } \\
\text { and fever, Bark); Reproductive system and sex health } \\
\text { (Abortive, Leaf) }\end{array}$ & Jihui Moca (Ch) & $\mathrm{CH} 99$ \\
\hline $\begin{array}{l}\text { Genipa americana } \\
\text { L. }\end{array}$ & $\begin{array}{l}\text { CULT: Personal adornment (Ornament - Maxëití, } \\
\text { Seeds); HUMFOOD: Food (Edible, Fruit) }\end{array}$ & Nanë (Ch); Bii (Sp) & JSM 6 \\
\hline $\begin{array}{l}\text { Geophila cordifolia } \\
\text { Miq. }\end{array}$ & $\begin{array}{l}\text { MEDVET: Infections and infestations (Amoebas, Leaf; } \\
\text { Anthelmintic, Leaf) }\end{array}$ & Mai yochi (Ch) & DOA 35 \\
\hline $\begin{array}{l}\quad \text { Ladenbergia } \\
\text { oblongifolia (Mutis) L. } \\
\text { Anderes }\end{array}$ & HUMFOOD: Food (Edible, Fruit) & Muela (Sp) & $\mathrm{CH} 100$ \\
\hline $\begin{array}{l}\text { Palicourea rigida } \\
\text { Kunth }\end{array}$ & $\begin{array}{l}\text { HUMFOOD: Food (Edible, Fruit); MEDVET: Skin and } \\
\text { subcutaneous tissue (Caracha, Trunk) }\end{array}$ & Áhuara Macha (Ch) & MOV 13 \\
\hline $\begin{array}{l}\text { Psychotria deflexa } \\
\text { DC. }\end{array}$ & CONST: Houses (To tie house, Bark) & Yotabi (Ch) & $\mathrm{CH} 101$ \\
\hline $\begin{array}{l}\text { Psychotria } \\
\text { iodotricha Müll. Arg. }\end{array}$ & HUMFOOD: Food (Edible, Fruit) & Bimi Chëxë (Ch) & $\mathrm{CH} 102$ \\
\hline $\begin{array}{l}\text { Psychotria lupulina } \\
\text { Benth. }\end{array}$ & MEDVET: Infections and infestations (Boro, Bark) & Ahuara Nihi (Ch) & $\mathrm{CH} 103$ \\
\hline $\begin{array}{l}\text { Psychotria } \\
\text { prunifolia (Kunth) } \\
\text { Steyerm. }\end{array}$ & $\begin{array}{l}\text { MEDVET: Digestive system (Diarrhea, Bark); General } \\
\text { Ailments with Unspecific Symptoms (Vomit, Bark) }\end{array}$ & Bimi Chëxë (Ch) & $\mathrm{CH} 104$ \\
\hline Psychotria sp. 1 & CULT: Personal adornment (Ornament - Maxëití, Fruit) & Bimi Chëxë (Ch) & JSM 25 \\
\hline Psychotria sp. 2 & $\begin{array}{l}\text { CULT: Personal adornment (Ornament - Maxëití, } \\
\text { Fruit); MEDVET: Digestive system (Diarrhea, Root) }\end{array}$ & Bimi Chëxë (Ch) & DOA 14 \\
\hline $\begin{array}{l}\text { Randia armata cf. } \\
\text { (Sw.) DC. }\end{array}$ & FUEL: Firewood (Firewood - Caro, Trunk) & Pata de Gallina (Sp) & $\mathrm{CH} 105$ \\
\hline $\begin{array}{l}\text { Uncaria guianensis } \\
\text { (Aubl.) J.F. Gmel. }\end{array}$ & $\begin{array}{l}\text { CULT: Personal adornment (Ornament - Matsamití, } \\
\text { Seeds); FUEL: Other fuel (Ceramics - Chomo, Trunk); }\end{array}$ & Cacatho (Ch); Uña de Gato (Sp) & $\begin{array}{l}\text { ESR 6, 20, JSM 53, } \\
\text { MOV 3, SCO } 7\end{array}$ \\
\hline
\end{tabular}


Table 1 Plant species used by the Chácobo (Continued)

\begin{tabular}{|c|c|c|c|}
\hline & $\begin{array}{l}\text { MEDVET: Digestive system (Diarrhea, Bark; Stomach } \\
\text { ache, Bark); Endocrine system (Liver pain, Bark); } \\
\text { General Ailments with Unspecific Symptoms (Chest } \\
\text { pain, Bark; Headache, Bark; Inflammation, Bark; Vomit, } \\
\text { Bark); Musculo-skeletal system (Bone pain, Bark; } \\
\text { Fractures, Bark; Hip pain, Bark); Respiratory system } \\
\text { (Cold and flu, Bark); Urinary system (Kidney infection, } \\
\text { Bark); UTEN\&TOOL: Domestic utensils (Basket - } \\
\text { Cacachuquëxnia, Trunk; Basket - Chichama, Bark; } \\
\text { Basket - Nishicacano, Trunk; Basket - Purupachi, Bark; } \\
\text { Basket - Yamachi, Trunk) }\end{array}$ & & \\
\hline Indet. sp. 1 & $\begin{array}{l}\text { CONST: Houses (To tie house, Bark); Thatch (To tie } \\
\text { roof, Bark) }\end{array}$ & & \\
\hline \multicolumn{4}{|l|}{ Rutaceae } \\
\hline $\begin{array}{l}\text { Citrus aurantiifolia } \\
\text { (Christm.) Swingle }\end{array}$ & $\begin{array}{l}\text { FUEL: Firewood (Firewood - Caro, Trunk); HUMFOOD: } \\
\text { Food (Edible, Fruit); MEDVET: Dental health } \\
\text { (Toothache, Seeds); Digestive system (Diarrhea, Root; } \\
\text { Stomach ache, Fruit and root); Endocrine system } \\
\text { (Liver pain, Fruit); General Ailments with Unspecific } \\
\text { Symptoms (Chest pain, Fruit; Headache, Fruit; Vomit, } \\
\text { Root); Infections and infestations (Malaria and fever, } \\
\text { Bark); Musculo-skeletal system (Bone pain, Bark, leaf } \\
\text { and root); Respiratory system (Cold and flu, Fruit and } \\
\text { leaf); Sensory system (Inflammation of eyes, Seeds); } \\
\text { Urinary system (Kidneys, Fruit) }\end{array}$ & Rimó (Ch); Limón (Sp) & \\
\hline Citrus limetta Risso & $\begin{array}{l}\text { MEDVET: Infections and infestations (Malaria and } \\
\text { fever, Root) }\end{array}$ & Lima (Sp) & \\
\hline $\begin{array}{l}\text { Citrus paradisi } \\
\text { Macfad. }\end{array}$ & $\begin{array}{l}\text { CONST: Houses (To tie house, Bark); HUMFOOD: Food } \\
\text { (Edible, Fruit); MEDVET: Digestive system (Diarrhea, } \\
\text { Fruit; Stomach ache, Bark and leaf); General Ailments } \\
\text { with Unspecific Symptoms (Vomit, Root); Infections } \\
\text { and infestations (Malaria and fever, Bark); Skin and } \\
\text { subcutaneous tissue (Caracha, Root; Wounds and } \\
\text { cuts, Root); UTEN\&TOOL: Domestic utensils (Basket - } \\
\text { Chichama, Bark) }\end{array}$ & Taraja (Ch); Toronja (Sp) & \\
\hline $\begin{array}{l}\text { Citrus reticulata } \\
\text { Blanco }\end{array}$ & $\begin{array}{l}\text { HUMFOOD: Food (Edible, Fruit); MEDVET: Digestive } \\
\text { system (Stomach ache, Leaf) }\end{array}$ & Mandarina (Sp) & \\
\hline $\begin{array}{l}\text { Citrus } \times \text { sinensis (L.) } \\
\text { Osbeck }\end{array}$ & $\begin{array}{l}\text { HUMFOOD: Food (Edible, Fruit); MEDVET: Digestive } \\
\text { system (Diarrhea, Bark, fruit and leaf); Endocrine } \\
\text { system (Liver pain, Leaf); Reproductive system and } \\
\text { sex health (Abortive, Root); Urinary system (Kidneys, } \\
\text { Fruit); UTEN\&TOOL: Domestic utensils (Pestle of Batan } \\
\text { - Chapi, Trunk; Pestle of Tacu, Trunk) }\end{array}$ & Naraja (Ch); Naranja (Sp) & \\
\hline $\begin{array}{l}\text { Metrodorea flavida } \\
\text { K. Krause }\end{array}$ & $\begin{array}{l}\text { CONST: Houses (House post- Jibamë, Trunk; } \\
\text { Muchacho - Ninotí, Trunk; Pasa ratón - Xoya jabatí, } \\
\text { Trunk; Roof beam - Canoxoco, Trunk; Tie - Xahui, } \\
\text { Bark; Tirante - Cano bëpotó, Trunk; Tirante largo - } \\
\text { Cano pixquëna, Trunk); FUEL: Firewood (Firewood - } \\
\text { Caro, Trunk); HUMFOOD: Food (Edible, Fruit); } \\
\text { UTEN\&TOOL: Domestic utensils (Pestle of Tacu, } \\
\text { Trunk); Labour tools (Hammer, Trunk) }\end{array}$ & $\begin{array}{l}\text { Paxa ini (Ch); Blanquillo / Palo Blanco / Palo Coca } \\
\text { / Palo Coloradillo (Sp) }\end{array}$ & SCO 25 \\
\hline Moniera trifolia L. & $\begin{array}{l}\text { CULT: Ritual (Fragile children, Leaf); MEDVET: Cultural } \\
\text { diseases and disorders (Bad air and scare - Ratëaina, } \\
\text { Leaf); Sensory system (Earache, Leaf) }\end{array}$ & Ororotso (Ch) & MSM 19 \\
\hline $\begin{array}{l}\text { Zanthoxylum } \\
\text { rhoifolium Lam. }\end{array}$ & FUEL: Firewood (Firewood - Caro, Trunk) & Coroquisi (Ch) & JSM 45 \\
\hline \multicolumn{4}{|l|}{ Salicaceae } \\
\hline $\begin{array}{l}\text { Casearia arborea } \\
\text { (Rich.) Urb. }\end{array}$ & $\begin{array}{l}\text { FUEL: Firewood (Firewood - Caro, Trunk); HUMFOOD: } \\
\text { Beberages (Beberage - Chicha, Seeds) }\end{array}$ & Jihui pohi (Ch) & SCO 41 \\
\hline Casearia & HUMFOOD: Food (Edible, Fruit) & Ihui Pama / Yobiberoxoco / Chana Jisicato (Ch) & $\mathrm{CH} 106$ \\
\hline
\end{tabular}


Table 1 Plant species used by the Chácobo (Continued)

\begin{tabular}{|c|c|c|c|}
\hline $\begin{array}{l}\text { Lunania parviflora } \\
\text { Spruce ex Benth. }\end{array}$ & $\begin{array}{l}\text { MEDVET: Digestive system (Diarrhea, Bark; Stomach } \\
\text { ache, Bark); Endocrine system (Liver pain, Bark); } \\
\text { General Ailments with Unspecific Symptoms (Vomit, } \\
\text { Bark and fruit); Musculo-skeletal system (Rheumatism, } \\
\text { Bark) }\end{array}$ & Nishi Tsanóna (Ch); Bejuco / Chacaka (Sp) & DOA 13 \\
\hline \multicolumn{4}{|l|}{ Sapindaceae } \\
\hline $\begin{array}{l}\text { Matayba } \\
\text { scrobiculata (H.B.K.) } \\
\text { Radkl. }\end{array}$ & FUEL: Firewood (Firewood - Caro, Trunk) & Sama negra (Sp) & $\mathrm{CH} 107$ \\
\hline Paullinia sp. & $\begin{array}{l}\text { FUEL: Firewood (Firewood - Caro, Trunk); HUMFOOD: } \\
\text { Food (Edible, Fruit); UTEN\&TOOL: Hunting \& fishing } \\
\text { tools (Barbasco - Axa, Trunk) }\end{array}$ & Shoshapo (Ch); Barbasco / Muela (Sp) & DOA 27 \\
\hline $\begin{array}{l}\text { Serjania lethalis A. } \\
\text { St. Hill }\end{array}$ & $\begin{array}{l}\text { CONST: Houses (Frame house, Trunk; Tirante - Cano } \\
\text { bëpotó, Trunk); FUEL: Firewood (Firewood - Caro, } \\
\text { Trunk); HUMFOOD: Food (Edible, Fruit); MEDVET: } \\
\text { Digestive system (Diarrhea, Bark; Stomach ache, Bark); } \\
\text { General Ailments with Unspecific Symptoms (Vomit, } \\
\text { Bark); UTEN\&TOOL: Hunting \& fishing tools (Barbasco } \\
\text { - Axacoro, Trunk); Labour tools (Sandpaper, Leaf) }\end{array}$ & Axa Coro / Carahina Nihi (Ch); Barbasco (Sp) & $\mathrm{CH} 108$ \\
\hline $\begin{array}{l}\text { Serjania } \\
\text { pyramidata Radkl. }\end{array}$ & CULT: Personal adornment (Ornament - Maxëití, Fruit) & Capë Itsa (Ch) & $\mathrm{CH} 109$ \\
\hline Serjania sp. & $\begin{array}{l}\text { UTEN\&TOOL: Hunting \& fishing tools (Barbasco - } \\
\text { Axacoro, Trunk) }\end{array}$ & Axa Coro (Ch); Barbasco (Sp) & DOA 6, SCO 33 \\
\hline $\begin{array}{l}\text { Talisia acutifolia } \\
\text { Radkl. }\end{array}$ & $\begin{array}{l}\text { HUMFOOD: Food (Edible, Fruit); UTEN\&TOOL: Labour } \\
\text { tools (Shovel, Trunk) }\end{array}$ & Pitón (Sp) & $\mathrm{CH} 110$ \\
\hline \multicolumn{4}{|l|}{ Sapotaceae } \\
\hline $\begin{array}{l}\text { Chrysophyllum } \\
\text { sparsiflorum Klotzsch } \\
\text { ex Miq. }\end{array}$ & FUEL: Firewood (Firewood - Caro, Trunk) & Quishpi (Ch); Quispi (Sp) & $\mathrm{CH} 111$ \\
\hline $\begin{array}{l}\text { Micropholis } \\
\text { guyanensis (A.DC.) } \\
\text { Pierre }\end{array}$ & $\begin{array}{l}\text { FUEL: Firewood (Firewood - Caro, Trunk); HUMFOOD: } \\
\text { Food (Edible, Fruit) }\end{array}$ & Toro Quirihua (Ch) & MOV 61 \\
\hline $\begin{array}{l}\quad \text { Micropholis } \\
\text { guyanensis cf. (A.DC.) } \\
\text { Pierre }\end{array}$ & HUMFOOD: Food (Edible, Fruit) & Coquino (Ch) & $\mathrm{CH} 112$ \\
\hline $\begin{array}{l}\text { Micropholis } \\
\text { lanceolata (C. Martius } \\
\text { \& Eichler) Pierre }\end{array}$ & HUMFOOD: Food (Edible, Fruit) & Bimi Muishi (Ch) & $\mathrm{CH} 113$ \\
\hline $\begin{array}{r}\text { Pouteria caimito } \\
\text { (Ruiz \& Pav.) Radlk. }\end{array}$ & $\begin{array}{l}\text { FUEL: Firewood (Firewood - Caro, Trunk); HUMFOOD: } \\
\text { Food (Edible, Fruit) }\end{array}$ & Quëo (Ch) & $\mathrm{CH} 114$ \\
\hline $\begin{array}{r}\text { Pouteria lucuma } \\
\text { (Ruiz \& Pav.) Radlk. }\end{array}$ & HUMFOOD: Food (Edible, Fruit) & Quëo (Ch); Lucuma (Sp) & $\mathrm{CH} 115$ \\
\hline $\begin{array}{l}\text { Pouteria } \\
\text { macrophylla (Lam.) } \\
\text { Eyma }\end{array}$ & $\begin{array}{l}\text { HUMFOOD: Food (Edible, Fruit); MEDVET: General } \\
\text { Ailments with Unspecific Symptoms (Vomit, Bark); } \\
\text { Skin and subcutaneous tissue (Puchichi) }\end{array}$ & Yahë (Ch) & $\mathrm{CH} 116$ \\
\hline $\begin{array}{l}\text { Pouteria nemorosa } \\
\text { Baehni }\end{array}$ & $\begin{array}{l}\text { HUMFOOD: Food (Edible, Fruit); MEDVET: Infections } \\
\text { and infestations (Scabies); Insect and athropod bites } \\
\text { (Insectbite); UTEN\&TOOL: Domestic utensils (Basket - } \\
\text { Nishicacano, Bark) }\end{array}$ & Bata Jihui / Batabí (Ch); Coquino (Sp) & $\mathrm{CH} 117$ \\
\hline $\begin{array}{l}\text { Pouteria ramiflora } \\
\text { (Mart.) Radkl. }\end{array}$ & $\begin{array}{l}\text { CONST: Houses (House post- Jibamë, Trunk; Xano, } \\
\text { Trunk); FUEL: Firewood (Firewood - Caro, Trunk); } \\
\text { UTEN\&TOOL: Domestic utensils (Batán - Xaxo, Trunk); } \\
\text { Transportation (Canoe, Trunk) }\end{array}$ & $\begin{array}{l}\text { Xanë Yobini (Ch); Tajibo blanco / Almendrillo } \\
\text { blanco (Sp) }\end{array}$ & MOV 12 \\
\hline \multicolumn{4}{|l|}{ Simaroubaceae } \\
\hline Simarouba amara & CONST: Houses (To tie house, Bark); MEDVET: & Tarari (Ch); Palo Amargo (Sp) & GOS 6, GCM 2 \\
\hline
\end{tabular}


Table 1 Plant species used by the Chácobo (Continued)

\begin{tabular}{|c|c|c|c|}
\hline & $\begin{array}{l}\text { and fruit); Endocrine system (Gallbladder, Bark; Liver } \\
\text { pain, Bark and leaf); General Ailments with Unspecific } \\
\text { Symptoms (Vomit, Bark); Infections and infestations } \\
\text { (Malaria and fever, Bark); Skin and subcutaneous } \\
\text { tissue (Caracha, Bark); Urinary system (Kidneys, Bark); } \\
\text { UTEN\&TOOL: Domestic utensils (Basket - Bano, Bark) }\end{array}$ & & \\
\hline \multicolumn{4}{|l|}{ Siparunaceae } \\
\hline $\begin{array}{l}\text { Siparuna } \\
\text { guianensis Aubl. }\end{array}$ & $\begin{array}{l}\text { CULT: Ritual (Fragile children, Bark); MEDVET: } \\
\text { Digestive system (Diarrhea, Bark); General Ailments } \\
\text { with Unspecific Symptoms (Vomit, Bark); Infections } \\
\text { and infestations (Malaria and fever, Leaf); Insect and } \\
\text { athropod bites (Buna bite, Bark; Insectbite, Bark); } \\
\text { Respiratory system (Cold and flu, Leaf); Skin and } \\
\text { subcutaneous tissue (Caracha); Snakebites and Ray } \\
\text { stings (Sankebites); UTEN\&TOOL: Domestic utensils } \\
\text { (Smoke to mosquito repelent) }\end{array}$ & $\begin{array}{l}\text { Shisho Itsa / Xaba ghishu itsa / Xabá shishohitsa } \\
\text { (Ch) }\end{array}$ & $\begin{array}{l}\text { BCM 13, GCM 4, } \\
\text { GOS 5, MOA 8, } \\
\text { MSM 3, } 11, \text { SCO } 8\end{array}$ \\
\hline $\begin{array}{l}\text { Siparuna krukovii } \\
\text { A.C. Sm. }\end{array}$ & $\begin{array}{l}\text { FUEL: Firewood (Firewood - Caro, Trunk); MEDVET: } \\
\text { Infections and infestations (Smallpox, Bark); Insect and } \\
\text { athropod bites (Buna bite, Bark; Insectbite, Bark) }\end{array}$ & Shisho Itsa / Xëto itsa (Ch) & $\begin{array}{l}\text { DOA 19, MOV 32, } \\
\text { RBU } 17829\end{array}$ \\
\hline Siparuna sp. & MEDVET: Urinary system (Kidneys, Root) & Xabá shishohitsa (Ch) & $\mathrm{BCM} 3$ \\
\hline \multicolumn{4}{|l|}{ Smilacaceae } \\
\hline $\begin{array}{l}\text { Smilax flavicaulis } \\
\text { Rusby }\end{array}$ & MEDVET: Digestive system (Diarrhea) & Cayú (Sp) & RBU 17861 \\
\hline $\begin{array}{l}\text { Smilax poeppigii } \\
\text { Kunth. }\end{array}$ & MEDVET: Digestive system (Diarrhea, Young leaf) & Patiari jomoxa (Ch); Guayaba (Sp) & $\mathrm{CH} 118$ \\
\hline Smilax sp. & $\begin{array}{l}\text { MEDVET: Urinary system (Kidneys, Leaf, root and } \\
\text { whole plant) }\end{array}$ & Yahuaxë (Ch) & JSM 18 \\
\hline \multicolumn{4}{|l|}{ Solanaceae } \\
\hline L. Capsicum annuum & $\begin{array}{l}\text { HUMFOOD: Food (Edible, Fruit); MEDVET: Skin and } \\
\text { subcutaneous tissue (Puchichi, Leaf) }\end{array}$ & Aji / Aji dulce / Aji rojo (Sp) & \\
\hline $\begin{array}{l}\text { Cestrum } \\
\text { strigillatum Ruiz \& } \\
\text { Pav. }\end{array}$ & $\begin{array}{l}\text { MEDVET: Skin and subcutaneous tissue (Caracha, } \\
\text { Bark) }\end{array}$ & Yahua taho (Ch) & $\mathrm{CH} 119$ \\
\hline $\begin{array}{l}\text { Lycianthes } \\
\text { glandulosa (Ruiz. \& } \\
\text { Pav.) Bitter }\end{array}$ & $\begin{array}{l}\text { CULT: Personal adornment (Ornament - Maxëití, Fruit; } \\
\text { Ornament - Shinoxëta, Fruit); HUMFOOD: Food } \\
\text { (Edible, Fruit) }\end{array}$ & Bimi Chëxë (Ch) & $\mathrm{CH} 120$ \\
\hline $\begin{array}{l}\text { Lycopersicon } \\
\text { esculentum Mill. }\end{array}$ & HUMFOOD: Food (Edible, Fruit) & Tomate (Sp) & \\
\hline Nicotiana rustica L. & $\begin{array}{l}\text { MEDVET: Cultural diseases and disorders (Bad air and } \\
\text { scare - Ratëaina, Leaf); Infections and infestations } \\
\text { (Boro, Leaf); Reproductive system and sex health } \\
\text { (Menstrual pain, Leaf); Sensory system (Earache, Leaf); } \\
\text { Skin and subcutaneous tissue (Caracha, Leaf); } \\
\text { Snakebites and Ray stings (Sankebites, Leaf) }\end{array}$ & Romë / Rumë (Ch); Tabaco (Sp) & \\
\hline $\begin{array}{l}\text { Solanum betaceum } \\
\text { Cav. }\end{array}$ & $\begin{array}{l}\text { MEDVET: Infections and infestations (Malaria and } \\
\text { fever, Bark) }\end{array}$ & & RBU 17864 \\
\hline $\begin{array}{l}\text { Solanum lorentzii } \\
\text { Bitter }\end{array}$ & $\begin{array}{l}\text { MEDVET: Dental health (Toothache, Root); General } \\
\text { Ailments with Unspecific Symptoms (Headache, Leaf); } \\
\text { Vomit, Whole plant (Infections and infestations); } \\
\text { Anthelmintic, Bark (Respiratory system); Cold and flu, } \\
\text { Bark (Cold and flu, Leaf); Sensory system (Earache, } \\
\text { Leaf); Urinary system (Kidney infection, Leaf) }\end{array}$ & $\begin{array}{l}\text { Jimi nihi / Nohini jihui / Nohini nihi (Ch); Uvita } \\
\text { (Sp) }\end{array}$ & $\begin{array}{l}\text { BCM 12, GOS 24, } \\
\text { MOV } 19\end{array}$ \\
\hline $\begin{array}{l}\text { Solanum } \\
\text { mammosum L. }\end{array}$ & $\begin{array}{l}\text { MEDVET: Infections and infestations (Smallpox, Leaf); } \\
\text { Skin and subcutaneous tissue (Caracha, Bark) }\end{array}$ & Popotoa (Ch); ManSilla (Sp) & \\
\hline $\begin{array}{l}\text { Solanum pensile } \\
\text { Sendtn. }\end{array}$ & CULT: Ritual (Good luck in fishing) & Cashixopá (Ch) & $\mathrm{CH} 120$ \\
\hline & & Yobini (Ch); Hoja hedionda (Sp) & $\mathrm{CH} 121$ \\
\hline
\end{tabular}


Table 1 Plant species used by the Chácobo (Continued)

\begin{tabular}{|c|c|}
\hline $\begin{array}{l}\text { Solanum placitum } \\
\text { C.V. Morton }\end{array}$ & $\begin{array}{l}\text { MEDVET: Cultural diseases and disorders (Bad air and } \\
\text { scare - Ratëaina) }\end{array}$ \\
\hline $\begin{array}{l}\text { Solanum } \\
\text { proteanthum Bohs }\end{array}$ & $\begin{array}{l}\text { CONST: Houses (Tirante - Cano bëpotó, Trunk); FUEL: } \\
\text { Firewood (Firewood - Caro, Trunk); MEDVET: Digestive } \\
\text { system (Diarrhea, Trunk); General Ailments with } \\
\text { Unspecific Symptoms (Vomit, Trunk) }\end{array}$ \\
\hline $\begin{array}{l}\text { Solanum } \\
\text { tuberosum L. }\end{array}$ & $\begin{array}{l}\text { HUMFOOD: Food (Edible, Root); MEDVET: General } \\
\text { Ailments with Unspecific Symptoms (Vomit, Root and } \\
\text { whole plant); Infections and infestations (Amoebas, } \\
\text { Seeds) }\end{array}$ \\
\hline \multicolumn{2}{|l|}{ Staphyleaceae } \\
\hline $\begin{array}{l}\quad \text { Turpinia } \\
\text { occidentalis subsp. } \\
\text { breviflora Croat }\end{array}$ & $\begin{array}{l}\text { HUMFOOD: Food (Edible, Fruit); MEDVET: General } \\
\text { Ailments with Unspecific Symptoms (Body pain, Root; } \\
\text { Headache, Leaf; Pain, Root); Skin and subcutaneous } \\
\text { tissue (Haemorrhage) }\end{array}$ \\
\hline \multicolumn{2}{|l|}{ Strelitziaceae } \\
\hline $\begin{array}{l}\text { Phenakospermum } \\
\text { guianensis Aubl. }\end{array}$ & $\begin{array}{l}\text { CONST: Houses (Hedge - Panë, Trunk; Tie - Xahui, } \\
\text { Leaf; Xapocoti, Leaf); Thatch (Huaracha roof, Leaf; } \\
\text { Ridgepole - Xobomapatí, Leaf; Roof - Xëhuahacacató, } \\
\text { Leaf); CULT: Clothes \& accessories (Skirt woman, Leaf); } \\
\text { Personal adornment (Ornament - Matsamití, Leaf; } \\
\text { Ornament - Maxëití, Leaf; Ornament - Mënëxëtí, Leaf); } \\
\text { FUEL: Firewood (Firewood - Caro, Bark); Other fuel } \\
\text { (Ceramics - Chomo, Bark); MEDVET: Digestive system } \\
\text { (Diarrhea, Exudate; Stomach ache, Exudate); } \\
\text { Endocrine system (Liver pain, Exudate); General } \\
\text { Ailments with Unspecific Symptoms (Vomit, Exudate); } \\
\text { Infections and infestations (Infections, Exudate; } \\
\text { Leishmaniasis, Exudate); Respiratory system (Cold and } \\
\text { flu, Exudate; Cough, Exudate); Skin and subcutaneous } \\
\text { tissue (Burns, Exudate; Caracha, Exudate; Skin fungus, } \\
\text { Leaf; Wounds and cuts, Exudate); Snakebites and Ray } \\
\text { stings (Sankebites, Exudate); Urinary system (Kidney } \\
\text { pain, Exudate; Kidneys, Exudate); UTEN\&TOOL: } \\
\text { Domestic utensils (Basket - Chichama, Bark; Basket - } \\
\text { Nishicacano, Bark; Basket - Purupachi, Bark; Basket - } \\
\text { Yamachi, Bark; Fan - Huëquëti, Leaf); Rope (Rope - } \\
\text { Rispichi, Leaf); Wrappers; Wrappers, Leaf) }\end{array}$ \\
\hline
\end{tabular}

Styracaceae

Styrax sp

Talinaceae

Talinum

paniculatum (Jacq.)

Gaertn.

Tectariaceae

Triplophyllum protensum (Afzel. ex. Sw.) Holttum

Thelypteridaceae

Thelypteris abrupta MEDVET: Sensory system (Earache, Leaf) (Desv.) Proctor

Trigoniaceae

Trigonia killipii J.F. MEDVET: Digestive system (Diarrhea, Bark); General Macbr.

Ailments with Unspecific Symptoms (Vomit, Bark); Infections and infestations (Malaria and fever, Bark)
Jihui Xoco / Strelitziaceae (Ch); Huallabilla de pampa / Papaya (Sp)

Papa (Sp)

\section{Mani Coro / Manihua (Ch); Patujú (Sp)}

Ahua Tishi (Ch); Ahuai (Sp)
Ailments with Unspecific Symptoms (Headache,

Trunk); Musculo-skeletal system (Swelling, Trunk);

Respiratory system (Cold and flu, Leaf); Sensory

system (Earache, Leaf)

MEDVET: Cultural diseases and disorders (Bad air and scare - Ratëaina, Leaf)

Toria huitaxo (Ch); Piñón morado (Sp)

$\mathrm{CH} 125$

Xëqui jahëhua (Ch)

$\mathrm{CH} 126$

Cashixopá (Ch)

Ulmaceae 
Table 1 Plant species used by the Chácobo (Continued)

\begin{tabular}{|c|c|c|c|}
\hline $\begin{array}{l}\text { Ampelocera } \\
\text { edentula Kuhlm. }\end{array}$ & $\begin{array}{l}\text { CONST: Houses (Muchacho - Ninotí, Trunk; Pasa ratón } \\
\text { - Xoya jabatí, Trunk; Ridgepole - Maracatí, Trunk; Roof } \\
\text { beam - Canoxoco, Trunk; Tie - Xahui, Bark; Tirante - } \\
\text { Cano bëpotó, Trunk; Tirante corto - Cano Bësëcamë, } \\
\text { Trunk; Tirante largo - Cano pixquëna, Trunk) }\end{array}$ & Palo Yodo (Sp) & $\mathrm{CH} 128$ \\
\hline $\begin{array}{l}\text { Celtis iguanea } \\
\text { (Jacq.) Sarg. }\end{array}$ & CONST: Thatch (Roof - Xëhuahacacató, Trunk) & Chichipa (Sp) & $\mathrm{CH} 129$ \\
\hline \multicolumn{4}{|l|}{ Urticaceae } \\
\hline $\begin{array}{l}\text { Cecropia ficifolia } \\
\text { Warb. ex Snethl. }\end{array}$ & $\begin{array}{l}\text { CONST: Houses (Hedge - Panë, Trunk; Tie - Xahui, } \\
\text { Bark); Thatch (To tie roof, Bark); CULT: Personal } \\
\text { adornment (Ornament - Amënoxëta, Leaf; Ornament } \\
\text { - Tsirispi, Bark); Recreational (Zampoña - Bistó, Bark); } \\
\text { FUEL: Firewood (Firewood - Caro, Trunk); HUMFOOD: } \\
\text { Food (Edible, Fruit); MEDVET: General Ailments with } \\
\text { Unspecific Symptoms (Vomit, Bark); Infections and } \\
\text { infestations (Scabies); UTEN\&TOOL: Domestic utensils } \\
\text { (Hammock - Nishi, Bark; Pestle of Tacu, Trunk); } \\
\text { Hunting \& fishing tools (Arrow - Bicobi, Bark; Arrow - } \\
\text { Paca, Bark; Arrow - Quërëquë, Bark; Arrow - Tahua } \\
\text { Quëspini, Bark; Arrow - Tiopi, Bark; Bow - Canatí, Bark); } \\
\text { Labour tools (Planting stick - Xësati, Trunk); Rope } \\
\text { (Rope - Rispichi, Bark) }\end{array}$ & Bocono / Tiopi (Ch); Ambaibo (Sp) & $\mathrm{CH} 130$ \\
\hline $\begin{array}{l}\text { Cecropia } \\
\text { sciadophylla Mart. }\end{array}$ & MEDVET: Respiratory system (Cold and flu) & Bocobí (Ch); Hierba de loro (Sp) & $\mathrm{CH} 131$ \\
\hline $\begin{array}{l}\text { Cecropia strigosa } \\
\text { Trécul }\end{array}$ & FUEL: Firewood (Firewood - Caro, Trunk) & Bocobí (Ch) & JSM 14 \\
\hline $\begin{array}{l}\text { Pourouma } \\
\text { cecropiifolia Mart. }\end{array}$ & $\begin{array}{l}\text { UTEN\&TOOL: Labour tools (Planting stick - Xësati, } \\
\text { Trunk) }\end{array}$ & Quëxqui xaquini (Ch) & $\mathrm{CH} 132$ \\
\hline $\begin{array}{l}\text { Pourouma } \\
\text { guianensis Aubl. }\end{array}$ & $\begin{array}{l}\text { CONST: Houses (Frame house, Trunk; Jihuixaca, Trunk; } \\
\text { Ridgepole - Maracatí, Trunk; Tirante - Cano bëpotó, } \\
\text { Trunk; To tie fence, Bark; To tie house, Bark); Thatch } \\
\text { (To tie roof, Bark); HUMFOOD: Food (Edible, Fruit) }\end{array}$ & Xaquini (Ch); Piraquina (Sp) & DOA 21, SCO 23 \\
\hline $\begin{array}{l}\text { Pourouma minor } \\
\text { Benoist }\end{array}$ & $\begin{array}{l}\text { ANIMFOOD: Fodder (Edible, Fruit); FUEL: Firewood } \\
\text { (Firewood - Caro, Trunk); UTEN\&TOOL: Hunting \& } \\
\text { fishing tools (Bow - Canatí, Trunk); Labour tools } \\
\text { (Sandpaper, Leaf) }\end{array}$ & Xaquini / Yahë (Ch) & DOA 31, MOV 34 \\
\hline $\begin{array}{l}\text { Urera baccifera (L.) } \\
\text { Gaudich ex Wedd. }\end{array}$ & $\begin{array}{l}\text { MEDVET: Blood and Cardio-vascular system } \\
\text { (Heartache, Bark, leaf and root); Infections and } \\
\text { infestations (Malaria and fever); Musculo-skeletal } \\
\text { system (Rheumatism, Leaf); Respiratory system (Cold } \\
\text { and flu, Bark and leaf); Sensory system (Inflammation } \\
\text { of eyes, Bark and leaf) }\end{array}$ & $\begin{array}{l}\text { Nahua Shishahua / Pia nihi (Ch); Pega pega / Pica } \\
\text { pica (Sp) }\end{array}$ & $\begin{array}{l}\text { DOA 49, GOS } 46 \\
\text { JSM } 55, \text { MOV } 56\end{array}$ \\
\hline \multicolumn{4}{|l|}{ Verbenaceae } \\
\hline $\begin{array}{l}\text { Aloysia triphylla } \\
\text { Royle }\end{array}$ & MEDVET: Digestive system (Stomach ache, Leaf) & Toronjil (Sp) & \\
\hline $\begin{array}{l}\text { Lantana cujabensis } \\
\text { Schauer }\end{array}$ & $\begin{array}{l}\text { CONST: Houses (Frame house, Trunk); HUMFOOD: } \\
\text { Food (Edible, Fruit); MEDVET: General Ailments with } \\
\text { Unspecific Symptoms (Headache, Leaf); Infections } \\
\text { and infestations (Malaria and fever, Bark and leaf); } \\
\text { Respiratory system (Cold and flu, Flower and leaf) }\end{array}$ & Bahua Rëxa (Ch); Hierba de loro (Sp) & JSM 19 \\
\hline Lantana trifolia $\mathrm{L}$. & $\begin{array}{l}\text { MEDVET: Infections and infestations (Malaria and } \\
\text { fever, Bark) }\end{array}$ & Urn (Ch) & $\mathrm{CH} 133$ \\
\hline Lantana sp. & $\begin{array}{l}\text { CONST: Houses (Frame house, Trunk); HUMFOOD: } \\
\text { Food (Edible, Fruit); MEDVET: Digestive system }\end{array}$ & Capëtërëbó (Ch); Biribá / Condura (Sp) & ESR 27 \\
\hline
\end{tabular}
Food (Edible, Fruit); MEDVET: Digestive system (Stomach ache, Fruit and trunk); Endocrine system (Liver pain, Seeds); Skin and subcutaneous tissue (Haemorrhage, Root) 
Table 1 Plant species used by the Chácobo (Continued)

\begin{tabular}{|c|c|c|c|}
\hline Petrea sp. 1 & $\begin{array}{l}\text { MEDVET: Digestive system (Diarrhea, Bark and leaf; } \\
\text { Stomach ache, Bark); General Ailments with } \\
\text { Unspecific Symptoms (Vomit, Bark) }\end{array}$ & Ponochí (Ch); Bejuco (Sp) & GOS 20, JSM 42 \\
\hline Petrea sp. 2 & $\begin{array}{l}\text { MEDVET: Digestive system (Diarrhea, Trunk); General } \\
\text { Ailments with Unspecific Symptoms (Vomit, Trunk) }\end{array}$ & Ponochí (Ch) & SCO 22 \\
\hline $\begin{array}{l}\text { Stachytarpheta } \\
\text { cayennensis (Rich.) } \\
\text { Vahl }\end{array}$ & $\begin{array}{l}\text { CULT: Ritual (Crying children); FUEL: Firewood } \\
\text { (Firewood - Caro, Trunk); MEDVET: Infections and } \\
\text { infestations (Malaria and fever, Leaf) }\end{array}$ & Camanó Nihi (Ch); Cola de rata (Sp) & ESR 24, GOS 2 \\
\hline $\begin{array}{l}\text { Vitex cymosa Bert. } \\
\text { ex Spreng. }\end{array}$ & HUMFOOD: Food (Edible, Fruit) & Tarumá (Sp) & $\mathrm{CH} 134$ \\
\hline \multicolumn{4}{|l|}{ Violaceae } \\
\hline $\begin{array}{l}\text { Leonia cymosa } \\
\text { Mart. }\end{array}$ & $\begin{array}{l}\text { FUEL: Firewood (Firewood - Caro, Trunk); HUMFOOD: } \\
\text { Food (Edible, Fruit) }\end{array}$ & Mai Rao (Ch) & $\mathrm{CH} 135$ \\
\hline $\begin{array}{l}\text { Rinorea guianensis } \\
\text { (Melch.) Ducke }\end{array}$ & $\begin{array}{l}\text { FUEL: Firewood (Firewood - Caro, Trunk); MEDVET: } \\
\text { Infections and infestations (Hepatitis, Trunk) }\end{array}$ & Mai Rao (Ch) & $\mathrm{CH} 136$ \\
\hline $\begin{array}{l}\text { Rinoreocarpus ulei } \\
\text { (Melch.) Ducke }\end{array}$ & $\begin{array}{l}\text { CONST: Houses (Muchacho - Ninotí, Trunk); Other } \\
\text { constructions (Floor - Machimbre, Trunk); CULT: } \\
\text { Recreational (Toys, Seeds); FUEL: Firewood (Firewood } \\
\text { - Caro, Trunk); MEDVET: Infections and infestations } \\
\text { (Malaria and fever, Bark); Reproductive system and } \\
\text { sex health (Abortive, Bark); Skin and subcutaneous } \\
\text { tissue (Acne); UTEN\&TOOL: Domestic utensils } \\
\text { (Furniture, Trunk; Tacú - Arusa timatí, Trunk) }\end{array}$ & $\begin{array}{l}\text { Jihui Joxo / Shihuë / Tapa ristí / Xoquë xëquërë } \\
\text { (Ch); Blanquillo / Cafesillo / Toco (Sp) }\end{array}$ & MOV 39, SCO 24 \\
\hline Indet. sp. 1 & FUEL: Firewood (Firewood - Caro, Trunk) & Bëpasti (Ch) & $\mathrm{CH} 136$ \\
\hline \multicolumn{4}{|l|}{ Vitaceae } \\
\hline Cissus erosa Rich. & $\begin{array}{l}\text { CONST: Houses (Frame house, Trunk; Hedge - Panë, } \\
\text { Trunk; Jihuixaca, Trunk; Roof beam - Canoxoco, Trunk; } \\
\text { Tirante - Cano bëpotó, Trunk; To tie house, Bark); } \\
\text { FUEL: Firewood (Firewood - Caro, Trunk); HUMFOOD: } \\
\text { Food (Edible, Fruit); MEDVET: Digestive system } \\
\text { (Diarrhea, Seeds) }\end{array}$ & Nai Nishi (Ch); Sirari (Sp) & $\mathrm{CH} 137$ \\
\hline Cissus sicyoides L. & $\begin{array}{l}\text { HUMFOOD: Food (Edible, Fruit); MEDVET: Snakebites } \\
\text { and Ray stings (Sankebites) }\end{array}$ & Carabó Coatí (Ch) & $\mathrm{CH} 138$ \\
\hline \multicolumn{4}{|l|}{ Vochysiaceae } \\
\hline $\begin{array}{l}\text { Qualea acuminata } \\
\text { Spruce ex Warm. }\end{array}$ & CULT: Personal adornment (Ornament - Maxëití, Fruit) & Omaca Bëro (Ch) & $\mathrm{CH} 139$ \\
\hline $\begin{array}{l}\text { Qualea grandiflora } \\
\text { Mart. }\end{array}$ & $\begin{array}{l}\text { CONST: Houses (Frame house, Trunk; Jihuixaca, Trunk; } \\
\text { To tie house, Bark); HUMFOOD: Food (Edible, Seeds); } \\
\text { MEDVET: Skin and subcutaneous tissue (Acne, Seeds) }\end{array}$ & Almendro (Sp) & RBU 17849 \\
\hline $\begin{array}{l}\text { Qualea paraensis } \\
\text { Ducke }\end{array}$ & $\begin{array}{l}\text { CONST: Houses (Hedge - Panë, Trunk; Muchacho - } \\
\text { Ninotí, Trunk; Pasa ratón - Xoya jabatí, Trunk; } \\
\text { Ridgepole - Maracatí, Trunk; Roof beam - Canoxoco, } \\
\text { Trunk; Tie - Xahui, Bark; Tirante - Cano bëpotó, Trunk; } \\
\text { Tirante largo - Cano pixquëna, Trunk); FUEL: Firewood } \\
\text { (Firewood - Caro, Trunk); HUMFOOD: Food (Edible, } \\
\text { Fruit) }\end{array}$ & $\begin{array}{l}\text { Jihui Sama / Jihui Xoco (Ch); Chocolate / } \\
\text { Chocolatillo (Sp) }\end{array}$ & $\mathrm{CH} 140$ \\
\hline Qualea sp. & $\begin{array}{l}\text { MEDVET: Skin and subcutaneous tissue (Caracha, Bark; } \\
\text { Caracha, Root; Puchichi, Bark; Skin infection, Bark) }\end{array}$ & Mëtëquë (Ch) & $\mathrm{CH} 141$ \\
\hline $\begin{array}{l}\text { Vochysia vismiifolia } \\
\text { Spruce ex Warm. }\end{array}$ & $\begin{array}{l}\text { CONST: Houses (Muchacho - Ninotí, Trunk; Pasa ratón } \\
\text { - Xoya jabatí, Trunk; Roof beam - Canoxoco, Trunk; } \\
\text { Tirante - Cano bëpotó, Trunk; Tirante largo - Cano } \\
\text { pixquëna, Trunk); CULT: Other cultural (Crafts, Trunk); } \\
\text { HUMFOOD: Food (Edible, Fruit); MEDVET: Digestive } \\
\text { system (Stomach ache, Bark) }\end{array}$ & Canú / Jihui Coshi / Cano (Ch); Cedro (Sp) & $\mathrm{CH} 142$ \\
\hline
\end{tabular}


Table 1 Plant species used by the Chácobo (Continued)

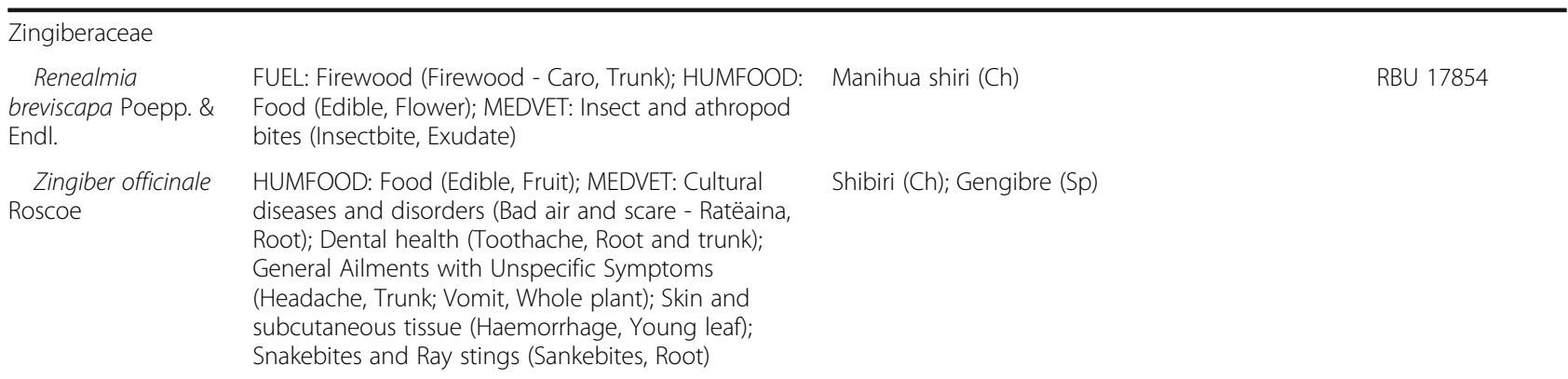

and linguistic practices [3, 4]. In 1964, Prost managed to buy a territory in the north of the Chácobo's ancestral lands, forming the community of Alto Ivón, and most of the remaining population moved there. In 1965, the Bolivian government finally assigned 43,000 ha of land to the Chácobo, although this area was less than $10 \%$ of their original territory. The influence of the SIL caused profound cultural change among the Chácobo, including the reported abandonment of traditional costume and dances in 1969 [4].

The official indigenous organization of the Chácobo (Central Indígena de la Región Amazónica de Bolivia (CIRABO) estimates a current population of the Chácobo community of about 1000 people (350+ adults), with Alto Ivón as the largest settlement. The current territory of the tribe according to CIRABO encompasses 450,000 ha, and is roughly equivalent to the original extent of the tribe's ancestral lands (Fig. 1). The elevation of the territory is about $200 \mathrm{~m}$, and much of the vegetation can be classified as humid tropical Amazon rainforest. However, the territory encompasses also large tracts of periodically inundated savannas, dominated by Mauritiella armata, and large, drier, savanna areas with forest islands. The average annual temperature is $26.8^{\circ} \mathrm{C}$, with an average annual rainfall of $1560 \mathrm{~mm}$. A distinct dry season lasts from June to November [7]. Today the Chácobo are governed by two indigenous organizations: The Capitanía Mayor Chácobo, closely linked to the evangelists, and the Chácobo- Pacahuara Association, recognized by the Central Indígena de la Región Amazónica de Bolivia (CIRABO), and supported by the Central de Pueblos Indigenas del Beni (CPIB) and the Confederacion de Pueblos Indigenas de Bolivia (CIDOB).

\section{Ethnobotanical and botanical collection}

Our project explored the current traditional knowledge (TK) on plant use of the Chácobo and Pacahuara in Beni, Bolivia and had three goals: 1) to discover and document current traditional plant knowledge through interviews and surveys, 2) to inventory the current flora of the region, and 3) to repatriate the acquired knowledge as well as previous data to the community.
After obtaining consent from CIRABO, and before starting fieldwork, we conducted a community meeting in May 2013, involving representatives of all 27 villages in the Chácobo Territory, in order to obtain prior informed consent from all communities. This session included the repatriation of the results of previous studies [45-47]. In addition, during the project all available material on Chácobo plant use was translated to Spanish and repatriated [48]. The Chácobo community itself choose 12 local counterparts to be trained as ethnobotanical interviewers and plant collectors. In September 2013 we conducted a two-week workshop on ethnobiological methods and plant collection, training the 12 selected counterparts, 10 of which finally acted as interveiwers. Training was conducted directly in the field in the central village of Alto Ivón, and involved theoretical exercises (overview on methodology of interviews, collection and herbarium techniques), as well as extensive practical exercises (structuring and testing of questionnaires, test interviews among the participants, field interviews with local community members, plant collection in the field, preparation of herbarium specimens, plant and artifact collection in the local community, data-basing, and initial data analysis).

From November 2013 to May 2015, Chácobo interviewers collected ethnobotanical information from 301 Chácobo participants (150 women, 151 men, representing almost the entire adult Chácobo population), and over 1500 plant samples were collected. Prior to starting the interviews, every interviewer obtained prior oral informed consent from each participant. Chácobo participants were divided into five age classes (18-30 years old: 58 men, 52 women; $31-40$ years old: 31 men, 36 women; 41-50 years old: 35 men, 36 women; $51-60$ years old: 15 men, 7 women; and >60 years old: 12 men, 19 women). Because the study attempted to interview the whole adult Chácobo population, there was originally no emphasis on achieving a balanced age or gender distribution. All interviews were conducted at the homes of the participants by asking participants to freelist their plant knowledge following [49]. All plant uses were categorized following [49]. All interviews were preferably 
conducted in Chácobo. In a few cases where participants were not fully fluent in Chácobo, interviewers used Spanish as common language. The plant material was collected under permission from the Ministry of Environment and Water of the Plurinational State of Bolivia, and was identified and deposited at the National Herbarium of Bolivia (LPB) under the collection numbers of the Chácobo collectors. Nomenclature follows www.TROPICOS.org. Use descriptions were coded after the fact into subcategories and, for some analyses, into six major categories: fodder, fuel, medical, cultural, construction, tool, and food.

All work was carried out following the International Society for Ethnobiology Code of Ethics [50], and under the framework provided by the Nagoya Protocol on Access to Genetic Resources and Fair and equitable sharing of benefits arising from their use of the Convention on Biological Diversity, the Chácobo community retains the copyright of the traditional knowledge of all informants. Any commercial use of any of the information requires prior consensus with informants and communities, and an agreement on the distribution of benefits.

\section{Data analysis}

The total number of unique species reported and unique uses reported for each use category were compared across communities, genders, and age groups (16-30, 31-40, 41-50, 51-60, and 61-82) for 292 informants (dropping for this analysis 8 informants for whom age was not indicated).

To gain a more nuanced look at how these qualities affected not only the number of reports but which species or uses were reported, we ordered informants using non-metric multi-dimensional scaling on distance matrices for plants and uses, and tested how well vectors (age) and factors (gender, ethnicity, community) fit the location of informants in the ordination, using the $R$ package vegan [51]. We used similar methods with plant family fit onto an ordination from distance matrices of plant-use combinations to test whether plant family explains the uses to which plants are put.

We used Indicator Value [52], as implemented in the $\mathrm{R}$ package labdsv [53] to combine occurrence frequency and mean abundance of species and uses to elucidate species and uses that had higher fidelity to and/or relative abundance in certain age groups or genders. For this analysis, the $P$ value is the probability of finding an equally high indicator value in random permutations. Species with significantly high indicator values had higher fidelity and relative abundance in certain age groups / genders (were 'indicators'). We

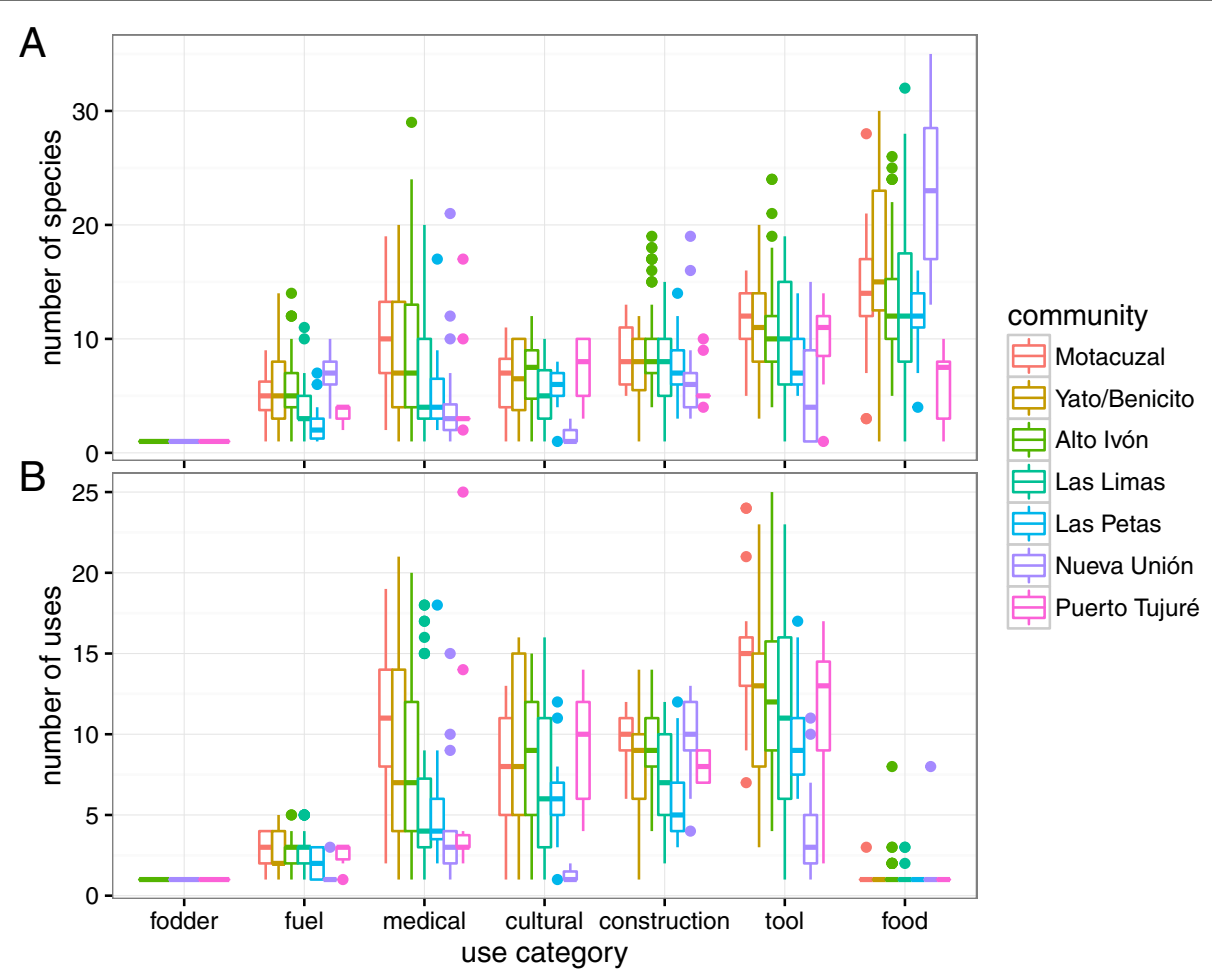

Fig. 2 Number of species (a) and uses (b) reported per interview reported in each use category for each community ( $\mathrm{N}$ : Motacuzal = 25, Yato Benicito $=51$, Alto Ivón $=83$, Las Limas $=45$, Las Petas $=15$, Nueva Unión $=20$, Puerto Tujuré $=11.40$ interviews without a community indicated are not shown) 


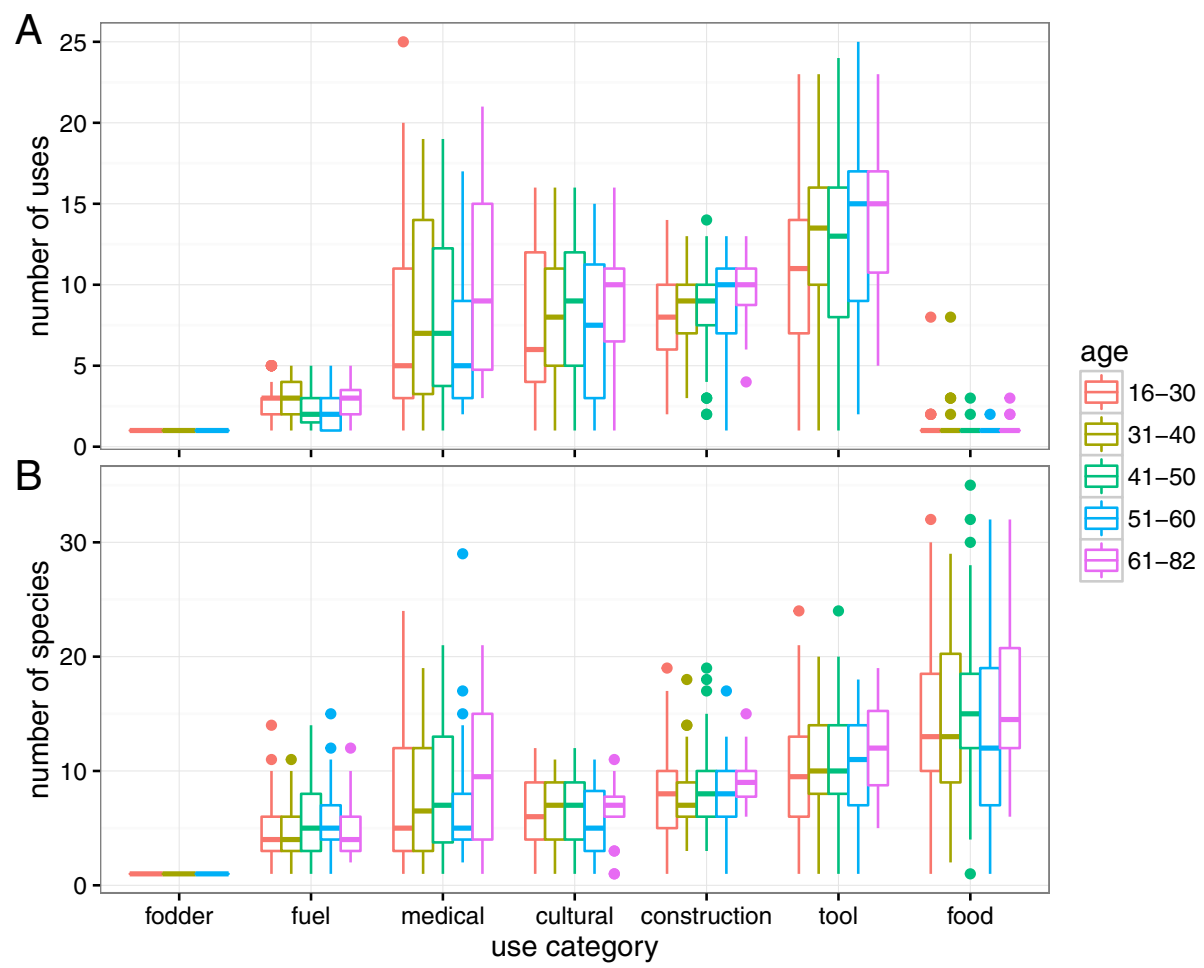

Fig. 3 Number of uses (a) and species (b) reported per interview reported in each use category for each age group (N: 16-30 =110, 31-40 =65, $41-50=68,51-60=25,61-81=24)$

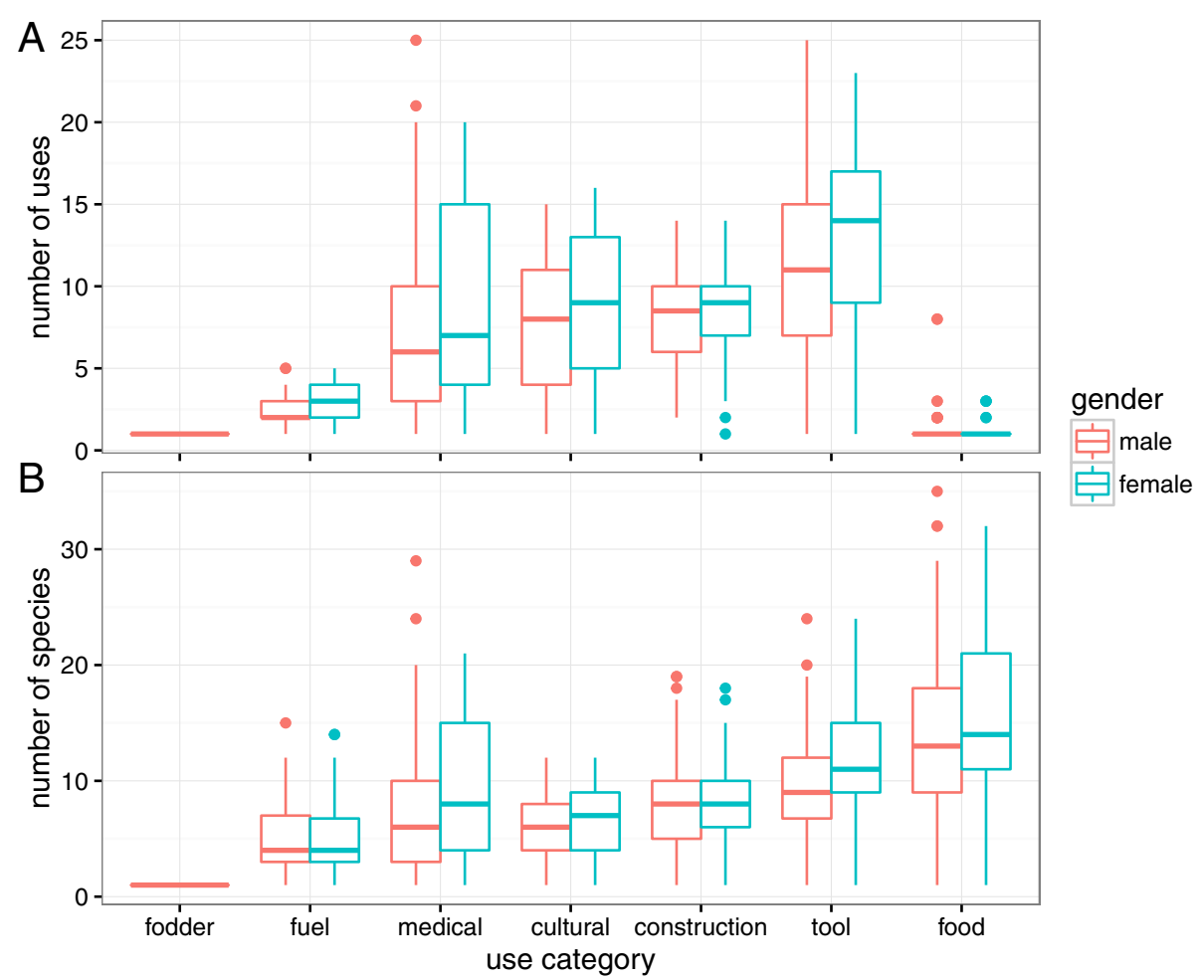

Fig. 4 Number of uses (a) and species (b) reported per interview in each use category for men $(N=154)$ and women $(N=138)$ 
further compared age and gender groups by informant consensus factor (ICF) for each use category, calculated as the number of use reports minus the number of taxa over the number of use reports minus one: (Nur - Nt)/(Nur - 1). We also measured consensus on species uses by quantifying what proportion of each species' mentions fall within a specific use category.

Plant species and plant family importance was ranked by four metrics: Community and Informant Cultural Importance (CIcom/CIinf) - the sum within species across all plant-uses of the number of informants (for Clinf) or communities (for CIcom) reporting a plant-use over the number of informants/ communities reporting the plant; Diversity of Uses $(\mathrm{Du})$ - the Shannon Index of uses [51]; and Use Value (UV), the number of reports of a species over total number of informants asked in a region [54].

To test whether greater knowledge of Chácobo language was associated with a more similar set of knowledge and / or a larger knowledge set of plants and uses, we used the ordination based on uses to examine whether interviewees who reported more Chácobo names tended to report a more similar set of uses, and used linear regression to test whether the number of Chácobo names reported was significantly greater for those who reported more species or more uses.

\section{Results}

The availability of previous field data gives the unique opportunity to study the long-term change in knowledge of an indigenous group in the age of globalization. Our study found 331 useful plant species in 241genera of 95 plant families, with leaves, roots and bark being the most commonly used plant parts (Table 1).

The larger Chácobo communities showed very similar patterns in the number of species used, with differences within communities usually greater than between, although Nueva Unión stood out in reporting more food species (Fig 2a). Likewise, all communities were similar in plant-uses (use descriptions for a species within each use category), although in this case Nueva Unión reported fewer use descriptions within the Utensils and tools and Cultural categories, while Motacuzal and Alto Ivón reported more medical uses (Fig. 2b). Within these categories, number of species and uses was fairly consistent across age groups, though we observed a trend for some categories of more species and uses known with

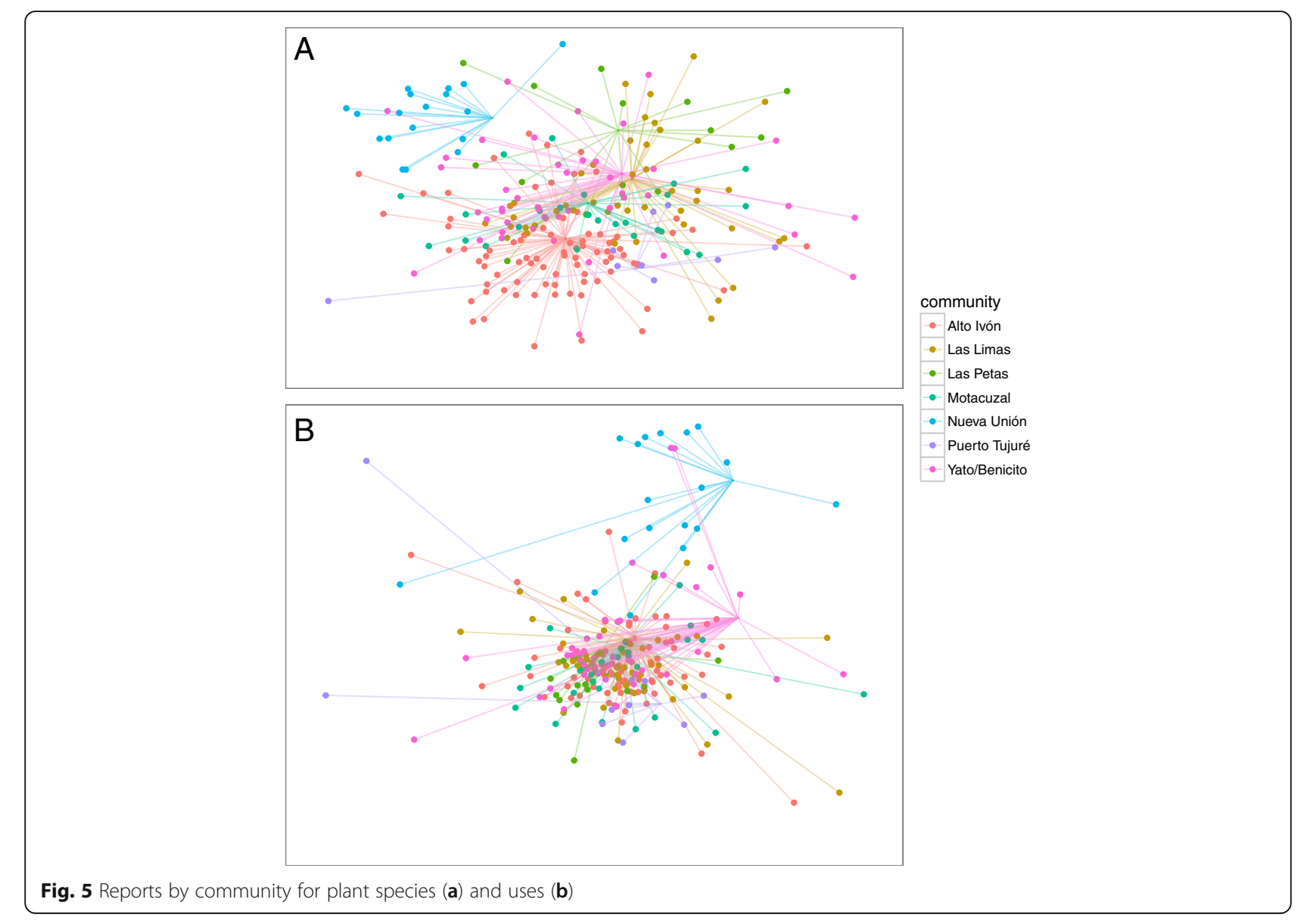


Table 2 Who uses what, and how?

\begin{tabular}{lll}
\hline & $r$-squared & $p$-value \\
\hline A. In plant-space (plant species mentioned) ordination & \\
age & -1.00 & 0.256 \\
gender & 0.00 & 0.878 \\
ethnicity & 0.04 & $0.015^{*}$ \\
community & 0.30 & $0.001^{* * *}$ \\
B. In use-space (uses mentioned for specific species) ordination \\
age & -0.96 & 0.638 \\
gender & 0.01 & 0.174 \\
ethnicity & 0.04 & 0.092 \\
community & 0.27 & $0.001^{* * *}$ \\
\hline
\end{tabular}

* = significant

$* * *$ highly significant

increasing age. The age group between 51 and 60 years (i.e. the first age group growing up under missionary rule), showed a slightly lower knowledge, especially evident in the medical and cultural categories but also in food plants (Fig. 3). These metrics are also quite similar across gender, although across most categories the average number of species and uses reported by women was slightly higher (Fig. 4).

\section{Who uses what and how?}

Despite the similarities among communities in total species and uses reported, we found that informant community significantly influenced both which plants and which uses individual informants reported (Table 2 a\&b). In contrast, and in accord with the results above, age and gender did not significantly influence either. Ethnicity of the participants influenced which plant species they used, but did not explain what they were used for. Given the very low $r^{2}$ values, it is clear that much variety in uses was not explained by any demographic and environmental variables explored (Table $2 \mathrm{a} \& \mathrm{~b}$ ). In the ordination, we can see this effect more clearly: although there was much overlap, the communities clearly structure which plants were reported. This difference was however much driven by the reports Nueva Unión (Fig. 5).

While age did not in itself explain the ordination well, we did find certain plants to be associated with age categories. In this we found no indicator plants or uses among the first three age groups (16-30, 31-40, 41-50), which suggests to some extent that plants and uses reported by these groups are less distinct than that of the second two age groups $(51-60,>60)$. The 51-60 age group was associated with by Styrax sp., Iryanthera juruensis, Xylopia ligustrifolia, Hirtella pilosissima, Inga sp. 1, and Piper nigrispicum, while the $>60$ group was indicated by Gustavia hexapetala, Astrocaryum aculeatum, Phenakospermum guianensis,
Table 3 Indicator values of species by Gender

\begin{tabular}{|c|c|c|c|}
\hline species & gender & indicator value & probability \\
\hline Hirtella pilosissima & $\mathrm{m}$ & 0.11 & 0.01 \\
\hline Schefflera morototoni & $\mathrm{m}$ & 0.09 & 0.02 \\
\hline Xylopia sp. & $\mathrm{m}$ & 0.07 & 0.01 \\
\hline Eschweilera albiflora & $\mathrm{m}$ & 0.04 & 0.05 \\
\hline Attalea phalerata & $f$ & 0.50 & 0.01 \\
\hline Gossypium barbadense & $f$ & 0.49 & 0.01 \\
\hline Phenakospermum guianensis & f & 0.47 & 0.03 \\
\hline Licania octandra subsp. pallida & $f$ & 0.45 & 0.01 \\
\hline Apeiba tibourbou & $f$ & 0.44 & 0.01 \\
\hline Capirona decorticans & $f$ & 0.43 & 0.00 \\
\hline Cecropia ficifolia & $f$ & 0.41 & 0.00 \\
\hline Musa $\times$ paradisiaca & $f$ & 0.39 & 0.04 \\
\hline Helicostylis tomentosa & $f$ & 0.38 & 0.01 \\
\hline Omphalea diandra & $f$ & 0.35 & 0.01 \\
\hline Uncaria guianensis & $f$ & 0.35 & 0.04 \\
\hline Bixa orellana & f & 0.35 & 0.00 \\
\hline Manihot esculenta & $f$ & 0.31 & 0.03 \\
\hline Ficus sp. & $f$ & 0.30 & 0.04 \\
\hline Tabebuia sp. & $f$ & 0.30 & 0.01 \\
\hline Oryza sativa & $f$ & 0.29 & 0.04 \\
\hline Brosimum utile subsp. ovatifolium & $f$ & 0.29 & 0.03 \\
\hline Amburana cearensis & $f$ & 0.28 & 0.03 \\
\hline Pouteria ramiflora & f & 0.28 & 0.00 \\
\hline Dioscorea latifolia & $f$ & 0.23 & 0.02 \\
\hline Piper piscatorum & f & 0.22 & 0.00 \\
\hline Xanthosoma sagittifolium & $f$ & 0.18 & 0.00 \\
\hline Nicotiana rustica & $f$ & 0.18 & 0.00 \\
\hline Woytkowskia spermatochorda & $f$ & 0.18 & 0.00 \\
\hline Styrax sp. & $f$ & 0.18 & 0.00 \\
\hline Xanthosoma striolatum & $f$ & 0.17 & 0.00 \\
\hline Persea americana & $f$ & 0.17 & 0.02 \\
\hline Bryophyllum sp. & f & 0.15 & 0.00 \\
\hline Chrysophyllum sparsiflorum & $f$ & 0.14 & 0.00 \\
\hline Erythroxylum coca & f & 0.13 & 0.00 \\
\hline Micropholis guyanensis & $f$ & 0.09 & 0.04 \\
\hline Myrcia regnelliana & $f$ & 0.08 & 0.00 \\
\hline Qualea paraensis & $f$ & 0.06 & 0.03 \\
\hline
\end{tabular}

Attalea phalerata, Apuleia leiocarpa, Bixa orellana, Hancornia speciosa, Zingiber officinale, and Eriotheca sp. Likewise, the use subcategory Firewood was associated with the 51-60 age group while the medicinal use subcategories: Skin and subcutaneous tissue, Sensory system, Respiratory system and Musculo-skeletal system all were associated with the $>60$ age group.

Likewise, although gender did not fit to the overall ordinations, there was a large number of plants 
Table 4 Indicator uses and gender association

\begin{tabular}{llll}
\hline Use subcategory & gender & indicator value & probability \\
\hline Domestic utensils & $\mathrm{f}$ & 0.53 & 0.01 \\
Personal adornment & $\mathrm{f}$ & 0.51 & 0.00 \\
Other fuel & $\mathrm{f}$ & 0.44 & 0.02 \\
Clothes \& accessories & $\mathrm{f}$ & 0.43 & 0.01 \\
Skin and subcutaneous tissue & $\mathrm{f}$ & 0.42 & 0.00 \\
Snakebites and Ray stings & $\mathrm{f}$ & 0.28 & 0.01 \\
Dental health & $\mathrm{f}$ & 0.27 & 0.02 \\
Cultural diseases and disorders & $\mathrm{f}$ & 0.25 & 0.00 \\
Insect and arthropod bites & $\mathrm{f}$ & 0.24 & 0.02 \\
Endocrine system & $\mathrm{f}$ & 0.24 & 0.04
\end{tabular}

associated with female, and a much smaller one with male respondents (Table 3 ).

Interestingly, all indicator uses were exclusively associated with women (Table 4).

\section{Informant consensus factors (ICF)}

Looking at specific use categories we found broadly similar trends across age categories and genders: tool, construction and food uses usually had the most use reports. We found a lower number of medicinal use reports, although the same number of respondents reported medicinal uses. Food uses consistently had less ICF than tool and construction uses, and medicinal uses even less. Cultural uses, while often reported by fewer informants and with fewer uses, show disproportionately high ICF (Table 5).

Plant relative importance metrics did show a different picture underlining the problems of using diversity indices. The Cultural Importance Index yielded wildly different species sets for Community and Individuals, and both Use Value Index and Use-diversity Index again yielded different sets as species as most important (Table 6).

Table 5 Who uses what, and how: informant consensus factor

\begin{tabular}{lllllll}
\hline age & gender & $\begin{array}{l}\text { Nur } \\
\text { use reports }\end{array}$ & informants & species & $\begin{array}{l}\text { mean ICF } \\
\text { across use } \\
\text { categories }\end{array}$ & $\begin{array}{l}\text { ICF sd across } \\
\text { categories }\end{array}$ \\
\hline $16-30$ & male & 3517 & 55 & 213 & 0.90 & 0.06 \\
$16-30$ & female & 3571 & 44 & 188 & 0.92 & 0.04 \\
$31-40$ & male & 1834 & 29 & 181 & 0.83 & 0.07 \\
$31-40$ & female & 2529 & 31 & 176 & 0.89 & 0.06 \\
$41-50$ & male & 2314 & 32 & 192 & 0.86 & 0.06 \\
$41-50$ & female & 2317 & 31 & 180 & 0.88 & 0.06 \\
$51-60$ & male & 1146 & 15 & 167 & 0.77 & 0.10 \\
$51-60$ & female & 562 & 8 & 123 & 0.68 & 0.12 \\
$61-82$ & male & 747 & 10 & 142 & 0.72 & 0.13 \\
$61-82$ & female & 1150 & 14 & 147 & 0.80 & 0.09 \\
\hline
\end{tabular}

Table 6 Plant importance metrics

\begin{tabular}{|c|c|c|c|c|}
\hline Top species by Clcom & Clcom & UV & Clinf & Du \\
\hline Euterpe precatoria & 4.78 & 1.37 & 1.89 & 1.97 \\
\hline Gossypium barbadense & 3.86 & 2.54 & 1.98 & 1.26 \\
\hline Attalea phalerata & 3.82 & 2.64 & 2.14 & 1.48 \\
\hline Xylopia peruviana & 3.77 & 2.97 & 2.12 & 1.23 \\
\hline Phenakospermum guianensis & 3.76 & 1.77 & 1.76 & 1.60 \\
\hline Top species by UV & UV & Clcom & Clinf & Du \\
\hline Vismia macrophylla & 4.20 & 2.73 & 1.55 & 0.59 \\
\hline Xylopia peruviana & 2.97 & 3.77 & 2.12 & 1.23 \\
\hline Attalea phalerata & 2.64 & 3.82 & 2.14 & 1.48 \\
\hline Gossypium barbadense & 2.54 & 3.86 & 1.98 & 1.26 \\
\hline Bactris gasipaes & 2.50 & 1.91 & 1.24 & 0.39 \\
\hline Astrocaryum aculeatum & 2.28 & 2.96 & 1.44 & 1.02 \\
\hline Attalea maripa & 1.96 & 3.33 & 1.87 & 1.46 \\
\hline Gynerium sagittatum & 1.95 & 2.41 & 1.57 & 0.87 \\
\hline Phenakospermum guianensis & 1.77 & 3.76 & 1.76 & 1.60 \\
\hline Licania octandra subsp. pallida & 1.73 & 1.81 & 1.25 & 0.45 \\
\hline Top species by Du & $\mathrm{Du}$ & Clcom & Clinf & UV \\
\hline Cedrela fissilis & 2.10 & 3.17 & 1.24 & 0.16 \\
\hline Citrus aurantiifolia & 2.05 & 2.40 & 1.06 & 0.13 \\
\hline Croton sp. 1 & 2.02 & 1.57 & 1.10 & 0.04 \\
\hline Jatropha gossypiifolia & 2.00 & 2.17 & 1.64 & 0.08 \\
\hline Euterpe precatoria & 1.97 & 4.78 & 1.89 & 1.37 \\
\hline Hymenaea courbaril & 1.82 & 3.00 & 1.17 & 0.32 \\
\hline Top species by Clinf & Clinf & Clcom & UV & Du \\
\hline Piper peltatum & 3.00 & 3.00 & 0.01 & 1.10 \\
\hline Attalea phalerata & 2.14 & 3.82 & 2.64 & 1.48 \\
\hline Xylopia peruviana & 2.12 & 3.77 & 2.97 & 1.23 \\
\hline
\end{tabular}

Most important species in each index in bold

Because the Cultural Importance Index tends to prioritize species with few informants, we highlighted the species that had both high index values in general, and also a large number of reports to elucidate species that were of high importance in all indices. As result, Vismia macrophylla, Xylopia peruviana, Attalea phalerata, Gossypium barbadense, Attalea maripa and Phenakospermum guianensis were elucidated as the most important species in the daily life of the Chácobo community (Fig. 6). Overall, however, informant consensus was very high in across all age groups and across all use categories (Fig. 7). Arecaceae, Fabaceae, Malvaceae and Rubiaceae were found to be the most important plant families used across most indices, although Moraceae did yield a higher ranking in Use Value (Table 7).

Results also indicated that qualities of plants did to a certain extent explain which uses they were put to. A large number of plant families had specifically Medicinal uses, while other sets of plant families were specifically 

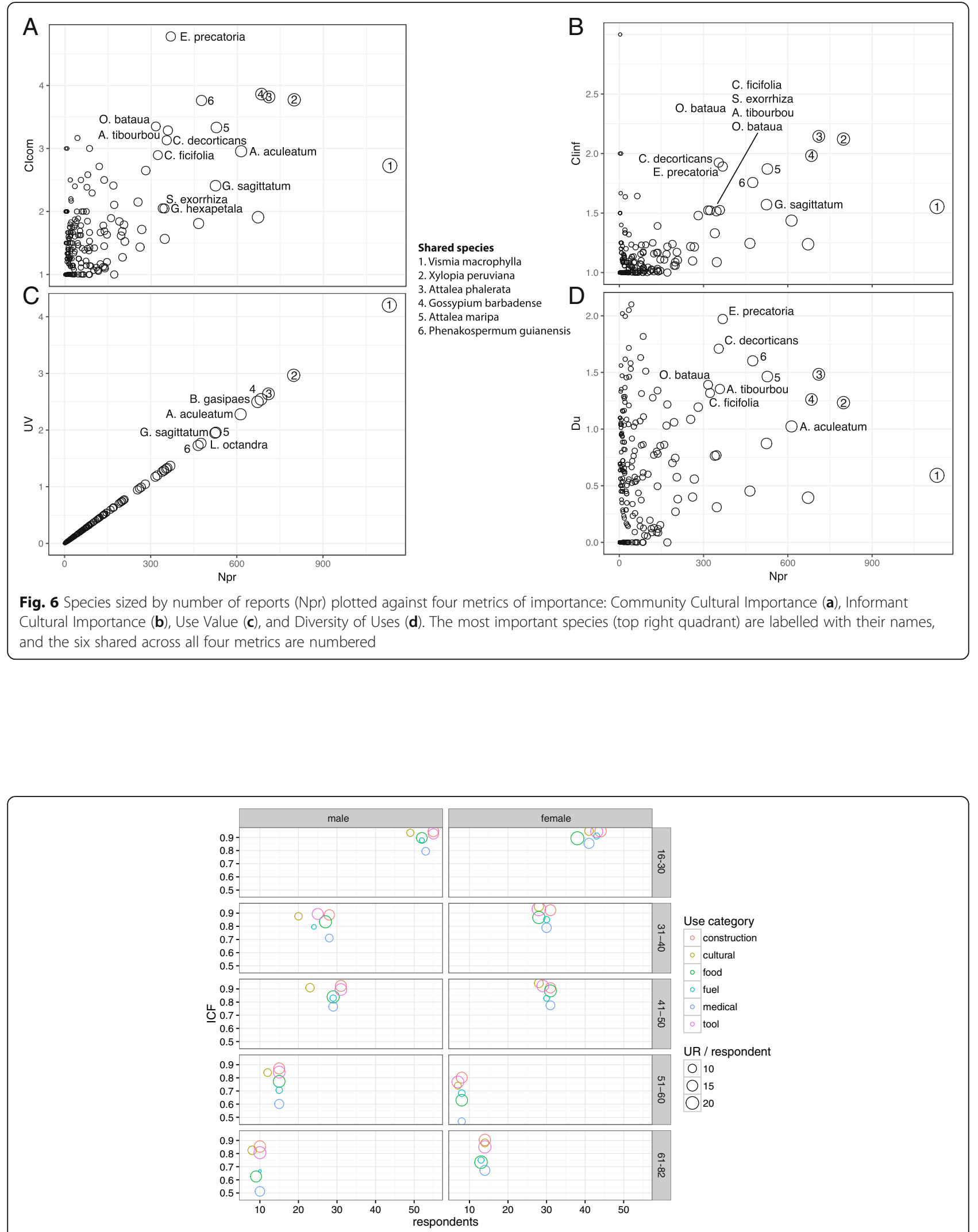

Fig. 7 Informant consensus factor (ICF) for each use category, among male and female respondants of each age group. Points are sized by the number of use reports (UR) per respondent 
Table 7 What is used? (plant relative importance metrics by family)

\begin{tabular}{|c|c|c|c|c|}
\hline Family & Clinf & Clcom & UV & $\mathrm{Du}$ \\
\hline Arecaceae & 5.1 & 8.7 & 14.5 & 1.9 \\
\hline Fabaceae & 3.4 & 6.9 & 5.0 & 2.0 \\
\hline Malvaceae & 3.1 & 6.9 & 5.0 & 1.9 \\
\hline Rubiaceae & 3.0 & 6.4 & 2.9 & 2.3 \\
\hline Poaceae & 2.5 & 5.5 & 3.9 & 1.6 \\
\hline Moraceae & 2.5 & 4.8 & 5.1 & 1.3 \\
\hline Annonaceae & 2.3 & 4.1 & 3.5 & 1.4 \\
\hline Chrysobalanaceae & 1.9 & 3.4 & 2.6 & 1.2 \\
\hline Euphorbiaceae & 1.9 & 4.4 & 2.0 & 1.9 \\
\hline Strelitziaceae & 1.8 & 3.8 & 1.8 & 1.6 \\
\hline Apocynaceae & 1.7 & 3.4 & 1.2 & 1.9 \\
\hline Talinaceae & 1.7 & 2.0 & 0.0 & 1.3 \\
\hline Lecythidaceae & 1.6 & 3.8 & 1.6 & 1.3 \\
\hline Urticaceae & 1.6 & 3.2 & 1.2 & 1.4 \\
\hline Hypericaceae & 1.6 & 2.7 & 4.2 & 0.6 \\
\hline Bignoniaceae & 1.5 & 3.4 & 1.2 & 1.8 \\
\hline Caryocaraceae & 1.5 & 1.5 & 0.0 & 1.1 \\
\hline Sapotaceae & 1.4 & 2.2 & 1.0 & 1.0 \\
\hline Simaroubaceae & 1.3 & 2.0 & 0.2 & 1.3 \\
\hline Rutaceae & 1.3 & 3.2 & 1.1 & 1.7 \\
\hline Anacardiaceae & 1.3 & 3.1 & 0.8 & 1.3 \\
\hline Meliaceae & 1.2 & 3.2 & 0.2 & 2.1 \\
\hline Costaceae & 1.2 & 2.3 & 0.3 & 1.5 \\
\hline Lamiaceae & 1.2 & 2.6 & 0.3 & 1.3 \\
\hline Aristolochiaceae & 1.2 & 2.0 & 0.2 & 1.1 \\
\hline Verbenaceae & 1.2 & 2.3 & 0.4 & 1.6 \\
\hline Piperaceae & 1.2 & 2.1 & 0.4 & 1.0 \\
\hline Burseraceae & 1.2 & 1.4 & 0.1 & 0.5 \\
\hline Melastomataceae & 1.2 & 1.7 & 0.6 & 0.7 \\
\hline Myrtaceae & 1.2 & 1.7 & 0.2 & 1.1 \\
\hline Solanaceae & 1.1 & 2.4 & 0.3 & 1.4 \\
\hline Sapindaceae & 1.1 & 1.8 & 0.5 & 0.7 \\
\hline Flacourtiaceae & 1.1 & 1.3 & 0.1 & 0.9 \\
\hline Cyperaceae & 1.1 & 1.9 & 0.2 & 0.9 \\
\hline Crassulaceae & 1.1 & 1.6 & 0.2 & 0.5 \\
\hline Zingiberaceae & 1.1 & 1.6 & 0.1 & 1.3 \\
\hline Malpighiaceae & 1.1 & 1.3 & 0.0 & 1.2 \\
\hline Amaryllidaceae & 1.1 & 1.8 & 0.0 & 1.9 \\
\hline
\end{tabular}

Most important species in each index in bold

used for Food, Utensils and tools, and Construction. Not surprisingly, data also revealed that plant families with high importance in all indices calculated (Arecaceae, Fabaceae, Malvaceae and Rubiaceae) had uses in all categories (Fig. 8).

Different use categories also had different levels of fidelity in the species that were reported for them. For instance, relatively few mentions in the construction and tool categories were of species that are uniquely associated with those categories. In contrast, a much greater proportion of mentions for medical uses were of species that were only used for medical uses. This pattern was also true of food plants (Fig. 9).

\section{Does language influence use knowledge?}

Interviewees who reported more Chácobo names did indeed tend to report more similar sets of knowledge, and knew more species and uses (Fig. 10). In addition, the number of plants or number of uses reported strongly increased with the number of Chácobo names participants knew (Fig. 11). Although in some degree this was a feature of the study (there was no way to informants to report more names than species), it was clear that very few of those participants with great knowledge of species or uses failed to report a large number of Chácobo names.

\section{Discussion}

While other studies found indecisive patterns of the influence of age, or accessibility to markets on traditional knowledge (negative [17, 23, 44, 55]; positive [25, 56, 57]), our study did not reveal any pattern that would link differences in plant-use knowledge to age or accessibility of a location, but simply to specific location and associated flora in each of the communities. In most communities the contact with nature still remains vital to the acquisition of knowledge $[58,59]$, and the facility to observe and identify the useful plants clearly adds to this.

The observation that local and indigenous languages often package rich traditional ecological knowledge has led to the question in many studies of whether indigenous language abilities influence plant knowledge, i.e. if native language speakers have a higher knowledge than participants only speaking a mainstream language $[44,60]$. In our study, the link between language proficiency and other metrics of traditional knowledge (plants and uses reported) does support at least the correlation of these variables, and suggest the possibility of simultaneous language and knowledge retention (or erosion).

The general trend found in relation to the difference in intergenerational knowledge suggests that any patterns are most likely a result of both knowledge transmission, as well as in situ learning, and be related to the time during which people acquire and use knowledge, with the older informants taking more responsibility in their households, who have a need to learn and apply their knowledge $[27,54,61]$. The knowledge of older people might not have been affected by the need to find new subsistence activities, and was thus 


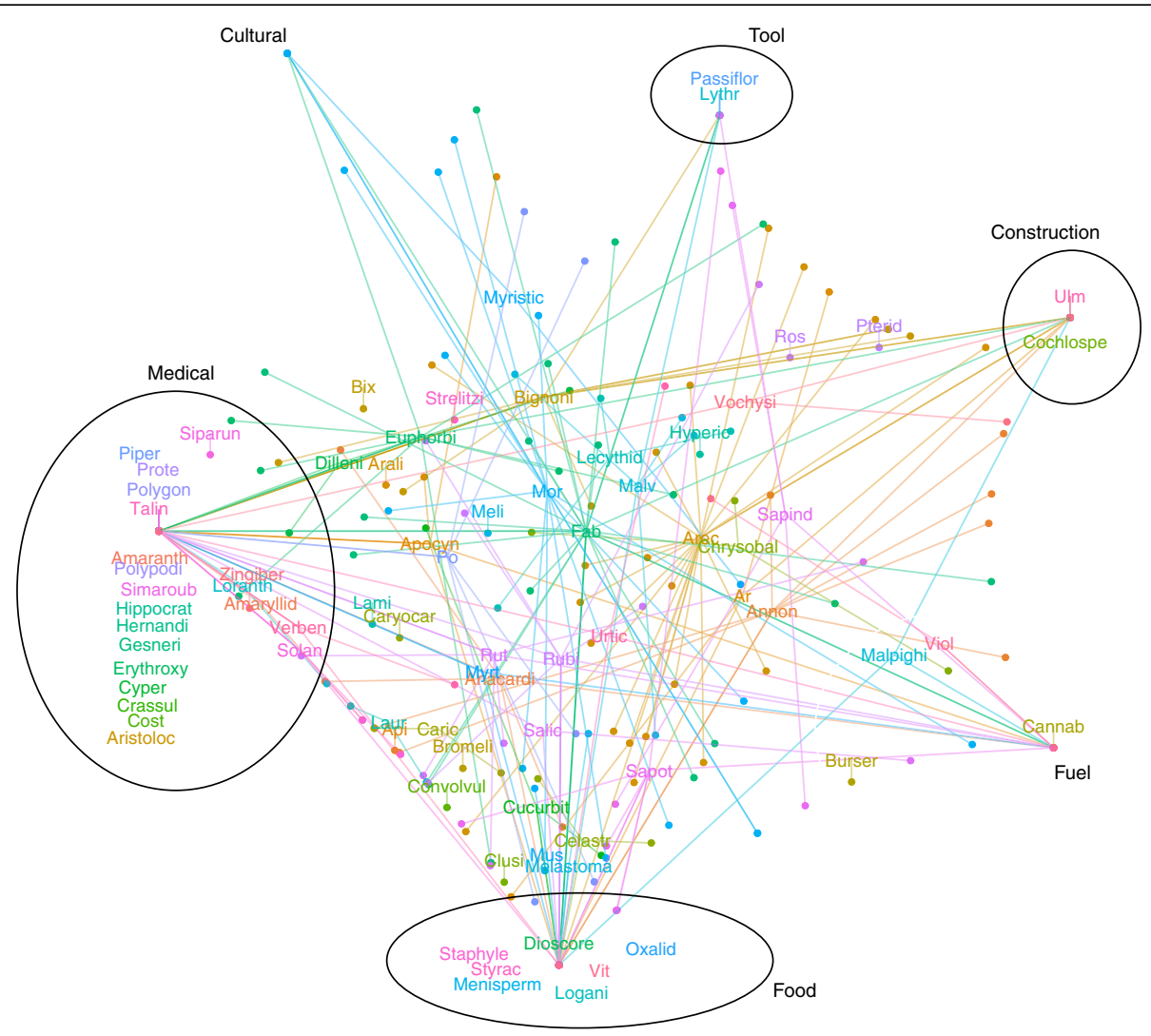

Fig. 8 Assemblage of by plant family $(r-$ squared $=0.39, p=0.001)$

preserved without external influence [62]. The fact that the only generation that did show decrease of traditional knowledge (albeit slight) was the generation of 41-50-year old participants, who had grown up under restrictive missionary rule, is noteworthy.

The hypothesis that people who are relatively isolated from the market economy share more traditional knowledge than people who live close to cities or larger towns [25], was not met in our study, because in most places the contact to nature still remains vital to the acquisition of knowledge [58, 59]. The predominance of the use for Human food in the more widely shared knowledge can be explained as a long and constant learning process that begins in early childhood, and is common in the more remote locations [26, 54].

There is no doubt that Chácobo daily life has changed in the course of the last century. Early accounts of the Chácobo all indicate the wide use of bark-cloth, and little enthusiasm for the rather conservative clothing style which missionaries tried to introduce [2, 5]. Boom [7] mentions however the complete disappearance of this custom. However, while the Chácobo use western style clothing available in the markets of Riberalta, traditional bark cloth is still widely used for cultural purposes, and most participants knew how to make it.

Changes in the use of traditional implements were very subtle. Most households still use large pounding tubs, as well as the large wooden boards used to pound food, which have not changed over time. Large clay pans for roasting jibe (Manihot flour), and smaller ceramic pots are also widely used. Even little stools from the petioles of Mauritia flexuosa and balsa wood (Ochroma sp.), first documented by Nordenskjöld [1] are still found in many houses, although they were completely missed in all previous studies. The production of burden baskets has not changed since [1], and the same species are still used today. However, only a few older women in the communities still have the skills to weave baskets, and modern implements like backpacks are clearly replacing traditional materials. Similarly, canoes are still an important means of transportation. However, while Nordenskjöld, Haenke and Kelm described canoes made from bark $[1,2,5]$, the modern variety is made of hollowed out tree trunks, which is already indicated in [7]. House construction and roofing have however not changed much in the last 100 years. Bows and arrows are still maintained as 


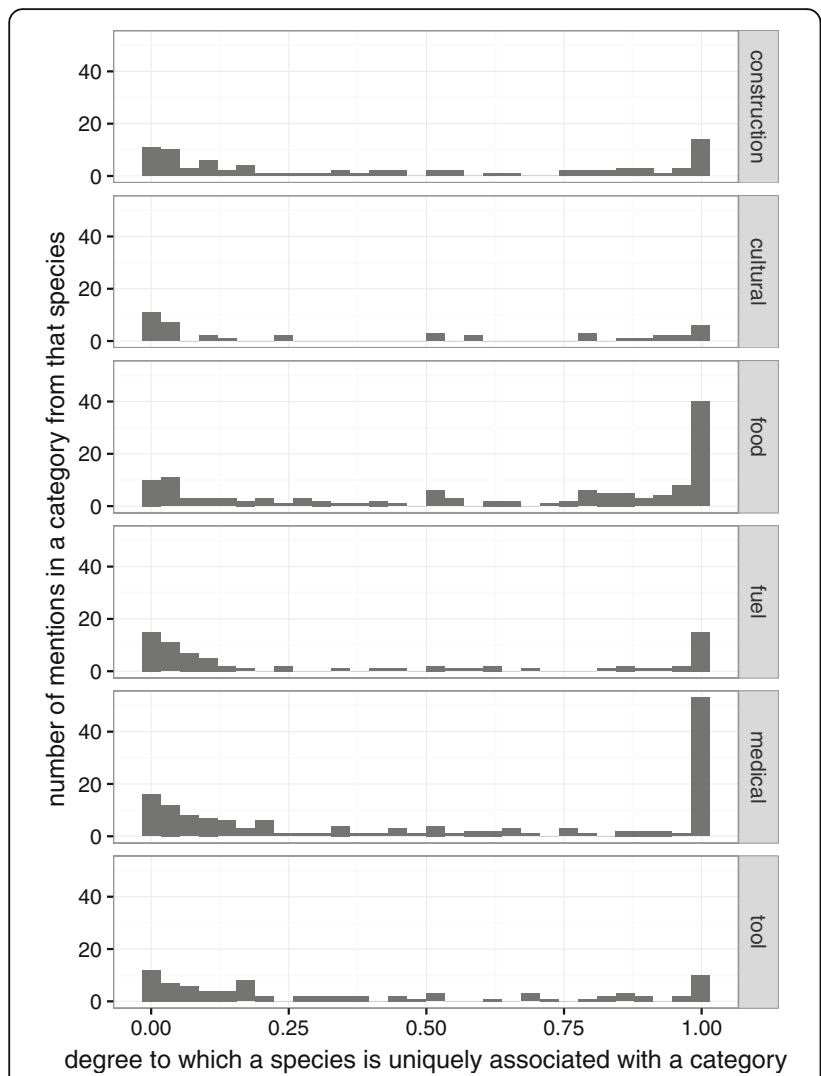

Fig. 9 Number of mentions that of a species plotted against that species' fidelity to the given use category

hunting implements, especially for fishing, and all arrow types found in previous studies are still used among the population, although 22 caliber rifles and 20 gauge shotguns are favored for hunting.

Based on previous reports, we originally hypothesized that many household artifacts as well as traditional clothing had disappeared from Chácobo life. Many of these artifacts were mentioned in the 1922-1970 accounts, but not in later studies. Boom [7] and Bergeron [8] in particular indicate that traditional tools and clothing had disappeared. This turned out to be an interview artifact. Early anthropologists, who focused on Chácobo daily life $[2,5]$, while Boom and Bergeron focused only on plants collected from one 1 ha forest plot [7, 8]. Our combined study indicates that in fact most artifacts of the Chácobo are still known, and also used, by a large part of the population. This includes traditional clothing that is still being prepared and used on important occasions, as well as hunting and household implements. In daily life however, no traditional clothing and ornaments are found anymore, and the large monkey tooth breast-plates mentioned by [1] and [2] have indeed disappeared.

In case of food, market access has indeed had an influence in Chácobo life. In the 1980's cassava (Manihot esculenta, Euphorbiaceae) was clearly the most important food for Chácobo, and seven varieties were planted (Boom 1987). Maize (Zea mays), was planted on $18 \%$ of the land, and upland rice (Oryza sativa) was only planted on $7 \%$ of the land [7]. Nowadays rice has become the staple food of the Chácobo, leaving cassava and maize in a more secondary role, However, all original traditional maize and cassava varieties, as well as traditional banana varieties, are still grown. In our work we also found all edible species mentioned by Boom (1987) as planted in home- and forest-gardens, but the Chácobo had incorporated many additional species, e.g. lemon (Citrus sinensis, Rutaceae) in home gardens, and Psidium, Myrica sp. and Eugenia sp. in the forest gardens. One noteworthy exception was the palm Huanimá (Bactris gasipaes var. chichagui, Arecaceae), actively sown formerly in abandoned clearings to collect palm fruits [7]. In 2015 the palm was only found rarely around the villages, and was no longer planted.

The Chácobo keep using a large number of plants for medicinal purposes although missionaries of the Summer Institute of Linguistics tried to eradicate traditional medicinal plant use and traditional agricultural practices, because they regarded this as pagan [4]. Early anthropological and missionary accounts mentioned hardly any medicinal species $[2,4,5]$, but this was clearly an interview artifact. Of the 360 plant species collected by Boom, 174 species were of medicinal value [7]. Bergeron recorded 399 useful plant species, of which 166 were classified as medicinal [8]. This compares favorably to the over 331 useful plant species elucidated in the current study. The Chácobo still favor the preparation of remedies by boiling the leaves, bark or fruits to cure diseases. While Boom did not find a true "healer" among the Chácobo [7], several Chácobo healers were identified in the present study. The knowledge of medicinal plants was particularly alive among older informants interviewed, but younger participants still retained much of such knowledge. The use of plant poisons, especially for fishing was mentioned as highly important by [7], and is still practiced today.

One of the most profound changes in Chácobo life seems to be a return to nomadic patterns, now mostly linked to commerce and income generation. The production of oil from the seeds of Brazil nuts (Berthollettia excels) was reported by Boom [7], but is little practiced nowadays - all nuts are now sold to large companies in Riberalta. The Brazil nut harvest takes place from January and March, and during that time now almost the entire Chácobo population migrates to the South of the territory where the largest concentration of Berthollettia is encountered. During the rest of the year Alto Ivón remains the main population center. However, 


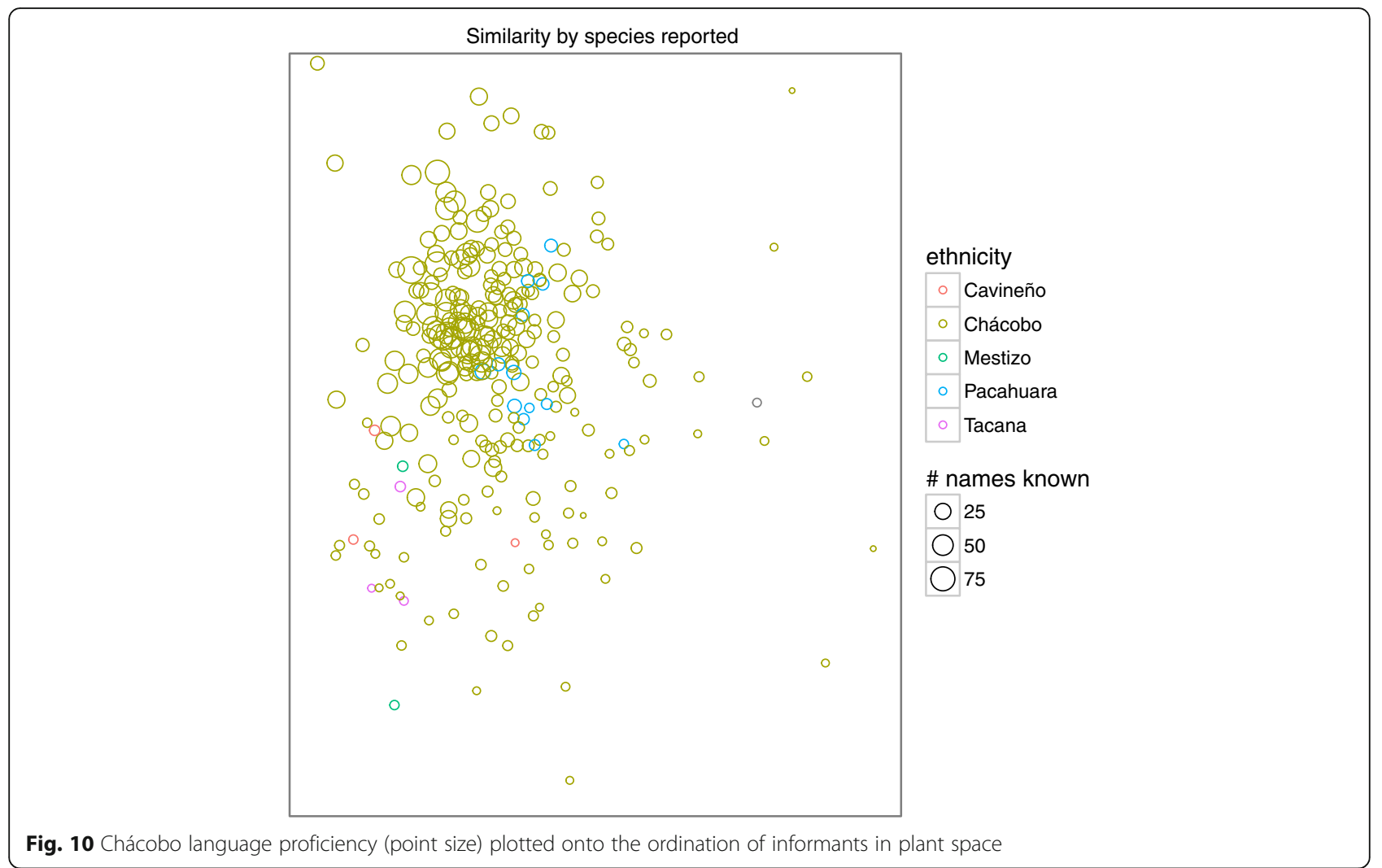

many Chácobo have "second" homes in Tokyo, where most of the fields are located at present, or in Triangulo, closer to their main fishing sources, and conveniently located at the road to Riberalta.

\section{Conclusions}

In this paper we illustrate the complexity of perspectives on knowledge at different ages, and the persistence of knowledge over almost a century. We found that traditional knowledge was only partially affected by the processes of exposure to a market economy, and that different knowledge domains experienced different trends as a result of these changes. Overall knowledge was widely distributed, similar to [63]. However, we did not observe a directional knowledge loss, contrasting [64].

We stress the importance to not directly conclude processes of knowledge loss, cultural erosion or acculturation when comparing the knowledge of different age groups. These results should be treated with caution, because they cannot rule out the role of other variables affecting knowledge, including changes in the composition of other important factors that might be affected by the influence of access to a market
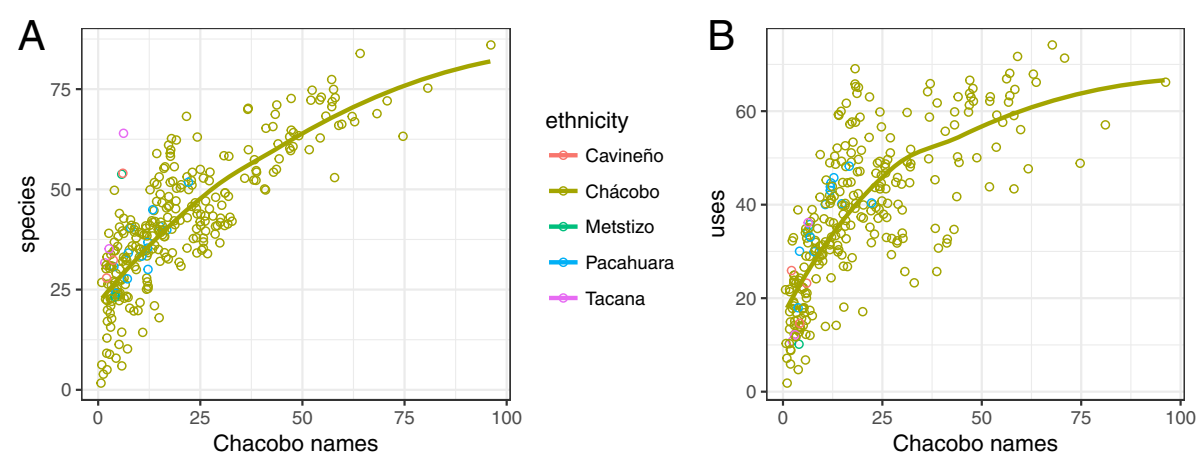

Fig. 11 The number of species (a) and uses (b) was significantly greater for those who reported more Chácobo names. Loess regression line (for Chácobo informants only) is shown 
economy. It is important to remember that learning, and accumulating experiences, require time. For this reason, the alternative explanation that the knowledge of older people tends to have accumulated over time, compared to the younger generation, should also be considered. It also needs to be taken into account that older generations might have different perceptions of their environment, because their points of reference are different from those of younger people. The ability to generate and apply knowledge in human populations enables actions and adjustments in response to current and future changes. Similarly, the ability to generate and apply knowledge, and not the knowledge itself, helps to increase the resilience of socio-ecological systems.

The analysis presented here clearly suggests that perceived knowledge "loss" might easily be an artifact of the researcher's presence, of limited time, and of a very limited number of participants. Training local interviewers provides an excellent tool yield more reliable information on traditional knowledge and its potential loss in the future.

In compliance with the Nagoya Protocol, the original field notebooks, as well as the complete dataset, and a guide on useful plants of the Chácobo was repatriated to the Chácobo [65]. All members of the tribe have access to the compiled interview data for purposes of learning and education. The data collected are a valuable resource to the community as a tool to preserve their traditional knowledge, and will encourage the launch of research projects and community activities so the information does not become static. Species identified as being most important to the community can be targeted for conservation and restoration activities.

\section{Acknowledgments}

We greatly thank Ravi Ortiz, President of the Central Indígena de la Región Amazónica de Bolivia (CIRABO), and Maro Ortiz, Capitan General of the TCO Chácobo, as well as all our Chácobo friends and counterparts, and the whole Chácobo population for all their friendship and support. We thank the National Geographic Society (Grant \#9244-13) for support of the fieldwork.

\section{Funding}

This study was funded by the National Geographic Society (Grant 9244-13) and endowment funds of the William L. Brown Center at Missouri Botanical Garden, for which we are grateful.

\section{Availability of data and materials}

The raw data contain the names of all participants, and cannot be shared publicly. Data without participant data can be obtained upon request after an access and benefit sharing agreement agreement with CIRABO.

\section{Authors' contributions}

NYPZ and RBU designed the study; NYPZ, RBU, ALHM, GOS, MOV, DOA, JSM, MSM, SC, BCM, GCM and ES conducted the fieldwork; ALMH curated and identified the collections and entered the original data; NYPZ and RBU analyzed the data and NYPZ, RBU and NPZ wrote the manuscript; REH conducted the statistical analysis; all authors read, corrected and approved the manuscript.

\section{Ethics approval and consent to participate}

Before conducting interviews, both the permission of CIRABO, and individual prior informed consent was obtained from all participants. No further ethics approval was required. All work conducted was carried out under the stipulations of the Nagoya Protocol on Access to Genetic Resources and the Fair and Equitable Sharing of Benefits Arising from their Utilization to the Convention on Biological Diversity. The right to use and authorship of any traditional knowledge of all participants is maintained, and any use of this information, other than for scientific publication, does require additional prior consent of the traditional owners, as well as a consensus on access to benefits resulting from subsequent use.

\section{Consent for publication}

This manuscript does not contain any individual person's data and further consent for publication is not required.

\section{Competing interests}

The authors declare that they have no competing interest.

\section{Publisher's Note}

Springer Nature remains neutral with regard to jurisdictional claims in published maps and institutional affiliations.

\section{Author details}

${ }^{1}$ Herbario Nacionál de Bolivia, Universidad Mayor de San Andrés, Casilla 10077 Correo Central, La Paz, Bolivia. ²Museo Nacional de Ciencias Naturales, Calle Ovidio Suarez 26, Cota Cota, La Paz, Bolivia. ${ }^{3}$ William L. Brown Center, Missouri Botanical Garden, P.O. Box 299, St. Louis, MO 63166-0299, USA.

${ }^{4}$ Instituto Linguistico Chácobo, Beni, Riberalta, Bolivia. ${ }^{5}$ Comunidad Chácobo de Alto Ivón, Beni, Bolivia. ${ }^{6}$ Comunidad Chácobo de Las Limas, Beni, Bolivia. ${ }^{7}$ Comunidad Chácobo de Firmeza, Beni, Bolivia. ${ }^{8}$ Comunidad Nueva Unión, Beni, Bolivia.

Received: 10 July 2017 Accepted: 3 September 2017

Published online: 10 October 2017

\section{References}

1. Nordenskjöld E. Indianer und Weisse im Nordosten Boliviens. Stuttgart: Strecker und Schröder; 1922.

2. Haenke W. The Chácobo in Bolivia. Ethnos. 1958;23:100-25.

3. Prost G. Notas linguisticas de Bolivia II: Phonemas de la lengua Chácobo. La Paz, SIL: Instituto Linguistico de Verano; 1960.

4. Prost MD. Costumbres, habilidades y cuadro de vida entre los Chácobos. La Paz, SIL: Instituto Linguistico de Verano; 1970.

5. Kelm H. Chácobo 1970. Tribus. 1972;21:129-246.

6. Córdoba LI. Misioneros-Patrones e indígenas-siringueros: El caucho entre los Chácobos del Beni (Siglo XX). Bol Americ. 2012;LXII(2-65):85-106.

7. Boom BM. Ethnobotany of the Chácobo Indians, Beni, Bolivia. Adv Econ Bot. 1987:4:1-68

8. Bergeron S. El uso de las plantas por los Chácobos (Alto Ivón, Beni, Bolivia). La Paz: Institut Franjáis d'Etudes Andines (IFEA); 1998

9. Muñoz V, Sauvain M, Bourdy G, Callapa J, Bergeron S, Rojas I, Bravo JA, Balderrama L, Ortiz B, Gimenez A, Deharo E. A search for natural bioactive compounds in Bolivia through a multidisciplinary approach. Part I. Evaluation of the antimalarial activity of plants used by the Chácobo Indians. J Ethnopharmacol. 2000;69:127-37.

10. Huntington HP. Using traditional ecological knowledge in science: methods and applications. Ecol Appl. 2000;10(5):270-1274.

11. Shackeroff JM, Campbell LM. 2007. Traditional ecological knowledge in conservation research: problems and prospects for their constructive engagement. Conserv Soc. 2007;5(3):343-60.

12. Begossi A. 1996. Use of ecological methods in Ethnobotany: diversity indices. Econ Bot. 1996;50(3):280-9.

13. Case RJ, Pauli G, Soejarto D, Ladio AH, Weigandt M. Cultural transmission of Ethnobotanical knowledge in a rural Community of Northwestern Patagonia. Argentina. Econ Bot. 2006;60:374-85.

14. Lozada M, Ladio AH, Weigandt M. Cultural transmission of Ethnobotanical knowledge in a rural Community of Northwestern Patagonia. Argentina Econ Bot. 2006;60:374-85.

15. Monteiro JM, Albuquerque UP. Freitas Lins-Neto EM, lima Araujo E, Cavalcanti Amorim E. Use patterns and knowledge of medicinal species 
among two rural communities in Brazil's semi-arid northeastern region. J Ethnopharmacol. 2006;105:173-86.

16. Turner NJ, Turner K. Where our women used to get the food: cumulative effects and loss of Ethnobotanical knowledge and practice; case study from coastal British Columbia. Botany. 2008:86:103-15.

17. Benz BF, Cevallos E, Santana M, Rosales A, Graf S. Losing knowledge about plant use in the sierra de Mazatlan biosphere reserve. Mexico Econ Bot. 2000;54(2):183-91.

18. Stone GD. Agricultural deskilling and the spread of genetically modified cotton in Warangal. Curr Anth. 2007;48:67-103.

19. Gómez-Baggethun E, Reyes-García V. Reinterpreting change in traditional ecological knowledge. Hum Ecol. 2013;41(4):643-7.

20. Berkes F, Colding J, Folke C. 2000. Rediscovery of traditional ecological knowledge as adaptive management. Ecol Appl. 2000;10(5):1251-62.

21. Colding J, Elmqvist T, Olsson P. Living with disturbance: building resilience in social-ecological systems. In: Berkes F, Colding J, Folke C, editors. Navigating social-ecological systems: building resilience for complexity and change. Cambridge: Cambridge University Press; 2003. p. 163-73.

22. Berkes F. Community-based conservation in a globalized world. Proc Natl Acad Sci. 2007;104:15188-93.

23. Sternberg R, Nokes C, Geissler P, Prince R, Okatcha F, Bundy D, Grigorenko E. The relationship between academic and practical intelligence: a case study in Kenya. Intell. 2001;29:401-18.

24. Godoy R, Reyes-García V, Byron E, Leonard W, Vadez V. The effect of market economies on the wellbeing of indigenous peoples and on their use of renewable natural resources. Ann Rev Anth. 2005;34:121-38.

25. Reyes-García V, Vadez V, Byron E, Apaza L, Leonard WR, Perez E, Wilkie D. Market economy and the loss of folk knowledge of plant uses: estimates from the Tsimane' of the Bolivian Amazon. Curr Anth. 2005; 46(4):651-6

26. Hanazaki N, Tamashiro JY, Leitão-Filho HF, Begossi A. Diversity of plant uses in two Caiçara communities form the Atlantic forest coast. Brazil Biodiv Cons. 2000;9:597-615.

27. Godoy R, Reyes-García V, Broesch J, Fitzpatrick IC, Giovarmini P, MRM R, Jha N, Huanca T, Leonard WR, TW MD, Tanner S, TAPS Bolivia Study Team. Long-term (secular) change of ethnobotanical knowledge of useful plants separating cohort and age effects. J Anth Res. 2009;65(1): 51-67.

28. Reyes-García V, Guèze M, Luz AC, Paneque-Gálvez J, Macía MJ, OrtaMartinez M, Pino J, Rubio-Campillo X. Evidence of traditional knowledge loss among a contemporary indigenous society. Evol Hum Behav. 2013; 34(4):249-57.

29. Reyes-García V, Luz AC, Gueze M, Paneque-Gálvez J, Macia MJ, Orta-Martínez M, Pino J. TAPS Bolivian study team. Secular trends on traditional ecological knowledge: an analysis of different domains of knowledge among Tsimane' men. Learn Indiv Diff. 2013;27:206-12.

30. Mackinson S, Nottestad L. Combining local and scientific knowledge. Rev Fish Bio Fisheries. 1998;8(4):481-90.

31. Luoga EJ, Witkowski ETF, Balkwill K. Differential utilization and ethnobotany of trees in Kitulanghalo forest reserve and surrounding communal lands, eastern Tanzania. Econ Bot. 2000:54(3):328-43.

32. Byg A. Humans and plants of the rain forest: factors affecting local knowledge and use of plants. University of Aarhus: Doctoral thesis; Department of Systematic Botany; 2004.

33. Byg A, Balslev H. Palms in indigenous and settler communities in southeastern Ecuador: farmers' perceptions and cultivation practices. Agrofor Syst. 2006;67:147-58.

34. Paniagua-Zambrana NY, Byg A, Svenning JC, Moraes M, Grandez C, Balslev H. Diversity of palm uses in the western Amazon. Biodivers Conserv. 2007; 16:2771-87.

35. Byg A, Balslev H. Diversity and use of palms in Zahamena, eastern Madagascar. Biodivers Conserv. 2001;10:951-70.

36. Byg A, Balslev H. Factors affecting local knowledge of palms in Nangaritza Valley in South-Eastern Ecuador. J Ethnobiol. 2004:24(2):255-78.

37. Takasaki Y, Barham BL, Coomes OT. Amazonian peasants, rain forest use and income generation: the role of wealth and geographical factors. Soc Nat Res. 2001;14:291-308.

38. Byg A, Vormisto J, Balslev H. Influence of diversity and road access on palm extraction at landscape scale in SE Ecuador. Biodivers Conserv. 2007;16:631-42.

39. Vandebroek I. The dual Intracultural and intercultural relationship between medicinal plant knowledge and consensus. Econ Bot. 2010;64(4):303-17.
40. Alburquerque UP, Muniz de Medeiros P. Systematic reviews and metaanalysis applied to Ethnobiological research. Ethnobiol Cons. 2012;1:6.

41. Moerman DE, Pemberton RW, Kiefer D. A comparative analysis of five medicinal floras. J Ethnobiol. 1999;19(1):49-67.

42. Molares S, Ladio A. Ethnobotanical review of the Mapuche medicinal flora: use patterns on a regional scale. J Ethnopharmacol. 2009;122(2):251-60.

43. Saslis-Lagoudakis CH, Williamson EM, Savolainen V, Hawkins JA. Crosscultural comparison of three medicinal floras and implications for bioprospecting strategies. J Ethnopharmacol. 2011;135(2):476-87.

44. Zent S. Acculturation and Ethnobotanical knowledge loss among the Piaroa of Venezuela: demonstration of a quantitative method for the empirical study of TEK change. In: Maffi L, editor. On biocultural diversity: linking language, knowledge, and the environment. Washington DC: Smithsonian Institution Press; 2001. p. 190-211.

45. Bussmann RW, Paniagua Zambrana NY. Traditional knowledge in a changing world - new insights from the Chácobo in Bolivia. In: Ponman B, Bussmann RW, editors. Medicinal plants and the legacy of Richard E. Schultes. Proc. botany 2011. Trujillo: Graficart; 2012. p. 23-34.

46. Paniagua Zambrana N, Bussmann RW, Blacutt E, Macia MJ, editors. Los Chácobo y las Palmeras. Graficart; 2011.

47. Bussmann RW, Paniagua Zambrana NY. La etnobotanica de los Chácobo: Traduccion de boom B:the Ethnobotany of the Chácobo Indians, Beni, Bolivia. Trujillo: Graficart; 2011.

48. Paniagua Zambrana NY, Bussmann RW, Tellez C, Vega C. Los Chácobo y su historia en el siglo XX. St. Louis: William L. Brown Center, MBG; 2014

49. Paniagua Zambrana NY, Macía MJ, Cámara-Leret R. Toma de datos etnobotánicos de palmeras y variables socioeconómicas en comunidades rurales - Ethnobotanical data gathering of palms and socio-economic variables in rural communities. Ecol Bol. 2010;45(3):44-68.

50. International Society of Ethnobiology. International Society of Ethnobiology Code of Ethics (with 2008 additions). Society of Ethnobiology; 2008. http:// ethnobiology.net/code-of-ethics/. Accessed 7 July 2017.

51. Oksanen J, Blanchet FG, Kindt R, Legendre P, Minchin PR, O'Hara, RB, Simpson GL, Solymos P, Henry M, Stevens H, Wagner H. vegan: Community Ecology Package. 2016. https://CRAN.R-project.org/package=vegan.

52. Dufrene M, Legendre P. Species assemblages and indicator species: the need for a flexible asymmetrical approach. Ecol Monogr. 1997; 67(3):345-66.

53. Roberts DW. labdsv: Ordination and Multivariate Analysis for Ecology. 2016. http://ecology.msu.montana.edu/labdsv/R.

54. Phillips O, Gentry AH. The useful plants of Tambopata, Peru: II. Additional hypothesis testing in quantitative ethnobotany. Econ Bot. 1993;47(1):33-43

55. Zent S. The quandary of conserving ethnoecological knowledge - a Piaroa example. In: Gragson TL, Blount BG, editors. Ethnoecology knowledge, resources, and rights. Athens: University of Georgia Press; 1999. p. 90-124.

56. Godoy R, Brokaw N, Wilkie D, Coloón D, Palermo A, Lye S, Wei S. On trade and cognition: markets and the loss of folk knowledge among the Tawahka Indians. J Anth Res. 1998;54:219-33.

57. Zarger R, Stepp JR. Persistence of botanical knowledge among Tzeltal Maya children. Curr Anth. 2004:45:413-8.

58. Atran S, Medin D, Ross N, Lynch E, Vapnarsky V, Ucan Ek E, Coley J, Timura C, Baran M. Folkecology, cultural epidemiology and the spirit of the commons. Curr Anth. 2002:43:421-50.

59. Lawrence A, Philipps OL, Reategui A, López M, Rose S, Wood D. Local values for harvested forest plants in Madre de Dios, Peru: towards a more contextualized interpretation of quantitative Ethnobotanical data. Biodivers Conserv. 2005;14:45-79.

60. Harrison KD. When languages die: the extinction of the World's languages and the erosion of human knowledge. New York: Oxford University Press; 2007.

61. Zarger RK. Acquisition and transmission of subsistence knowledge by Q'eqchi' Maya in Belize. In: Stepp JR, Wyndham FS, Zarger RK, editors. Etnobiology and biocultural diversity. Athens: International Society of Ethnobiology; 2002. p. 592-603.

62. Guest G. Market integration and the distribution of ecological knowledge within an Ecuadorian fishing community. J Ecol Anth. 2002;6:38-49.

63. Reyes-García V, Godoy R, Vadez V, Apaza L, Byron E, Huanca T, Leonard WR, Pérez E, Wilkie D. Ethnobotanical knowledge shared widely among Tsimane' Amerindians. Bolivia Sci. 2003;29:1707. 
64. Reyes-García V, Gueze M, Luz AC, Paneque-Galvez J, Macía MJ, Orta-Martínez M, Pino J, Rubio-Campillo X. Evidence of traditional knowledge loss among a contemporary indigenous society. Evol Hum Behav. 2013;34(4):249-57. Doi: http://dx.doi.org/10.1016/

65. Paniagua-Zambrana NY, Bussmann RW. La Etnobotánica de los Chácobo en el Siglo XXI. St. Louis: William L. Brown Center; 2017.

Submit your next manuscript to BioMed Central and we will help you at every step:

- We accept pre-submission inquiries

- Our selector tool helps you to find the most relevant journal

- We provide round the clock customer support

- Convenient online submission

- Thorough peer review

- Inclusion in PubMed and all major indexing services

- Maximum visibility for your research

Submit your manuscript at www.biomedcentral.com/submit 